\title{
Layered Manganese Bismuth Tellurides with GeBi4Te7- and GeBi6Te10-type Structures: Towards Multifunctional Materials
}

Daniel Souchay, Markus Nentwig, Daniel Günther, Simon Keilholz, Johannes de Boor, Alexander Zeugner, Anna Isaeva, Michael Ruck, Anja U. B. Wolter, Bernd Büchner, Oliver Oeckler

Submitted date: 07/06/2019 - Posted date: 17/06/2019

Licence: CC BY-NC-ND 4.0

Citation information: Souchay, Daniel; Nentwig, Markus; Günther, Daniel; Keilholz, Simon; Boor, Johannes de; Zeugner, Alexander; et al. (2019): Layered Manganese Bismuth Tellurides with GeBi4Te7- and GeBi6Te10-type Structures: Towards Multifunctional Materials. ChemRxiv. Preprint.

The crystal structures of new layered manganese bismuth tellurides with the compositions Mn0.85(3)Bi4.10(2)Te7 and Mn0.73(4)Bi6.18(2)Te10 were determined by single-crystal X-ray diffraction, including the use of microfocused synchrotron radiation. These analyses reveal that the layered structures deviate from the idealized stoichiometry of the 12P-GeBi4Te7 (space group P3m1) and 51R-GeBi6Te10 (space group R3m) structure types they adopt. Modified compositions Mn1-xBi4+2x/3Te7 ( $x=0.15-0.2)$ and Mn1-xBi6+2x/3Te10 ( $x=0.19-0.26)$ assume cation vacancies and lead to homogenous bulk samples as confirmed by Rietveld refinements. Electron diffraction patterns exhibit no diffuse streaks that would indicate stacking disorder. The alternating quintuple-layer [M2Te3] and septuple-layer [M3Te4] slabs (M = mixed occupied by Bi and Mn) with 1:1 sequence (12P stacking) in Mn0.85Bi4.10Te7 and 2:1 sequence (51R stacking) in Mn0.81Bi6.13Te10 were also observed in HRTEM images. Temperature-dependent powder diffraction and differential scanning calorimetry show that the compounds are high temperature phases, which are metastable at ambient temperature. Magnetization measurements are in accordance with a Mnll oxidation state and point at predominantly ferromagnetic coupling in both compounds. The thermoelectric figures of merit of n-type conducting Mn0.85Bi4.10Te7 and Mn0.81Bi6.13Te10 reach zT $=0.25$ at $375{ }^{\circ} \mathrm{C}$ and $z \mathrm{~T}=$ 0.28 at $325^{\circ} \mathrm{C}$, respectively. Although the compounds are metastable, compact ingots exhibit still up to $80 \%$ of the main phases after thermoelectric measurements up to $400{ }^{\circ} \mathrm{C}$.

File list (2)

MnBiTe_CHEMRXIV.pdf (1.91 MiB)

view on ChemRxiv - download file 


\title{
Layered Manganese Bismuth Tellurides with $\mathrm{GeBi}_{4} \mathrm{Te}_{7}-$ and $\mathrm{GeBi}_{6} \mathrm{Te}_{10}$-type Structures: Towards Multifunctional Materials
}

\author{
Daniel Souchay, ${ }^{a}$ Markus Nentwig, ${ }^{a}$ Daniel Günther, ${ }^{a}$ Simon Keilholz, ${ }^{a}$ Johannes de Boor, \\ Alexander Zeugner, ${ }^{\mathrm{c}}$ Anna Isaeva, ${ }^{\mathrm{e}}$ Michael Ruck, ${ }^{\mathrm{c}}$ Anja U. B. Wolter, ${ }^{\mathrm{d}}$ Bernd Büchner, ${ }^{\mathrm{d}, \mathrm{e}}$ Oliver \\ Oeckler $^{\mathrm{a}, *}$ \\ a. Institute for Mineralogy, Crystallography and Materials Science; Faculty of Chemistry and Mineralogy, Leipzig University \\ Scharnhorststr. 20, 04275 Leipzig, Germany. \\ ${ }^{b .}$ Institute of Materials Research, German Aerospace Center, Linder Höhe, 51170 Cologne, Germany \\ c. Faculty of Chemistry and Food Chemistry, Technische Universität Dresden, 01062 Dresden, Germany \\ d. Leibniz-Institute for Solid State and Materials Research, Helmholtzstr. 10, 01069 Dresden, Germany \\ e. Institute of Solid State Physics, Technische Universität Dresden, 01062 Dresden, Germany \\ Corresponding Author*E-Mail: oliver.oeckler@gmx.de
}

\begin{abstract}
The crystal structures of new layered manganese bismuth tellurides with the compositions $\mathrm{Mn}_{0.85(3)} \mathrm{Bi}_{4.10(2)} \mathrm{Te}_{7}$ and $\mathrm{Mn}_{0.73(4)} \mathrm{Bi}_{6.18(2)} \mathrm{Te}_{10}$ were determined by single-crystal $\mathrm{X}$-ray diffraction, including the use of microfocused synchrotron radiation. These analyses reveal that the layered structures deviate from the idealized stoichiometry of the $12 P-\mathrm{GeBi}_{4} \mathrm{Te}_{7}$ (space group $P \overline{3} m 1$ ) and $51 R-\mathrm{GeBi}_{6} \mathrm{Te}_{10}$ (space group $R \overline{3} m$ ) structure types they adopt. Modified compositions $\mathrm{Mn}_{1-}$ ${ }_{x} \mathrm{Bi}_{4+2 x / 3} \mathrm{Te}_{7}(x=0.15-0.2)$ and $\mathrm{Mn}_{1-x} \mathrm{Bi}_{6+2 x / 3} \mathrm{Te}_{10}(x=0.19-0.26)$ assume cation vacancies and lead to homogenous bulk samples as confirmed by Rietveld refinements. Electron diffraction patterns exhibit no diffuse streaks that would indicate stacking disorder. The alternating quintuple-layer $\left[\mathrm{M}_{2} \mathrm{Te}_{3}\right]$ and septuple-layer $\left[\mathrm{M}_{3} \mathrm{Te}_{4}\right]$ slabs $(\mathrm{M}=$ mixed occupied by $\mathrm{Bi}$ and $\mathrm{Mn}$ ) with 1:1 sequence (12P stacking) in $\mathrm{Mn}_{0.85} \mathrm{Bi}_{4.10} \mathrm{Te}_{7}$ and 2:1 sequence (51R stacking) in $\mathrm{Mn}_{0.81} \mathrm{Bi}_{6.13} \mathrm{Te}_{10}$ were also observed in HRTEM images. Temperature-dependent powder diffraction and differential scanning calorimetry show that the compounds are high-temperature phases, which are metastable at ambient temperature. Magnetization measurements are in accordance with a $\mathrm{Mn}^{\prime \prime}$ oxidation state and point at predominantly ferromagnetic coupling in both compounds. The thermoelectric figures of merit of $n$-type conducting $\mathrm{Mn}_{0.85} \mathrm{Bi}_{4.10} \mathrm{Te}_{7}$ and $\mathrm{Mn}_{0.81} \mathrm{Bi}_{6.13} \mathrm{Te}_{10}$ reach $z T=0.25$ at $375^{\circ} \mathrm{C}$ and $z T=0.28$ at $325^{\circ} \mathrm{C}$, respectively. Although the compounds are metastable, compact ingots exhibit still up to $80 \%$ of the main phases after thermoelectric measurements up to $400^{\circ} \mathrm{C}$.
\end{abstract}

\section{Introduction}

Layered chalcogenides have received much attention due to their exceptional properties. These include topologically nontrivial electronic structures, charge-density waves, superconductivity or promising thermoelectric properties. ${ }^{1-7}$ For thermoelectric waste-heat recovery and Peltier cooling near room temperature (RT), the layered semiconductor $\mathrm{Bi}_{2} \mathrm{Te}_{3}$ and its substitution variants with $\mathrm{Sb}$ and $\mathrm{Se}$ are used in technical applications. ${ }^{8}$ The thermoelectric performance of $\mathrm{Bi}_{2} \mathrm{Te}_{3}$ has been optimized e.g. by Se substitution and $\mathrm{Cu}$ doping. ${ }^{9}$ In addition to its thermoelectric properties, angle-resolved photoemission spectroscopy (ARPES) has proved that $\mathrm{Bi}_{2} \mathrm{Se}_{3}$ and $\mathrm{Bi}_{2} \mathrm{Te}_{3}$ are topological insulators. ${ }^{3,12-14}$ Variants of $\mathrm{Bi}_{2} \mathrm{Te}_{3}$ or $\mathrm{Bi}_{2} \mathrm{Se}_{3}$ doped with transition metals such as $\mathrm{Cr}$ or Fe exhibit different magnetic interactions caused by the dopants; they may represent a new class of magnetic topological insulators in the field of spintronics. ${ }^{15,16}$ Probably motivated by its natural abundance, $\mathrm{Mn}$, has widely been used as a dopant in $\mathrm{Bi}_{2} \mathrm{Te}_{3}$; and structural, electrical and magnetic properties have been studied. ${ }^{17-22}$ For example, thin-film topological insulators based on $\mathrm{Mn}$ - or $\mathrm{Cr}$-doped $\mathrm{Bi}_{2} \mathrm{Te}_{3}$ are potential candidates for highly sensitive anomalous Hall effect sensors. ${ }^{17,23}$ In contrast to the ordinary Hall effect caused by the Lorentz force, the anomalous Hall effect arises from the spin-orbit interaction of spin-polarized charge carriers in conductive ferromagnetic materials and provides an alternative approach for magnetic sensing.

Layered $\mathrm{Bi}_{2} \mathrm{Te}_{3}$ exhibits a $15 R$ stacking sequence of three slabs per unit cell separated by van der Waals gaps (cf. Section 3.3, Fig. 5), each slab composed of double layers of $\left[\mathrm{BiTe}_{6}\right]$ octahedra often called "quintuple layer" as it consists of five atom layers. Many compounds can be derived from $\mathrm{Bi}_{2} \mathrm{Te}_{3}$ by formally inserting $T t T e(T t=\mathrm{Pb}, \mathrm{Ge}, \mathrm{Sn})$ units. $^{24}$ In addition to its thermoelectric behavior, $\mathrm{SnBi}_{2} \mathrm{Te}_{4}$ shows a pressureinduced electronic topological transition between 3.5 and $5.0 \mathrm{GPa} .{ }^{25}$ ARPES yields evidence for topological surface states with Dirac dispersion in the indirect bandgap of bulk $\mathrm{Pb}\left(\mathrm{Bi}_{2-\mathrm{S}} \mathrm{Sb}_{\mathrm{x}}\right) \mathrm{Te}_{4}{ }^{26}$ The $\mathrm{GeBi}_{2} \mathrm{Te}_{4}$-type structure of these compounds is described by a $21 R$ stacking sequence, whose "septuple" layers comprise three triple layers of condensed octahedra as described by ${ }_{\infty}^{2}\left[\mathrm{Te}_{3 / 3} M\left(\mu-\mathrm{Te}_{3 / 6}\right) M\left(\mu-\mathrm{Te}_{3 / 6}\right) M T e_{3 / 3}\right]$ ( $M=\mathrm{Ge}, \mathrm{Bi}$; usually disordered), again separated by van der Waals gaps. ${ }^{27,28}$ Formally adding one $\mathrm{Bi}_{2} \mathrm{Te}_{3}$-type quintuple layer per $\mathrm{GeBi}_{2} \mathrm{Te}_{4}$-type septuple building block results in the $\mathrm{GeBi}_{4} \mathrm{Te}_{7}$ structure type with a $12 P$ stacking sequence. ${ }^{27,29}$ 
Insertion of a second $\mathrm{Bi}_{2} \mathrm{Te}_{3}$-type layer results in the $\mathrm{GeBi}_{6} \mathrm{Te}_{10}$ structure type, described by a $51 R$ stacking sequence. From another point of view, these structures can be understood as consisting of distorted rocksalt-type slabs similar to those in $\mathrm{GeBi}_{2} \mathrm{Te}_{4}$ and in $\mathrm{Bi}_{2} \mathrm{Te}_{3}$, separated by van der Waals gaps. ${ }^{24} \mathrm{Mn}$ doping and its influence on the thermoelectric properties was also reported for the layered compound $\mathrm{Ge}_{4} \mathrm{Sb}_{2} \mathrm{Te}_{7}$ crystallizing with a $\mathrm{Ge}_{3} \mathrm{As}_{2} \mathrm{Te}_{6}$-type structure. ${ }^{30} \mathrm{MnBi}_{2} \mathrm{Te}_{4}$ has been reported to be the first compound of the series $M T e\left(\mathrm{Bi}_{2} \mathrm{Te}_{3}\right)_{n}$ where $M$ is a transition metal represented by manganese. ${ }^{31}$ Single-crystal data of $\mathrm{MnBi}_{2} \mathrm{Te}_{4}$ revealed $\mathrm{Mn} / \mathrm{Bi}$ antisite disorder; the magnetic properties are strongly anisotropic and antiferromagnetic ordering is observed below $24 \mathrm{~K}^{32,33}$ Investigations on the phase diagram of the system $\mathrm{Mn} / \mathrm{Bi} / \mathrm{Te}$ indicated that there are further layered compounds in that system, ${ }^{34}$ and estimates concerning their structures were suggested. In heterostructured $\mathrm{Bi}_{2} \mathrm{Se}_{3} / \mathrm{MnBi}_{2} \mathrm{Se}_{4}$ thin films, which were grown by means of molecular beam epitaxy, $\mathrm{MnBi}_{2} \mathrm{Se}_{4}$ crystallizes in the same structure type as bulk $\mathrm{MnBi}_{2} \mathrm{Te}_{4} \cdot{ }^{35}$ We have now synthesized further members of the homologous series ( $\mathrm{MnTe})\left(\mathrm{Bi}_{2} \mathrm{Te}_{3}\right)_{n}$ with $\mathrm{GeBi}_{4} \mathrm{Te}_{7}$-type ${ }^{27,29}$ or $\mathrm{GeBi}_{6} \mathrm{Te}_{10}$-type ${ }^{24}$ structures. According to single-crystal $\mathrm{X}$-ray data, single-phase syntheses and chemical analyses, their chemical compositions signifycantly deviate from the idealized formulae. Measurements of transport properties with respect to thermoelectric behavior represent one step towards characterizing these potential multifunctional materials.

\section{Experimental}

Synthesis: Bulk samples were obtained from the elements $\mathrm{Mn}$ (chunks, Onyxmet, 99.9\%), Bi (Alfa Aesar, 99.999\%) and Te ingots (Haines \& Maassen, 99.9\%). Mn was heated under vacuum with small silica glass powder at $1000{ }^{\circ} \mathrm{C}$ for 1 day to completely remove brownish $\mathrm{MnO}_{2}$ from the surface. After this cleaning procedure, $\mathrm{Mn}$ was stored under argon to avoid oxidation. Stoichiometric mixtures (approximately $2 \mathrm{~g}$ ) of the elements according to the various sum formulae mentioned in the following sections were sealed in graphitized flatbottomed silica glass ampules (inner diameter: $12 \mathrm{~mm}$, wall thickness: $1.5 \mathrm{~mm}$ ) under argon atmosphere, placed in tube furnaces and heated from RT to $950{ }^{\circ} \mathrm{C}$. The samples were kept at these conditions for $1 \mathrm{~d}$ and subsequently cooled to RT by quenching at air. The resulting ingots were then annealed at $575{ }^{\circ} \mathrm{C}$ for 1 week, again followed by quenching at air. Discshaped ingots used for thermal conductivity measurements were obtained by using flat-bottomed silica-glass ampules. The samples were polished to a plane-parallel thickness of $1.07 \mathrm{~mm}\left(\mathrm{Mn}_{0.81} \mathrm{Bi}_{6.13} \mathrm{Te}_{10}\right)$ or $1.29 \mathrm{~mm}\left(\mathrm{Mn}_{0.85} \mathrm{Bi}_{4.10} \mathrm{Te}_{7}\right)$, by using SiC grinding powder. Cuboid-shaped samples for measurements of the electrical conductivity and the Seebeck coefficient were fabricated using a diamond wire saw and polished with SiC grinding powder. The samples are dark gray with metallic luster. Upon exposure to air over months, no hydrolysis, oxidation or decomposition were observed, even for powder samples.

Powder diffraction: For powder X-ray diffraction (PXRD) at RT, the samples were crushed and spread on Mylar foil. Data were recorded on a Huber G670 diffractometer (Guinier geometry with imaging-plate detector and integrated read-out system) using $\mathrm{Cu}-K_{\alpha 1}$ radiation [Ge(111) monochromator, $\lambda=$ $1.54051 \AA$ A]. WINXPOW ${ }^{36}$ was used for data evaluation and TOPAS ${ }^{37}$ for Rietveld refinements. Reflection profiles were described with fundamental parameters using a direct convolution approach. Crystallite strain was described using a Voigt function, and preferred orientation was refined with spherical harmonics of the $4^{\text {th }}$ order. The background of each diffraction pattern was modelled by a set of 18 parameters (shifted Chebychev polynomial). Structure models with their equivalent isotropic displacement parameters were taken from the single-crystal data. Temperature-dependent measurements in rotating silica glass capillaries under dry $\mathrm{Ar}$ atmosphere were obtained with synchrotron radiation (beamline ID11, ESRF, Grenoble) on a Huber diffractometer ( $\lambda$ $=0.18972 \AA$ ) with a FReLoN $2 \mathrm{~K} \mathrm{CCD}$ detector. ${ }^{44} \mathrm{~A}$ hot-gas blower (GSB 1300, FMB Oxford) with a maximal heating rate of $20 \mathrm{~K} \mathrm{~min}^{-1}$ was used. For temperature calibration, hexagonal BN was used since its $c$ lattice parameter increases with temperature almost linearly. ${ }^{38}$ In order to adjust the measured temperatures of the heating and cooling curves according to the calibration, a second-order polynomial fit was used for interpolation.

Single-crystal X-ray diffraction: X-ray diffraction data of a $\mathrm{Mn}_{0.85} \mathrm{Bi}_{4.10} \mathrm{Te}_{7}$ single-crystal were obtained on a STOE STADIVARI diffractometer (Ag- $K_{\alpha 1}$ radiation, $\lambda=0.56086 \AA$ ) with a Dectris Pilatus $300 \mathrm{k}$ detector. Integration was done with $X$-Area ${ }^{39}$ and numerical absorption correction using X-RED ${ }^{40}$ and X-SHAPE. ${ }^{41,42}$ Single-crystal diffraction data of $\mathrm{Mn}_{0.73} \mathrm{Bi}_{6.18} \mathrm{Te}_{10}$ were obtained using microfocused synchrotron radiation (beamline ID11, ESRF, Grenoble) ${ }^{43}$ on a Huber diffractometer $(\lambda=0.30996 \AA)$ with a FReLoN $2 \mathrm{~K}$ CCD detector. ${ }^{44}$ Integration was done using CrysAlis Pro ${ }^{45}$ and semiempirical absorption correction was applied with SADABS. ${ }^{46}$ Incomplete absorption in the CCD phosphor as a function of beam incidence was taken into account. ${ }^{47}$ Solution and refinement of both structures was done with SHELX2014. ${ }^{48}$ Further details on the crystal structure analyses can be obtained from the Fachinformationszentrum Karlsruhe, 76344 Eggenstein-Leopoldshafen, Germany (fax: +49-7247-808-666; e-mail: crysdata@fiz-karlsruhe.de) on quoting the depository numbers $1891486 \quad\left(\mathrm{Mn}_{0.85} \mathrm{Bi}_{4.10} \mathrm{Te}_{7}\right)$ and 1891488 $\left(\mathrm{Mn}_{0.73} \mathrm{Bi}_{6.18} \mathrm{Te}_{10}\right)$. Crystal structures were visualized with Diamond. $^{49}$

Thermal analysis: $\mathrm{Mn}_{0.85} \mathrm{Bi}_{4.10} \mathrm{Te}_{7}$ and $\mathrm{Mn}_{0.81} \mathrm{Bi}_{6.13} \mathrm{Te}_{10}$ powders were analyzed by means of differential scanning calorimetry (DSC) using a Setaram Labsys ATD-DSC device with k-probe $\left(\mathrm{Ni}-\mathrm{Cr} / \mathrm{Ni}-\mathrm{Al} ; T_{\max }=800{ }^{\circ} \mathrm{C}\right.$ ) thermocouples and $\mathrm{Al}_{2} \mathrm{O}_{3}$ as a reference compound. Weighted amounts of each specimen (ca. $50 \mathrm{mg}$ ) were sealed in small evacuated silica ampules and exposed to two consecutive heating and cooling cycles from RT up to $800^{\circ} \mathrm{C}$ at the rate of $2 \mathrm{~K} \mathrm{~min}^{-1}$.

Electron microscopy: Scanning electron microscopy (SEM) and energy-dispersive X-ray spectroscopy (EDX) were done using a Zeiss LEO 1530 instrument (acceleration voltage $20 \mathrm{kV}$ ) equipped with an EDX detector (INCA software, ${ }^{50}$ Oxford Instruments). Selected-area electron diffraction (SAED), high- 
resolution transmission electron microscopy (HRTEM) and further EDX were executed on a Philips CM-200 STEM ( LaB $_{6}$ cathode, $200 \mathrm{kV}$, super-twin lens, point resolution $0.23 \mathrm{~nm}$ ) equipped with RTEM 136-5 EDX detector (EDAX, Genesis software ${ }^{51}$ ). A double-tilt low-background sample holder (Gatan) was used. For TEM investigations, the bulk material was manually cut with a diamond saw, glued on a copper ring, mechanically ground to a thickness of approximately $30 \mu \mathrm{m}$, polished using a dimple grinder (Gatan) and finally Ar-ionthinned (Duo-Mill, Gatan). Evaluation of SAED data was done using the AnalySIS software. ${ }^{52}$ For HRTEM and SAED simulations, jEMS ${ }^{53}$ was used. Micrographs and diffraction patterns were evaluated using Digital Micrograph. ${ }^{54}$

Thermoelectric characterization: Thermal diffusivity $(\kappa)$ was measured under He atmosphere using a Linseis LFA1000 apparatus equipped with an InSb detector (aperture diameter $3 \mathrm{~mm}$ ). Simultaneous heat loss and finite pulse corrections were applied using Dusza's model. ${ }^{55}$ Values were averaged from five measurement points at each temperature. For $k$ calculation, they were multiplied with the Dulong-Petit heat capacity $\left(\mathrm{Mn}_{0.85} \mathrm{Bi}_{4.10} \mathrm{Te}_{7}: C_{\mathrm{p}}=0.1659 \mathrm{~J} \mathrm{~g}^{-1} \mathrm{~K}^{-1} ; \mathrm{Mn}_{0.81} \mathrm{Bi}_{6.13} \mathrm{Te}_{10}\right.$ : $C_{\mathrm{p}}=0.1624 \mathrm{~J} \mathrm{~g}^{-1} \mathrm{~K}^{-1}$ ) and the density as derived by the weight and the volume determined by Archimedes' principle with a precision of $0.03 \mathrm{~g} \mathrm{~cm}^{-3} \quad\left(\mathrm{Mn}_{0.85} \mathrm{Bi}_{4.10} \mathrm{Te}_{7}: \quad 7.53 \mathrm{~g} \mathrm{~cm}^{-3}\right.$; $\mathrm{Mn}_{0.81} \mathrm{Bi}_{6.13} \mathrm{Te}_{10}: 7.65 \mathrm{~g} \mathrm{~cm}^{-3}$ ). Densities were at least $98.5 \%$ of the corresponding $\mathrm{X}$-ray densities. DSC measurements (cf. Fig. $\mathrm{S} 1$ - $\mathrm{S}$ denotes items in the Electronic Supplementary Information, ESI + ) confirm that $C_{\mathrm{p}}$ corresponds to the DulongPetit value within experimental error although DSC measurements of $\mathrm{Bi}_{2} \mathrm{Te}_{3}{ }^{56}$ indicate that $C_{\mathrm{p}}$ near RT is still below the Dulong-Petit value. However, other related compounds such as $\left(\mathrm{Sn}_{1-\mathrm{x}} \mathrm{Pb}_{\mathrm{x}}\right) \mathrm{Bi}_{2} \mathrm{Te}_{4}{ }^{57}$ or $\mathrm{GeBi}_{4} \mathrm{Te}_{7}{ }^{58}$ reach this value near RT. The Seebeck coefficient $S$ (in $\mu \mathrm{V} \mathrm{K}^{-1}$ ) and the electrical conductivity $\sigma$ (in $\mathrm{S} \mathrm{cm}^{-1}$ ) were measured on cuboid samples $\left(\mathrm{Mn}_{0.81} \mathrm{Bi}_{6.13} \mathrm{Te}_{10}: 8.13 \mathrm{~mm} \times 1.25 \mathrm{~mm} \times 1.76 \mathrm{~mm}\right.$, $\left.\mathrm{Mn}_{0.85} \mathrm{Bi}_{4.10} \mathrm{Te}_{7}: 6.92 \mathrm{~mm} \times 1.09 \mathrm{~mm} \times 1.91 \mathrm{~mm}\right)$ simultaneously under $\mathrm{He}$ atmosphere using a Linseis LSR-3 instrument with $\mathrm{NiCr} / \mathrm{Ni}$ and $\mathrm{Ni}$ contacts and a continuous reversal of the polarity of the thermocouples (bipolar setup). Measurements comprised three heating/cooling cycles 50$400-50^{\circ} \mathrm{C}$ with $25^{\circ} \mathrm{C}$ steps at $10 \mathrm{~K} \mathrm{~min}^{-1}$ heating rate and three data points per temperature. The errors of $S$ and $\sigma$ are smaller than $10 \%$; for $\kappa$, they are ca. $5 \%$. The combined uncertainty may amount to $\sim 15 \%$ for the $z T$ value.

Magnetic measurements: Temperature- and field-dependent magnetic measurements were performed on pressed powder samples (ca. $10 \mathrm{mg}$ ) using a Superconducting Quantum Interference Device (SQUID) magnetometer (MPMS ${ }^{\circledR} 3$ ) from Quantum Design. Temperature-dependent zero-field-cooled (ZFC) and field-cooled (FC) warming magnetization measurements were performed at magnetic fields of $0.02 \mathrm{~T}$ and $1 \mathrm{~T}$ in the temperature range from $2-320 \mathrm{~K}$ and fielddependent magnetization measurements were done at $2 \mathrm{~K}$ and at $300 \mathrm{~K}$.

\section{Results and discussion}

\subsection{Phase composition and homogeneity}

Compounds with nominal compositions $\mathrm{MnTe}\left(\mathrm{Bi}_{2} \mathrm{Te}_{3}\right)_{n}$ with $\mathrm{n}=$ 2 or 3 may be expected to crystallize in the $\mathrm{GeBi}_{4} \mathrm{Te}_{7}{ }^{27,29}$ or $\mathrm{GeBi}_{6} \mathrm{Te}_{10}{ }^{24}$ structure types. Corresponding reactions, however, did not lead to single-phase samples. Samples with the nominal composition $\mathrm{MnBi}_{4} \mathrm{Te}_{7}$ contain two phases, i.e. a mixture of $\mathrm{GeSb}_{2} \mathrm{Te}_{4}$-type and $\mathrm{GeBi}_{4} \mathrm{Te}_{7}$-type compounds (Fig. $\mathrm{S} 2, \mathrm{ESI}+$ ). The nominal composition $\mathrm{MnBi}_{6} \mathrm{Te}_{10}$ yields a mixture $\mathrm{GeBi}_{4} \mathrm{Te}_{7}$-type and $\mathrm{GeBi}_{6} \mathrm{Te}_{10}$-type phases (Fig. S3, ESIt). In contrast, nominal compositions such as $\mathrm{Mn}_{0.85} \mathrm{Bi}_{4.10} \mathrm{Te}_{7}$ (derived from single-crystal data, cf. section 3.3) and $\mathrm{Mn}_{0.81} \mathrm{Bi}_{6.13} \mathrm{Te}_{10}$ (which was suggested by preliminary single-crystal data) lead to samples that appear to be single-phase according to Rietveld refinements based on PXRD data (Fig. 1 and Tables S1, $\mathrm{S} 2$, and $\mathrm{S} 3$ in the $\mathrm{ESI}+$ ). In both cases, the refined parameters of the single-crystal structure analyses were used for the Rietveld refinement and only lattice parameters were refined. For $\mathrm{GeBi}_{6} \mathrm{Te}_{10}$-type samples, they agreed with those of the single-crystal. For $\mathrm{Mn}_{0.85} \mathrm{Bi}_{4.10} \mathrm{Te}_{7}$, lattice parameters from PXRD differ slightly from those of the single crystal but correspond to those of the $\mathrm{GeBi}_{4} \mathrm{Te}_{7}$-type phase in heterogeneous samples with the nominal composition $\mathrm{MnBi}_{6} \mathrm{Te}_{10}$, from which the single crystal was isolated (Table $\mathrm{S} 4, \mathrm{ESI}+$ ). The deviations from the stoichiometric compositions $\mathrm{GeBi}_{4} \mathrm{Te}_{7}$ and $\mathrm{GeBi}_{6} \mathrm{Te}_{10}$ are consistent with the EDX data obtained from $\mathrm{Mn}_{0.85} \mathrm{Bi}_{4.10} \mathrm{Te}_{7}$ and $\mathrm{Mn}_{0.81} \mathrm{Bi}_{6.13} \mathrm{Te}_{10}$ bulk samples (Table S5, ESIt). The measured Mn concentrations match the nominal compositions significantly better than those expected for stoichiometric $\mathrm{MnBi}_{4} \mathrm{Te}_{7}$ and $\mathrm{MnBi}_{6} \mathrm{Te}_{10}$. Very small amounts of a manganese telluride side phase were detected in the bulk sample $\mathrm{Mn}_{0.85} \mathrm{Bi}_{4.10} \mathrm{Te}_{7}$ by SEM-EDX; in $\mathrm{Mn}_{0.81} \mathrm{Bi}_{6.13} \mathrm{Te}_{10}$, however, appeared to be phase-pure (Fig. S4, ESI+). Note that nominal compositions $\mathrm{Mn}_{0.92} \mathrm{Bi}_{4.08} \mathrm{Te}_{7}$ and $\mathrm{Mn}_{0.85} \mathrm{Bi}_{6.15} \mathrm{Te}_{10}$ derived from refinements not assuming charge neutrality (section 3.3) but full occupation of all Wyckoff positions yield no single phases according to Rietveld refinements, at least not with the synthesis route described above (Fig. S5, ESI+).

The composition has been varied in order to check whether the compounds form solid solutions. Charge neutrality assuming $\mathrm{Mn}^{\prime \prime}, \mathrm{Bi}^{\mathrm{III}}, \mathrm{Te}^{-11}$ and cation vacancies was taken into account as these compounds exhibit small bandgaps (section 3.6). The composition can be varied in the range of $x=0.15-$ 0.20 for $\mathrm{Mn}_{1-x} \square_{x / 3} \mathrm{Bi}_{4+2 x / 3} \mathrm{Te}_{7}$ and in the range of $x=0.19-0.26$ for $\mathrm{Mn}_{1-x} \square_{x / 3} \mathrm{Bi}_{6+2 x / 3} \mathrm{Te}_{10}$. The homogeneity of the corresponding bulk samples has been confirmed by Rietveld refinements and EDX measurements (see Fig. S6, and Table S6, $\mathrm{ESI}+$ ). Lattice parameters do not change significantly (Tables S4, and S7, ESI + ). This might be due to vacancies compensating the effect of different atom radii. 

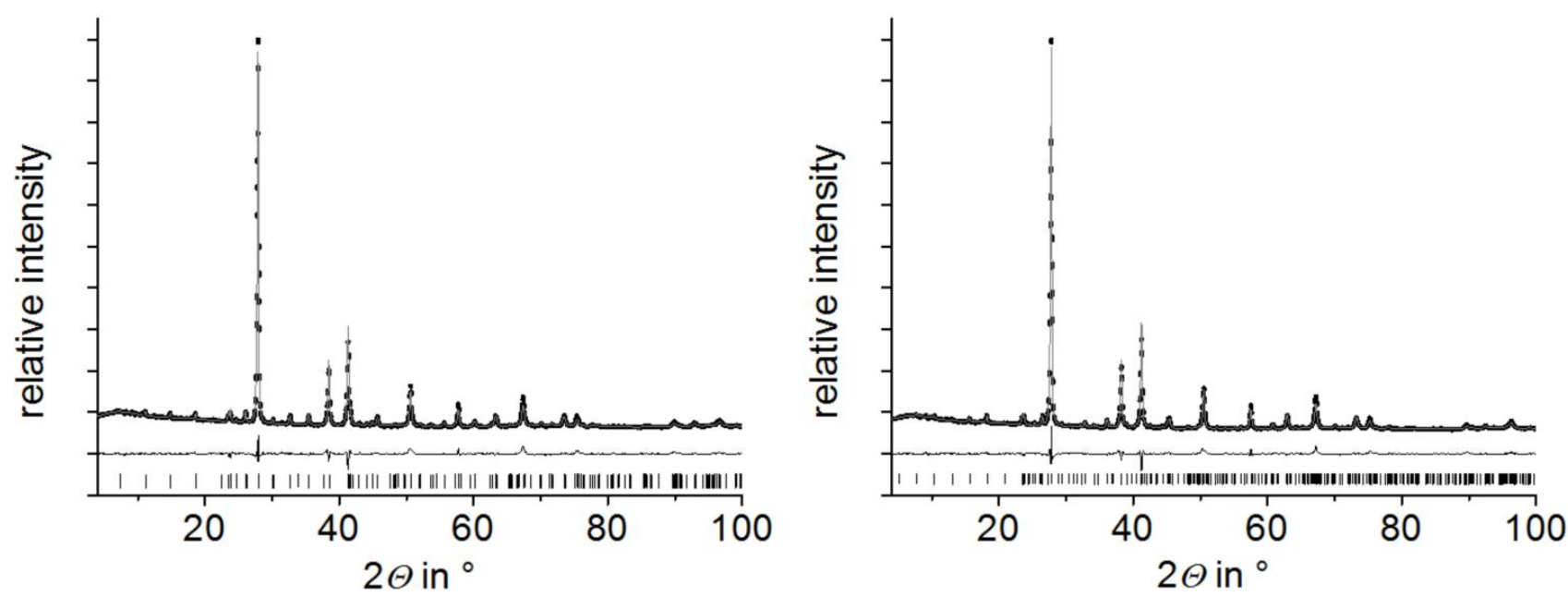

Fig. 1 PXRD patterns of $\mathrm{Mn}_{0.85} \mathrm{Bi}_{4.10} \mathrm{Te}_{7}$ (left) and $\mathrm{Mn}_{0.81} \mathrm{Bi}_{6.13} \mathrm{Te}_{10}$ (right); Rietveld refinements taking into account structure models based on SCXRD refinements (section 3.3) for $\mathrm{Mn}_{0.85} \mathrm{Bi}_{4.10} \mathrm{Te}_{7}\left(\mathrm{GeBi}_{4} \mathrm{Te}_{7}\right.$-type structure), $\mathrm{Mn}_{0.73} \mathrm{Bi}_{6.18} \mathrm{Te}_{10}\left(\mathrm{GeBi}_{6} \mathrm{Te}_{10}\right.$-type structure, the slightly different $\mathrm{Mn}$ content has no influence on the Rietveld refinement); experimental

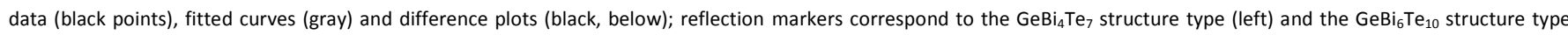
(right), respectively.

3.2 Stability of manganese bismuth tellurides with $\mathrm{GeBi}_{4} \mathrm{Te}_{7}$ or $\mathrm{GeBi}_{6} \mathrm{Te}_{10}$ structure type as a function of particle size

Annealing at $585^{\circ} \mathrm{C}$ and subsequent quenching affords phasepure samples of $\mathrm{Mn}_{0.85} \mathrm{Bi}_{4.10} \mathrm{Te}_{7}$ with $\mathrm{GeBi}_{4} \mathrm{Te}_{7}$-type structure and $\mathrm{Mn}_{0.81} \mathrm{Bi}_{6.13} \mathrm{Te}_{10}$ with $\mathrm{GeBi}_{6} \mathrm{Te}_{10}$-type structure according to PXRD patterns. Temperature-programmed PXRD data show no changes except thermal expansion up to ca. $210{ }^{\circ} \mathrm{C}$ (Fig. 2). At this temperature, both compounds start decomposing into phases with $\mathrm{Bi}_{2} \mathrm{Te}_{3}$ structure type and a $\mathrm{Mn}$-rich phase as visible in samples after thermoelectric measurements (section 3.6, Fig. S7, ESIt). The decomposition of fine powdered samples is complete at $270{ }^{\circ} \mathrm{C}$ for $\mathrm{Mn}_{0.85} \mathrm{Bi}_{4.10} \mathrm{Te}_{7}$ and at $295{ }^{\circ} \mathrm{C}$ for $\mathrm{Mn}_{0.81} \mathrm{Bi}_{6.13} \mathrm{Te}_{10}$. Fig. 2 shows the disappearance of characteristic low-angle reflections of the long-periodic structures and the emergence of typical reflections of the $\mathrm{Bi}_{2} \mathrm{Te}_{3}$ structure type upon decomposition (Fig S8, ESI + ). Temperature-programmed PXRD data of $\mathrm{MnBi}_{2} \mathrm{Te}_{4}$ show similar decomposition. ${ }^{31,32}$ Reference 34 does not report this decomposition as temperature-dependent PXRD was not used but is crucial to detect the metastability. In addition, the decomposition of bulk samples is much slowet as discussed later in this chapter. As this decomposition extends over a wide temperature range, it cannot be detected in DSC measurements (Fig. 3 and Fig. 4), which has been discussed in detail for $\mathrm{MnBi}_{2} \mathrm{Te}_{4}{ }^{32}$ However, there are characteristic DSC signals for other effects, whose tentative assignment is listed for $\mathrm{Mn}_{0.85} \mathrm{Bi}_{4.10} \mathrm{Te}_{7}$ in Table S8 and Fig. S9 (ESIt) and for $\mathrm{Mn}_{0.81} \mathrm{Bi}_{6.13} \mathrm{Te}_{10}$ in Table S9 and Fig. S10 (ESI + ). Upon heating of $\mathrm{Mn}_{0.85} \mathrm{Bi}_{4.10} \mathrm{Te}_{7}$, two endothermic signals are observed (Fig. 3). We attribute the first signal to the melting of $\mathrm{Bi}_{2} \mathrm{Te}_{3}$ (a shoulder on the low-temperature side of the first signal) and of $\mathrm{Mn}_{0.85} \mathrm{Bi}_{4.10} \mathrm{Te}_{7}$, since the starting material was partially decomposed (Fig. S11, ESIt). It is followed by the melting of another compound, possibly $\mathrm{MnBi}_{2} \mathrm{Te}_{4}$, whose slow exothermic formation is unlikely to be detected. ${ }^{32,33}$ The first cooling curve shows three exothermic signals, which can be assigned to the solidification of $\mathrm{Bi}_{2} \mathrm{Te}_{3}, \mathrm{Mn}_{0.85} \mathrm{Bi}_{4.10} \mathrm{Te}_{7}$ and $\mathrm{MnBi}_{2} \mathrm{Te}_{4}$, respectively, as tentatively confirmed by PXRD (Fig. $\mathrm{S} 12, \mathrm{ESI}+$ ). The second heating cycle is similar.
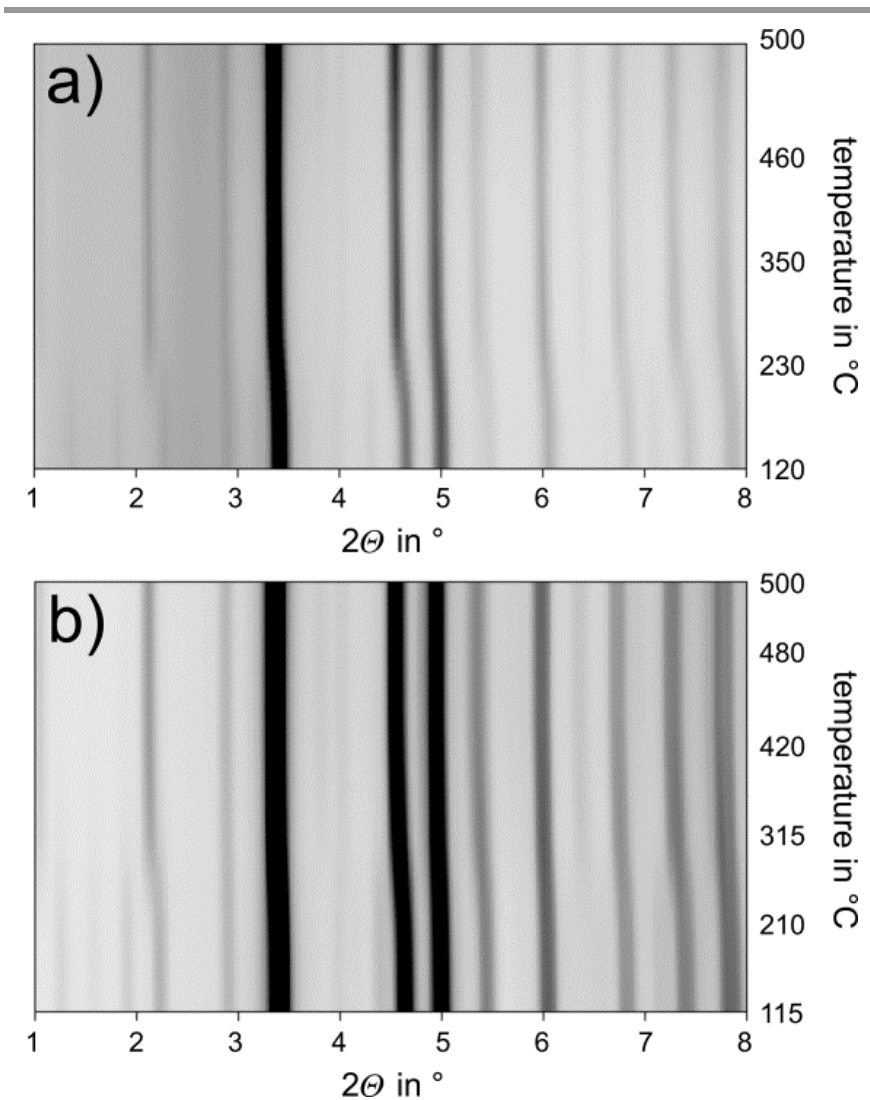

Fig. 2 Temperature-programmed PXRD starting from phase-pure samples with the compositions (a) $\mathrm{Mn}_{0.85} \mathrm{Bi}_{4.10} \mathrm{Te}_{7}$ and (b) $\mathrm{Mn}_{0.81} \mathrm{Bi}_{6.13} \mathrm{Te}_{10}$, synchrotron radiation $(\lambda=$ $0.18972 \AA$ Å), heating rate $20 \mathrm{~K} \mathrm{~min}^{-1}$. 

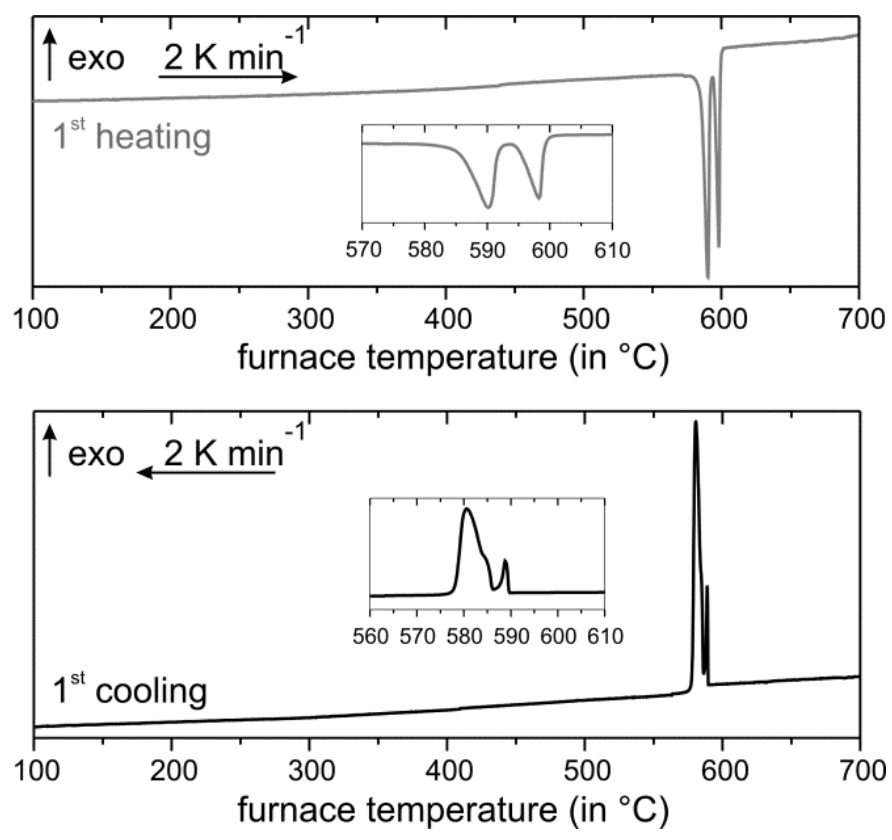

Fig. $3 \mathrm{DSC}$ of $\mathrm{Mn}_{0.85} \mathrm{Bi}_{4.10} \mathrm{Te}_{7}$ : first heating (top) and cooling (bottom) curves.

The DSC curve upon heating of $\mathrm{Mn}_{0.81} \mathrm{Bi}_{6.13} \mathrm{Te}_{10}$ shows four endothermic signals (Fig. 4). The first one might indicate small amounts of a Bi-rich bismuth telluride, which could form next to $\mathrm{MnTe}_{2}$ by redox decomposition (compare Fig. S13, ESIt). In analogy with the above interpretation for the $\mathrm{Mn}_{0.85} \mathrm{Bi}_{4.10} \mathrm{Te}_{7}$ sample, the following signals probably correspond to the almost simultaneous melting of $\mathrm{Bi}_{2} \mathrm{Te}_{3}$ and $\mathrm{Mn}_{0.81} \mathrm{Bi}_{6.13} \mathrm{Te}_{10}$, then of $\mathrm{Mn}_{0.85} \mathrm{Bi}_{4.10} \mathrm{Te}_{7}$, and of $\mathrm{MnBi}_{2} \mathrm{Te}_{4}$. The cooling curve hosts a broad unstructured signal that may indicate glassy behavior or partial crystallization of disordered compounds (Fig. 4). We speculate that just above the melting point of $\mathrm{Bi}_{2} \mathrm{Te}_{3}$, the $\mathrm{Mn}$-containing ternaries undergo a series of stepwise structure transformations. The DSC experiment was probably too fast to resolve these transitions. PXRD after the DSC measurement indicates a $\mathrm{Bi}_{2} \mathrm{Te}_{3}$-type structure mixed with $\mathrm{GeBi}_{4} \mathrm{Te}_{7}$ - and $\mathrm{GeBi}_{6} \mathrm{Te}_{10^{-}}$and possibly $\mathrm{GeBi}_{2} \mathrm{Te}_{4}$-type structures (Fig. S14, ESI+). The second DSC heating cycle is similar but shows fewer signals during heating (Table S9 and Fig. S10, ESIt).

Due to these complex phase relationships, manganese bismuth tellurides with $\mathrm{GeBi}_{4} \mathrm{Te}_{7}$-type or $\mathrm{GeBi}_{6} \mathrm{Te}_{10}$-type structure cannot be obtained by quenching or slowly cooling the melt. Annealing in the existence range of the compounds is essential. As they constitute high-temperature phases that decompose at lower temperatures, quenching after the annealing step is beneficial.
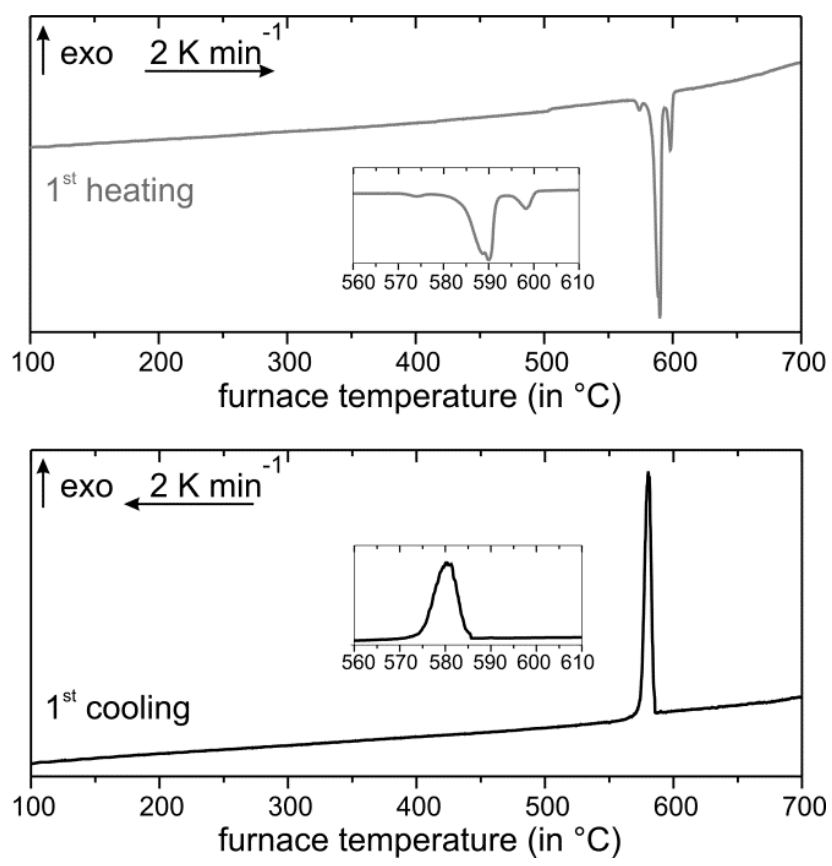

Fig. 4 DSC of $\mathrm{Mn}_{0.81} \mathrm{Bi}_{6.13} \mathrm{Te}_{10}$ : first heating (top) and cooling (bottom) curves.

However, ex situ SEM images and EDX measurements after three heating cycles up to $400{ }^{\circ} \mathrm{C}$, which were performed for thermoelectric characterization (section 3.6), show that the decomposition is much slower in compact ingots; the samples still consist mainly of the initial phase (Fig. S15 and Table S10, ESIt). Corresponding Rietveld refinements reveal ca. $80 \%$ of the main phase along with possibly $\mathrm{Mn}$-doped $\mathrm{Bi}_{2} \mathrm{Te}_{3}{ }^{59}$ (space group $R \overline{3} m$ ) and $\mathrm{MnTe}_{2}{ }^{60}$ with pyrite-type structure (space group Pa3) (Fig. S7, ESI+). Thus, the metastability with respect to decomposition is best shown using very fine powders.

As mentioned above, this metastability was also observed for $\mathrm{MnBi}_{2} \mathrm{Te}_{4}$, where the decomposition products should be nonstoichiometric Bi-rich bismuth tellurides ${ }^{61-63}$ " $\mathrm{Bi}_{2} \mathrm{Te}_{3-x}$ " and $\mathrm{MnTe}_{2-\mathrm{y}}{ }^{31,32}$ According to temperature-programmed PXRD, $\mathrm{GeBi}_{4} \mathrm{Te}_{7}$ - and $\mathrm{GeBi}_{6} \mathrm{Te}_{10}$-type compounds are not formed from decomposed samples during cooling (Fig. S16 and S17, ESIt). This could mean that the reaction is too slow at $500{ }^{\circ} \mathrm{C}$ and below, or that the decomposition products are spatially segregated, resulting in strongly inhibited solid-state reactivity. A possible reason for the increased stability of the bulk material compared to the finely ground samples could be that the metastable compounds decompose faster after many defects were brought into the crystal structure by crushing and that stresses in compact samples may hinder decomposition.

In order to exclude alternative explanations such as reactions with the silica-glass capillary or impurities, crushed samples of $\mathrm{Mn}_{0.81} \mathrm{Bi}_{6.13} \mathrm{Te}_{10}$ and $\mathrm{Mn}_{0.85} \mathrm{Bi}_{4.15} \mathrm{Te}_{7}$ were annealed in silicaglass ampules at $300{ }^{\circ} \mathrm{C}$ for 1 day, so that most of the single phases decomposed to a Bi-rich $\mathrm{Bi}_{2} \mathrm{Te}_{3}$-like phase and $\mathrm{MnTe}_{2}$ (pyrite type, $P a \overline{3}$ ) (Fig. S18, ESIt). After this treatment, the samples were used as starting material for our synthesis route, i.e. they were melted again, followed by annealing and quenching. This again leads to phase-pure samples according to PXRD (Fig. S19, ESIt). 
3.3 Crystal structures of $\mathrm{Mn}_{0.85(3)} \mathrm{Bi}_{4.10(2)} \mathrm{Te}_{7}$ and

$\mathrm{Mn}_{\mathbf{0 . 7 3 ( 4 )}} \mathrm{Bi}_{6.18(2)} \mathrm{Te}_{10}$

The crystal structures of representative crystals of manganese bismuth tellurides with $\mathrm{GeBi}_{4} \mathrm{Te}_{7}$-type and $\mathrm{GeBi}_{6} \mathrm{Te}_{10}$-type structures were elucidated from X-ray diffraction data. In the structure refinements, charge neutrality was used as a constraint assuming oxidation states of II for $\mathrm{Mn}$ and III for $\mathrm{Bi}$. The presence of $\mathrm{Mn}^{\prime \prime}$ is also in accordance with the magnetization measurements, i.e., the effective moment $\mu_{\text {eff }}$ is in agreement with the value expected for $\mathrm{Mn}^{\text {" }}$ for both compounds (cf. section 3.5). Furthermore, other oxidation states seem unlikely as the oxidation potential of $\mathrm{Te}$ is not expected to enable higher oxidation states of the cations. Lower oxidation states of $\mathrm{Bi}$ are typically characterized by homoatomic bonds. ${ }^{64}$ In the related compound $\mathrm{MnBi}_{2} \mathrm{Te}_{4}$, the exclusive presence of $\mathrm{Mn}^{2+}$ was shown by X-ray absorption spectroscopy and confirmed by magnetic susceptibility measurements. ${ }^{32,33}$ Mixed occupancies of $\mathrm{Mn}$ and $\mathrm{Bi}$ on all cation sites were refined as indicated by the scattering density present and the resulting $R$-values. Cation vacancies were assumed to be located only on the Wyckoff positions $1 b$ for $\mathrm{Mn}_{0.85} \mathrm{Bi}_{4.10} \mathrm{Te}_{7}$ and $3 a$ for $\mathrm{Mn}_{0.73} \mathrm{Bi}_{6.18} \mathrm{Te}_{10}$, which represent the center of the $\mathrm{GeBi}_{2} \mathrm{Te}_{4}$-type building blocks, since vacancies close to the van der Waals gaps are very unfavorable due to a resulting very low coordination number 2 for Te atoms at the van der Waals gap.

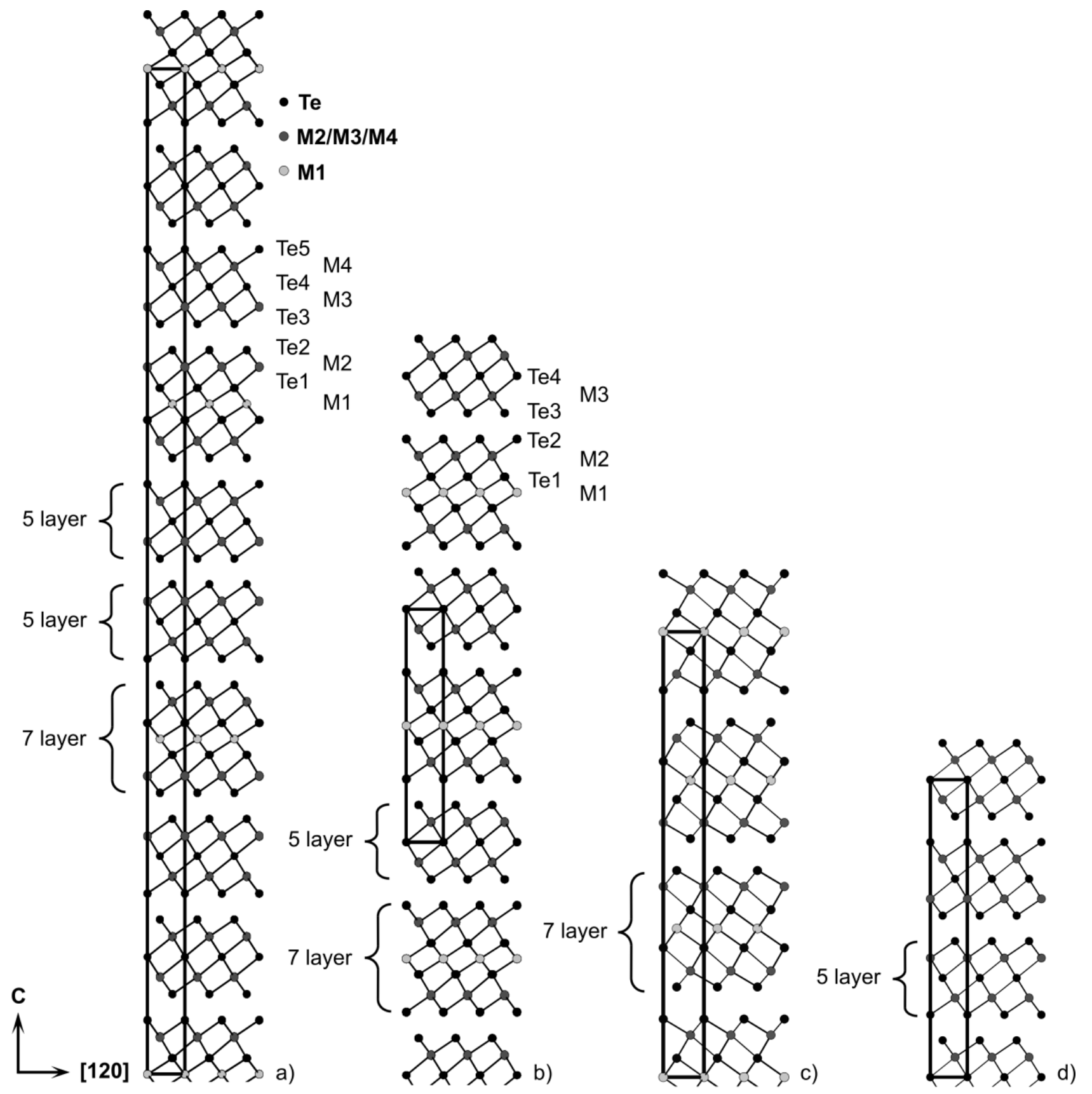

Fig. 5 Crystal structures of a) $\mathrm{Mn}_{0.81} \mathrm{Bi}_{6.13} \mathrm{Te}_{10}$ with $\mathrm{GeBi}_{6} \mathrm{Te}_{10}$-type structure; b) $\mathrm{Mn}_{0.85} \mathrm{Bi}_{4.10} \mathrm{Te}_{7}$ with $\mathrm{GeBi}_{4} \mathrm{Te}_{7}$-type structure; c) $\mathrm{Mn}_{0.85} \mathrm{Bi}_{2.1} \mathrm{Te}_{4}{ }^{32}$ with $\mathrm{GeBi}_{2} \mathrm{Te}_{4}$-type structure; d) $\mathrm{Bi}_{2} \mathrm{Te}_{3}{ }^{24}$ - for cation distribution, including mixed sites, cf. Tables 2 and 4 ( $\mathrm{M} 1$ is the Mn-rich site). 
$\mathrm{Mn}_{\mathbf{0 . 8 5 ( 3 )}} \mathrm{Bi}_{4.10(2)} \mathrm{Te}_{7}$

Crystallographic data and details of the structure refinement for a crystal with the refined composition $\mathrm{Mn}_{0.85(3)} \mathrm{Bi}_{4.10(2)} \mathrm{Te}_{7}$ isolated from a heterogeneous sample with the nominal composition $\mathrm{MnBi}_{6} \mathrm{Te}_{10}$ are listed in Table 1, atomic positions and displacement parameters are given in Table 2 . In contrast to $\mathrm{Mn} / \mathrm{Bi}$ intermixing on the cation sites, the vacancy concentration of $5.1(17) \%$ on the $1 b$ site seems not very significant; the assumption of an idealized composition $\mathrm{MnBi}_{4} \mathrm{Te}_{7}$ results in almost the same residuals ( $R 1=0.0332$ for $I>2 \sigma(I))$. However, such an idealized composition yields no single-phase samples (cf. section 3.1). The EDX analysis of the investigated crystal (Fig. S20, ESIT) yields the composition $\mathrm{Mn}_{5.8(5)} \mathrm{Bi}_{35.9(5} \mathrm{Te}_{58.3(3)}$, which confirms a deficiency of $\mathrm{Mn}$ in good agreement with the nominal composition of $\mathrm{Mn}_{0.85} \mathrm{Bi}_{4.10} \mathrm{Te}_{7}=\mathrm{Mn}_{7.1} \mathrm{Bi}_{34.3} \mathrm{Te}_{58.6}$ (Table S11, ESI ${ }^{+}$).

A refinement without assuming charge neutrality but full site occupancies (i.e., no vacancies) also results in similar $R$-values and a composition $\mathrm{Mn}_{0.92} \mathrm{Bi}_{4.08} \mathrm{Te}_{7}$; however, corresponding reactions also yield no single-phase products (cf. section 3.1). $\mathrm{Mn}_{0.85} \mathrm{Bi}_{4.10} \mathrm{Te}_{7}$ crystallizes in the space group $P \overline{3} m 1$ and can be described by a $12 P$ stacking sequence with two different building blocks (Fig. 5b): double layers of edge-sharing [ $\mathrm{BiTe}_{3 / 3} \mathrm{Te}_{3 / 6}$ ] octahedra similar to those in $\mathrm{Bi}_{2} \mathrm{Te}_{3}{ }^{24}$ (Fig. 5d) and $\mathrm{GeBi}_{2} \mathrm{Te}_{4}$-type (Fig. $5 \mathrm{c}$ ) septuple layers of condensed octahedra described by ${ }_{\infty}^{2}\left[\mathrm{Te}_{3 / 3} M\left(\mu-\mathrm{Te}_{3 / 6}\right) M\left(\mu-\mathrm{Te}_{3 / 6}\right) M T e_{3 / 3}\right]$. The atomic interaction within each layer is much stronger than the interlayer van-der-Waals-like bonding. Similar lattice parameters were reported for $\mathrm{Mn}$-doped BiTe (space group $P \overline{3} m 1 ; a=4.3783(1) \AA, c=23.8107(8) \AA),{ }^{65}$ whose BiSe-type structure consists of $\mathrm{Bi}_{2} \mathrm{Te}_{3}$-like layers separated by double layers of $\mathrm{Bi}$ atoms resembling those in elemental $\mathrm{Bi}$. However, such a structure model cannot reproduce our diffraction data.

\section{$\mathbf{M n}_{\mathbf{0 . 7 3 ( 4 )}} \mathrm{Bi}_{6.18(2)} \mathrm{Te}_{10}$}

Crystallographic data and details of the structure refinement for a crystal with the refined composition $\mathrm{Mn}_{0.73(4)} \mathrm{Bi}_{6.18(2)} \mathrm{Te}_{10}$ isolated from a heterogeneous sample with the nominal composition $\mathrm{MnBi}_{6} \mathrm{Te}_{10}$ are given in Table 1; atomic positions and displacement parameters are listed in Table 3. Based on the above mentioned constraints, the refinement yields a significant vacancy concentration of $9(2) \%$ on the site $1 b$. Constraining to the stoichiometric composition $\mathrm{MnBi}_{6} \mathrm{Te}_{10}$ leads to higher residuals $(R 1=0.0315$ for $I>2 \sigma(I))$ and such an idealized composition does not lead to single-phase samples (cf. section 3.1). Assuming full occupancies without constraining to charge neutrality yields a composition of $\mathrm{Mn}_{0.85} \mathrm{Bi}_{6.15} \mathrm{Te}_{10}$, again not suitable for the synthesis of singlephase samples. The EDX analysis of the crystal used for data collection (Fig. S21 and Table S12, ESIt) confirms a Mn $\mathrm{Mn}_{0.73} \mathrm{Bi}_{6.18} \mathrm{Te}_{10}$ obtained in the structure refinement. In space group $R \overline{3} m$, the asymmetric unit consists of distorted $\mathrm{NaCl}-$ type septuple building blocks similar to those in $\mathrm{GeBi}_{4} \mathrm{Te}_{7}$, which are separated by two $\mathrm{Bi}_{2} \mathrm{Te}_{3}$-like layers, resulting in a deficiency and is in good agreement with the composition $51 R$ stacking sequence (Fig. 5a). Again, $\mathrm{Mn} / \mathrm{Bi}$ intermixing, especially on the $3 a$, is a characteristic feature of this structure.

Table 1 Crystallographic data for the single-crystal structure determination of $\mathrm{Mn}_{0.85(3)} \mathrm{Bi}_{4.10(2)} \mathrm{Te}_{7}$ with $\mathrm{GeBi}_{4} \mathrm{Te}_{7}$-type structure and $\mathrm{Mn}_{0.73(4)} \mathrm{Bi}_{6.18(2)} \mathrm{Te}_{10}$ with $\mathrm{GeBi}_{6} \mathrm{Te}_{10^{-}}$ type structure.

\begin{tabular}{|c|c|c|}
\hline $\begin{array}{l}\text { chemical } \\
\text { formula }\end{array}$ & $\begin{array}{c}\mathrm{Mn}_{0.85(3)} \square_{0.05(2)} \mathrm{Bi}_{4.10(2)}{ }^{\top} \\
\mathrm{e}_{7} \\
\end{array}$ & $\mathrm{Mn}_{0.73(4)} \square_{0.09(2)} \mathrm{Bi}_{6.18(2)} \mathrm{Te}_{10}$ \\
\hline$M\left(\right.$ in $\left.\mathrm{g} \mathrm{mol}^{-1}\right)$ & 1796.72 & 2608.1 \\
\hline$F(000)$ & 726 & 3154 \\
\hline $\begin{array}{l}\text { crystal system / } \\
\text { space group }\end{array}$ & $\begin{array}{c}\text { trigonal / P3m1 } \\
\text { (no. 164) }\end{array}$ & $\begin{array}{l}\text { trigonal / } R \overline{3} m \\
\text { (no. 166) }\end{array}$ \\
\hline lattice & $a=4.3591(3)$ & $a=4.3698(3)$, \\
\hline $\begin{array}{c}\text { parameters (in } \\
\AA \text { A) }\end{array}$ & $c=23.769(2)$ & $c=101.829(8)$ \\
\hline$V\left(\right.$ in $\left.\AA^{3}\right)$ & $391.41(6)$ & $1683.9(3)$ \\
\hline Z & 1 & 3 \\
\hline$\rho\left(\right.$ in $\left.\mathrm{g} \mathrm{cm}^{-3}\right)$ & 7.63 & 7.72 \\
\hline$\mu\left(\right.$ in $\left.\mathrm{mm}^{-1}\right)$ & 32.26 & 13.45 \\
\hline $\begin{array}{l}\text { absorption } \\
\text { correction }\end{array}$ & numerical & semiempirical $^{46}$ \\
\hline radiation & $\lambda=\begin{array}{l}\mathrm{Ag}-K_{\alpha}, \\
0.56086 \AA\end{array}$ & $\begin{array}{l}\text { synchrotron, } \\
\lambda=0.30996 \AA\end{array}$ \\
\hline $\begin{array}{l}\text { independent } \\
\text { reflections }\end{array}$ & 594 & 723 \\
\hline$d_{\min }($ in $\AA$ ) & 0.68 & 0.72 \\
\hline $\begin{array}{c}\text { refined } \\
\text { parameter / } \\
\text { restraints }\end{array}$ & $27 / 3$ & $36 / 4$ \\
\hline$\theta_{\min } / \theta_{\max }\left(\right.$ in $\left.^{\circ}\right)$ & $2.03 / 24.30$ & $1.83 / 12.43$ \\
\hline $\begin{array}{l}\text { extinction } \\
\text { coefficient }\end{array}$ & - & $0.0045(3)$ \\
\hline$R_{\sigma} / R_{\mathrm{int}}$ & 0.0322 / 0.0649 & 0.0549 / 0.0706 \\
\hline$R$ indices & $R 1=0.0331$ & $R 1=0.0303$ \\
\hline$[I>2 \sigma(I)]$ & $w R 2=0.0874$ & $w R 2=0.0703$ \\
\hline $\begin{array}{l}R \text { indices } \\
\text { (all data) }\end{array}$ & $\begin{array}{r}R 1=0.0357, \\
w R 2=0.0895\end{array}$ & $\begin{array}{c}R 1=0.0312, \\
w R 2=0.0712\end{array}$ \\
\hline GoF (all) & 1.08 & 1.20 \\
\hline $\begin{array}{c}\Delta \rho_{\min } / \Delta \rho_{\max } \\
\quad\left(\text { in e } \AA^{-3}\right)\end{array}$ & $-1.52 / 1.53$ & $-3.19 / 2.10$ \\
\hline
\end{tabular}


Table 2 Wyckoff positions, atomic coordinates, site occupancies and coefficients of the anisotropic as well as equivalent isotropic displacement parameters (in $\AA^{2}$ ) of $\left.\mathrm{Mn}_{0.85} \mathrm{Bi}_{4.10} \mathrm{Te}_{7}\left(U_{\text {eq }}=1 / 3\left[U_{11}+U_{22}+U_{33}\right)\right]\right)$.

\begin{tabular}{|c|c|c|c|c|c|}
\hline Atom & W. p. & $x$ & $y$ & $z$ & occ. \\
\hline Mn1/ & $1 b$ & 0 & 0 & $1 / 2$ & $0.694(11) /$ \\
\hline Bi1/ & & & & & $0.255(6) /$ \\
\hline$\square$ & & & & & $0.051(17)$ \\
\hline $\mathrm{Mn} 2 /$ & $2 d$ & $1 / 3$ & $2 / 3$ & 0.3423 & $0.0414(4) /$ \\
\hline $\mathrm{Bi} 2$ & & & & & $0.959(3)$ \\
\hline Mn3/ & $2 d$ & $1 / 3$ & $2 / 3$ & 0.0860 & $0.035(3) /$ \\
\hline $\mathrm{Bi3}$ & & & & & $0.965(3)$ \\
\hline Te1 & $2 d$ & $1 / 3$ & $2 / 3$ & 0.5680 & 1 \\
\hline Te2 & $2 c$ & 0 & 0 & 0.2703 & 1 \\
\hline Te3 & $2 d$ & $1 / 3$ & $2 / 3$ & 0.8413 & 1 \\
\hline Te4 & $1 a$ & 0 & 0 & 0 & 1 \\
\hline Atom & \multicolumn{2}{|c|}{$U_{11}=U_{22}=2 U_{12}$} & $U_{33}$ & $U_{23}=U_{13}$ & $U_{\text {eq }}$ \\
\hline Mn1/ & \multicolumn{2}{|c|}{$0.0334(7)$} & $0.0314(10)$ & 0 & $0.0328(6)$ \\
\hline \multicolumn{6}{|l|}{$\mathrm{Bi} 1 / \square$} \\
\hline $\mathrm{Mn} 2 /$ & \multirow{2}{*}{\multicolumn{2}{|c|}{$0.0315(2)$}} & $0.0368(4)$ & 0 & $0.0333(2)$ \\
\hline $\mathrm{Bi} 2$ & & & & & \\
\hline Mn3/ & \multirow{2}{*}{\multicolumn{2}{|c|}{$0.0300(3)$}} & $0.0352(3)$ & 0 & $0.0318(2)$ \\
\hline $\mathrm{Bi3}$ & & & & & \\
\hline Te1 & \multicolumn{2}{|c|}{$0.0336(3)$} & $0.0291(5)$ & 0 & $0.0321(3)$ \\
\hline Te2 & \multicolumn{2}{|c|}{$0.0295(3)$} & $0.0315(5)$ & 0 & $0.0302(3)$ \\
\hline Te3 & \multicolumn{2}{|c|}{$0.0290(3)$} & $0.0308(5)$ & 0 & $0.0296(3)$ \\
\hline Te4 & \multicolumn{2}{|c|}{$0.0269(4)$} & $0.0269(6)$ & 0 & $0.0269(3)$ \\
\hline
\end{tabular}

\section{Comparison of selected interatomic distances with $\mathrm{Bi}_{2} \mathrm{Te}_{3}$ and} $\mathrm{Mn}_{\mathbf{0 . 8 5}} \mathrm{Bi}_{2.1} \mathrm{Te}_{4}{ }^{32}$

Selected interatomic distances are listed in Table S13 (ESI $\left.{ }^{\dagger}\right)$. Bond lengths in the $\mathrm{Bi}_{2} \mathrm{Te}_{3}$-like quintuple layers in $\mathrm{Mn}_{0.85} \mathrm{Bi}_{4.10} \mathrm{Te}_{7}$, i.e. $d(\mathrm{M3}-\mathrm{Te})=3.0543(7) \AA$ and $d(M 3-\mathrm{Te} 4)=$ 3.2410 (4) $\AA$ (labelling cf. Fig. 5), deviate by only $0.4 \%$ from interatomic distances in $\mathrm{Bi}_{2} \mathrm{Te}_{3}{ }^{66}$ itself $[d(\mathrm{Bi}-\mathrm{Te} 2)=3.067 \AA$, $d(\mathrm{Bi}-\mathrm{Te} 1)=3.254 \AA]$; they are slightly shorter by $\sim 0.01 \AA$ as the cation position contains $3 \%-4 \%$ of $\mathrm{Mn}^{2+}$, whose radius $(0.81 \AA$ for CN 6), which is smaller than that of $\mathrm{Bi}^{3+}\left(1.17 \AA\right.$ for $\mathrm{CN} \mathrm{6).}{ }^{67}$ The quintuple layers in $\mathrm{Mn}_{0.73(4)} \mathrm{Bi}_{6.18(2)} \mathrm{Te}_{10}[d(\mathrm{M3}-\mathrm{Bi} 3)=$ $3.0628(5) \AA, d(M 3-T e 4)=3.2395(5) \AA, d(M 4-T e 4)=$ $3.2536(5) \AA, d(M 4-T e 5)=3.0594(5) \AA]$ exhibit the same tendency and deviate only up to $0.4 \%$ from the interatomic distances in $\mathrm{Bi}_{2} \mathrm{Te}_{3}$. All cation-anion bond lengths in the septuple slab of $\mathrm{Mn}_{0.85} \mathrm{Bi}_{4.10} \mathrm{Te}_{7}[d(M 2-\mathrm{Te2})=3.0436(7) \AA$, $d(\mathrm{M} 2-\mathrm{Te} 1)=3.2987(9) \AA, d(\mathrm{M} 1-\mathrm{Te} 1)=2.9909(7) \AA]$ and $\mathrm{Mn}_{0.73} \mathrm{Bi}_{6.18} \mathrm{Te}_{10}[d(\mathrm{M} 2-\mathrm{Te} 2)=3.0473(5) \AA, d(M 2-\mathrm{Te} 1)=$ 3.3055(6) $\AA, d(M 1-\mathrm{Te} 1)=2.9969(4) \AA$ ) host more bismuth are thus slightly longer than the corresponding bond lengths in $\mathrm{Mn}_{0.85} \mathrm{Bi}_{2.1} \mathrm{Te}_{4}[d(\mathrm{M} 1-\mathrm{Te} 2)=3.027(1) \AA, \quad d(\mathrm{M} 1-\mathrm{Te} 1)=$ 3.291(1) $\AA, d(M 2-T e 1)=2.977(1) \AA] .{ }^{32}$ On the other hand, the distances across the van der Waals gaps between the quintuple and the septuple slab in $\mathrm{Mn}_{0.85} \mathrm{Bi}_{4.10} \mathrm{Te}_{7}[d(\mathrm{Te} 2-\mathrm{Te} 3)$ $=3.6559(7) \AA ̊]$ and $\mathrm{Mn}_{0.73} \mathrm{Bi}_{6.18} \mathrm{Te}_{10}[\mathrm{~d}(\mathrm{Te} 2-\mathrm{Te} 3)=3.6516(5) \AA]$ decrease slightly with higher bismuth concentration.
Table 3 Wyckoff positions, atomic coordinates, site occupancies and coefficients of the anisotropic as well as equivalent isotropic displacement parameters (in $\AA^{2}$ ) for $\mathrm{Mn}_{0.73} \mathrm{Bi}_{6.18} \mathrm{Te}_{10}\left(U_{\text {eq }}=1 / 3\left[U_{11}+U_{22}+U_{33}\right]\right.$.

\begin{tabular}{|c|c|c|c|c|c|}
\hline Atom & W. p. & $x$ & $y$ & $z$ & occ. \\
\hline Mn1/ & $3 a$ & 0 & 0 & 0 & $0.634(16) /$ \\
\hline $\mathrm{Bi} 1 /$ & & & & & $0.275(6) /$ \\
\hline$\square$ & & & & & $0.09(2)$ \\
\hline $\mathrm{Mn} 2 /$ & $6 c$ & 0 & 0 & $0.29647(2)$ & $0.017(4) /$ \\
\hline $\mathrm{Bi} 2$ & & & & & $0.983(3)$ \\
\hline $\mathrm{Mn3} /$ & $6 c$ & 0 & 0 & $0.23671(2)$ & $0.015(4) /$ \\
\hline $\mathrm{Bi} 3$ & & & & & $0.985(3)$ \\
\hline Mn4/ & $6 c$ & 0 & 0 & $0.47010(2)$ & $0.014(4) /$ \\
\hline $\mathrm{Bi} 4$ & & & & & $0.986(3)$ \\
\hline Te1 & $6 c$ & 0 & 0 & $0.34922(2)$ & 1 \\
\hline Te2 & $6 c$ & 0 & 0 & $0.05365(2)$ & 1 \\
\hline Te3 & $6 c$ & 0 & 0 & $0.41290(2)$ & 1 \\
\hline Te4 & $6 c$ & 0 & 0 & $0.11658(2)$ & 1 \\
\hline Te5 & $6 c$ & 0 & 0 & $0.17957(2)$ & 1 \\
\hline Atom & $U_{11}=U_{22}=2 U_{12}$ & & $U_{33}$ & $U_{23}=U_{13}$ & $U_{\text {eq }}$ \\
\hline Mn1/ & $0.0221(5)$ & & $0.0238(8)$ & 0 & $0.0227(4)$ \\
\hline \multicolumn{6}{|l|}{$\mathrm{Bi} 1 / \square$} \\
\hline $\mathrm{Mn} 2 /$ & $0.02252(17)$ & & $0.0278(3)$ & 0 & $0.02428(16)$ \\
\hline \multicolumn{6}{|l|}{$\mathrm{Bi} 2$} \\
\hline $\mathrm{Mn3} /$ & $0.0208(2)$ & & $0.0269(3)$ & 0 & $0.02283(19)$ \\
\hline \multicolumn{6}{|l|}{$\mathrm{Bi3}$} \\
\hline Mn4/ & $0.0208(2)$ & & $0.0265(3)$ & 0 & $0.02269(19)$ \\
\hline \multicolumn{6}{|l|}{$\mathrm{Bi} 4$} \\
\hline Te1 & $0.0233(2)$ & & $0.0207(4)$ & 0 & $0.0224(2)$ \\
\hline Te2 & $0.0191(2)$ & & $0.0229(4)$ & 0 & $0.0204(2)$ \\
\hline Te3 & $0.0192(2)$ & & $0.0204(4)$ & 0 & $0.0196(2)$ \\
\hline Te4 & $0.0174(2)$ & & $0.0176(4)$ & 0 & $0.0175(2)$ \\
\hline Te5 & $0.0190(3)$ & & $0.0205(4)$ & 0 & $0.0195(2)$ \\
\hline
\end{tabular}

\subsection{TEM investigations}

Structured diffuse scattering was not detected in single-crystal $\mathrm{X}$-ray diffraction patterns of the manganese bismuth tellurides with $\mathrm{GeBi}_{4} \mathrm{Te}_{7}$ or $\mathrm{GeBi}_{6} \mathrm{Te}_{10}$ structure type (Fig. S22), thus stacking disorder is not pronounced in these compounds. In order to further analyze possible stacking faults or superstructures along [001], selected area electron diffraction patterns (SAED) were recorded. Fig. 6 and Fig. 7 show experimental diffraction patterns and simulated ones based on the results of the crystal structure analyses (section 3.3). The absence of diffuse streaks along [001]* indicates that there is no significant amount of stacking faults. Indexing of the patterns corresponds to the lattice symmetry and unit cell parameters found in the X-ray diffraction experiments. In order to visualize the long-range ordered stacking of the different slabs, HRTEM images were acquired (Fig. 8 and Fig. $\mathrm{S} 23$ and $\mathrm{S} 24, \mathrm{ESI}+$ ). The structural entities of quintuple slabs as in $\mathrm{Bi}_{2} \mathrm{Te}_{3}$ and septuple slabs as in $\mathrm{MnBi}_{2} \mathrm{Te}_{4}$ can be clearly identified. Simulated HRTEM images based on the results of the crystal structure analyses fit the experimental ones quite well and thus confirm the structure models (Fig. 8 and Fig. 9). Note that single vacancies have very little influence on the contrasts of atom columns that consist of several atoms and can thus not be detected in such images. 


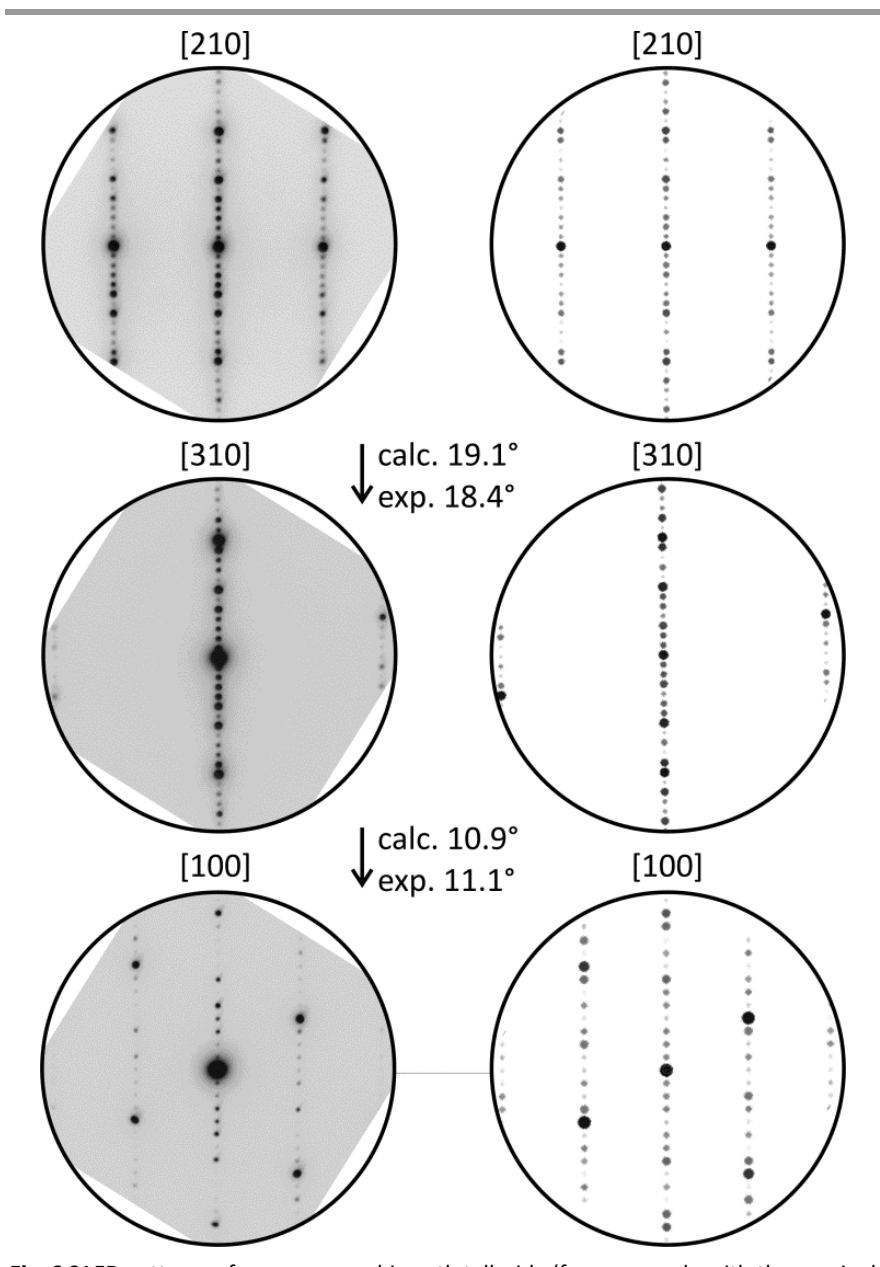

Fig. 6 SAED patterns of a manganese bismuth telluride (from a sample with the nomina composition $\mathrm{MnBi}_{6} \mathrm{Te}_{10}$ ) with the $\mathrm{GeBi}_{4} \mathrm{Te}_{7}$-type structure and corresponding simulated patterns (kinematical approximation based on the model for $\mathrm{Mn}_{0.85} \mathrm{Bi}_{4.10} \mathrm{Te}_{7}$ from the single-crystal structure analysis) with experimental and calculated tilt angles.
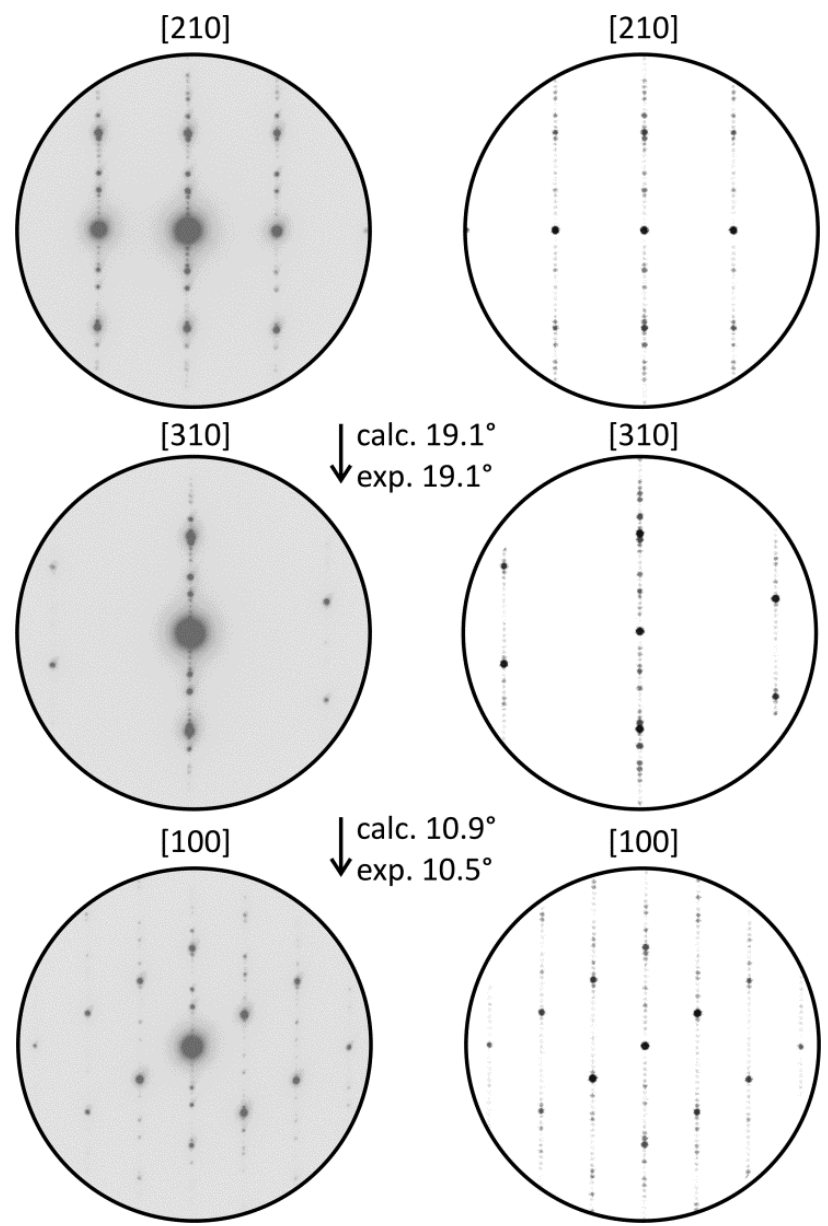

Fig. 7 SAED patterns of a manganese bismuth telluride (from a sample with the nominal composition $\mathrm{Mn}_{0.77} \mathrm{Bi}_{6.15} \mathrm{Te}_{10}$ ) with the $\mathrm{GeBi}_{6} \mathrm{Te}_{10}$-type structure and corresponding simulated diffraction patterns (kinematical approximation, based on the model for $\mathrm{Mn}_{0.73} \mathrm{Bi}_{6.18} \mathrm{Te}_{10}$ from the single crystal structure analysis) with experimental and calculated tilt angles. 


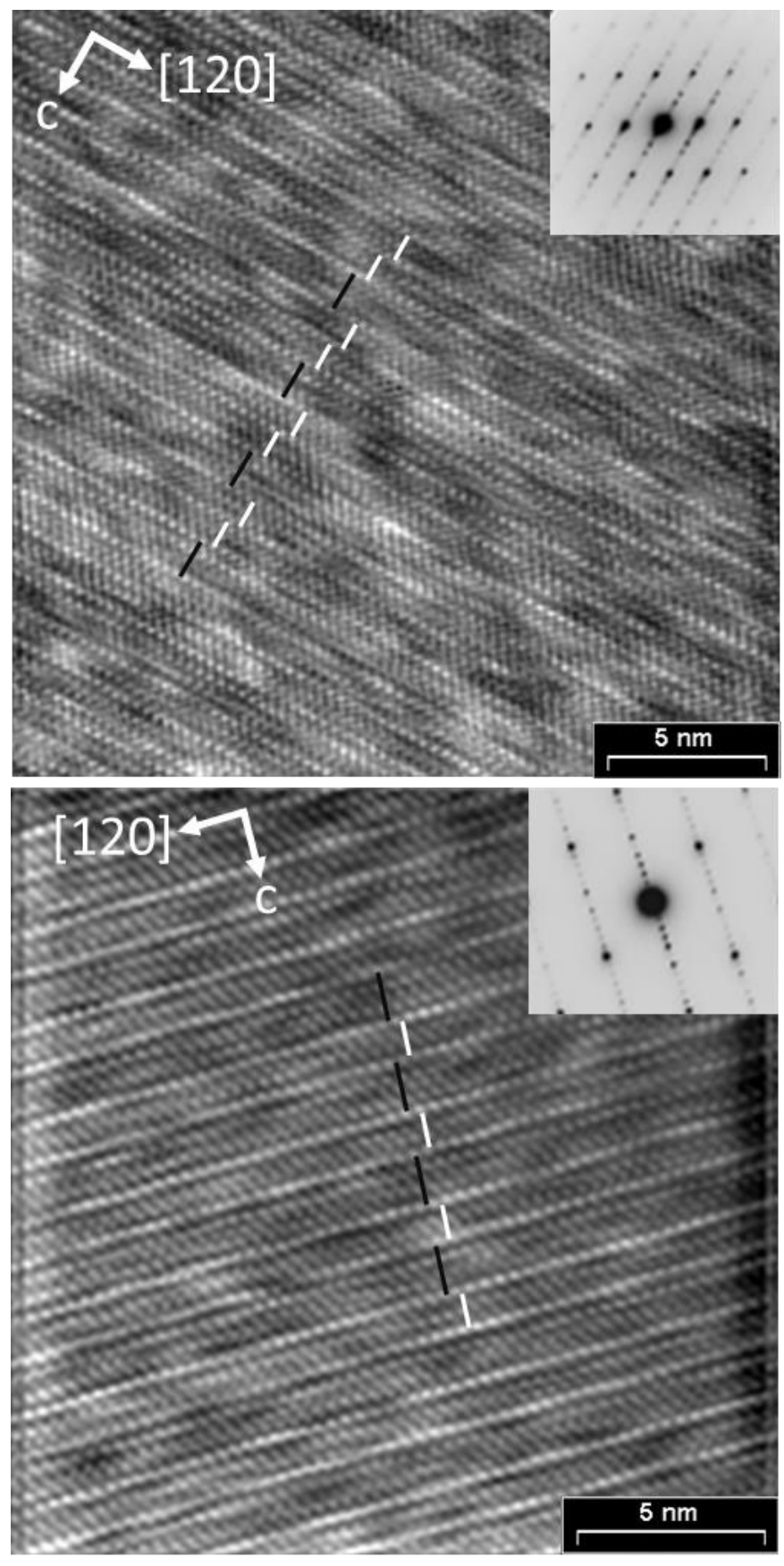

Fig. 8 HRTEM images (zone axis [100], Fourier filtered) of manganese bismuth telluride with the $\mathrm{GeBi}_{4} \mathrm{Te}_{7}$ (bottom) and $\mathrm{GeBi}_{6} \mathrm{Te}_{10}$ (top) structure types, each with a corresponding SAED pattern; inset: simulation based on the single-crystal data of $\mathrm{Mn}_{0.85} \mathrm{Bi}_{4.10} \mathrm{Te}_{7}(\Delta f=-85 \mathrm{~nm}, t=8.36 \mathrm{~nm}$; beam semiconvergence $1.2 \mathrm{mrad}$, defocus spread $15 \mathrm{~nm})$ and $\mathrm{Mn}_{0.73} \mathrm{Bi}_{6.18} \mathrm{Te}_{10}(\Delta f=-67 \mathrm{~nm}, t=0.88 \mathrm{~nm}$; beam semiconvergence $1.2 \mathrm{mrad}$, defocus spread $15 \mathrm{~nm}$ ); white bars symbolize quintuple $\mathrm{Bi}_{2} \mathrm{Te}_{3}$-like slab and black lines symbolize septuple layers characteristic of $\mathrm{MnBi}_{2} \mathrm{Te}_{4}$.
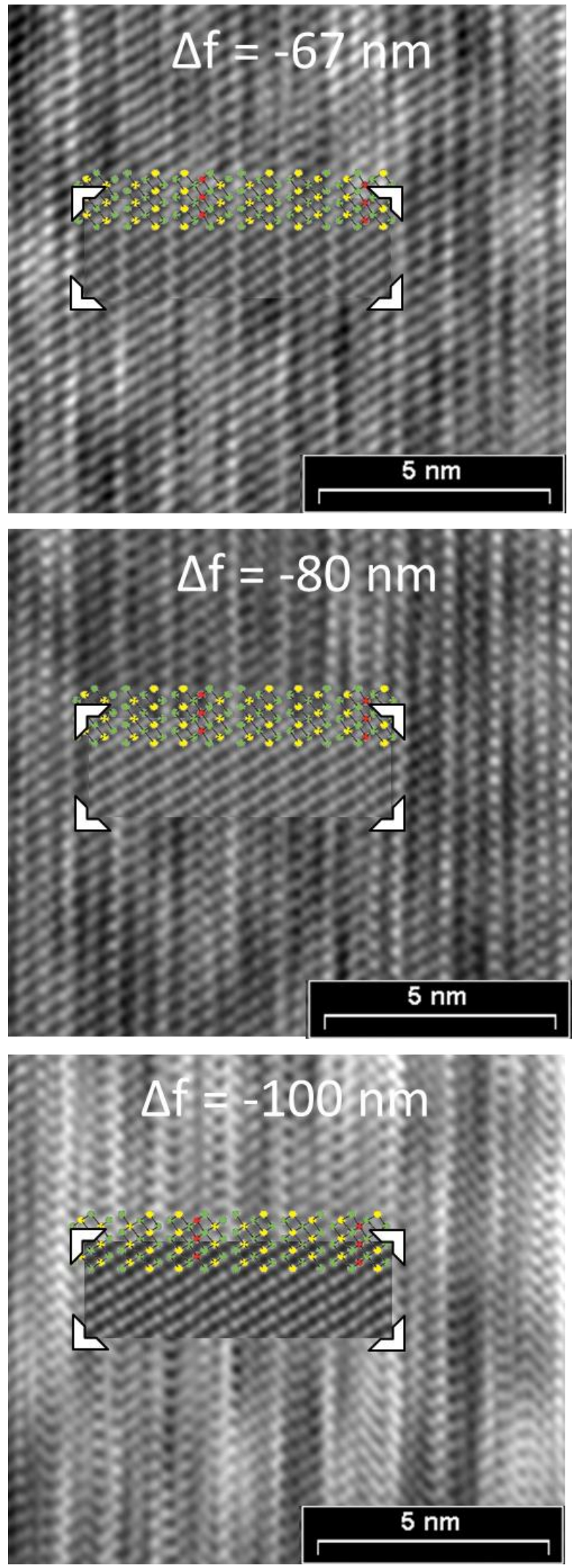

Fig. 9 HRTEM defocus series (zone axis [100], Fourier filtered) from a manganese bismuth telluride with the $\mathrm{GeBi}_{6} \mathrm{Te}_{10}$-type structure, insets: $\mathrm{GeBi}_{6} \mathrm{Te}_{10}$-type structure (green $=\mathrm{Te}$; yellow $=\mathrm{Bi}$-rich; red $=\mathrm{Mn}$-rich: for the exact cation distribution, including mixed sites cf. Tables 2 and 4) and simulated images based on the single-crystal data of $\mathrm{Mn}_{0.73} \mathrm{Bi}_{6.18} \mathrm{Te}_{10}, t=0.88 \mathrm{~nm}$; beam semiconvergence $1.2 \mathrm{mrad}$, defocus spread $15 \mathrm{~nm}$ ), defocus values $\Delta f$ are given in the images. 


\subsection{Magnetic properties}

Temperature- and field-dependent magnetization was measured on pellets from single-phase powders with the compositions $\mathrm{Mn}_{0.85} \mathrm{Bi}_{4.10} \mathrm{Te}_{7}$ and $\mathrm{Mn}_{0.81} \mathrm{Bi}_{6.13} \mathrm{Te}_{10}$. In low magnetic fields of $\mu_{0} H=0.02 \mathrm{~T}$, both compounds demonstrate a temperature-driven phase transition from the paramagnetic into magnetically ordered phases. For $\mathrm{Mn}_{0.85} \mathrm{Bi}_{4.10} \mathrm{Te}_{7}$, an antiferromagnetic transition can clearly be discerned at $\mathrm{T}_{\mathrm{N}}=$ $13 \mathrm{~K}$ in low fields (see peak in the inset of Fig. 10a at $13 \mathrm{~K}$ ), which is followed by a subsequent rearrangement of the microscopic spin alignment at lower temperatures, as indicated by an upturn of the magnetization curve. Given the ferromagnetic hysteresis at $\mathrm{T}=2 \mathrm{~K}$ in Fig. 11a, a predominantly ferromagnetic alignment with a large ferromagnetic component of the spins can be envisaged at lowest temperatures. The microscopic spin arrangement and the origin of these two transitions for $\mathrm{Mn}_{0.85} \mathrm{Bi}_{4.10} \mathrm{Te}_{0}$ should, however, be elucidated in more detail in the future using single crystals. In comparison, for $\mathrm{Mn}_{0.81} \mathrm{Bi}_{6.13} \mathrm{Te}_{10}$ a very strong upturn of the magnetization below $T_{C}=12 \mathrm{~K}$ together with the splitting of the zerofield-cooled and field-cooled magnetization data indicate a transition into a ferromagnetic phase in this compound.

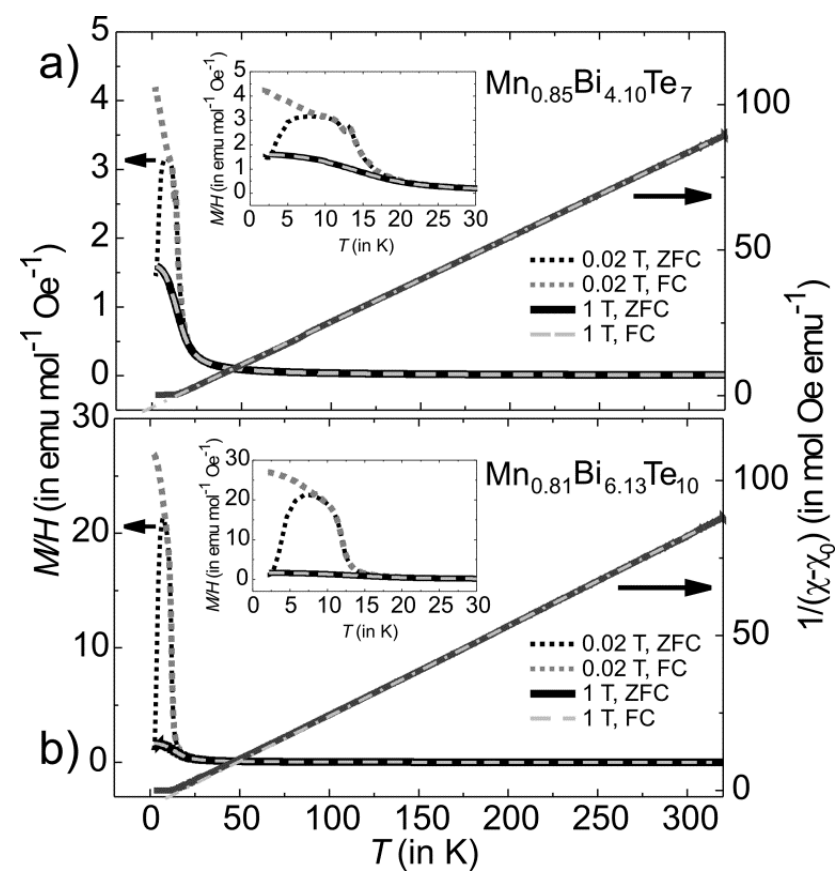

Fig. 10 Magnetization $M / H$ and reciprocal susceptibility of (a) $\mathrm{Mn}_{0.85} \mathrm{Bi}_{4.10} \mathrm{Te}_{7}$ and (b) $\mathrm{Mn}_{0.81} \mathrm{Bi}_{6.13} \mathrm{Te}_{10}$ as a function of temperature measured at various applied magnetic fields. The extrapolated line on the right axis is a Curie-Weiss fit to the hightemperature data indicating a value $\theta_{\mathrm{CW}}$ of $14(2)$ and $17(2) \mathrm{K}$ for $\mathrm{Mn}_{0.85} \mathrm{Bi}_{4.10} \mathrm{Te}_{7}$ and $\mathrm{Mn}_{0.81} \mathrm{Bi}_{6.13} \mathrm{Te}_{10}$, respectively. A small offset $\chi_{0} \sim-0.0007(3)$ emu mol ${ }^{-1} \mathrm{Oe}^{-1}$ ) was added to the data to account for the contribution of closed diamagnetic electronic shells.

The effective paramagnetic moment per formula unit can be estimated from the Curie-Weiss fit of the high-temperature data (Fig. 10) and constitutes 5.7(1) $\mu_{B}$ for $\mathrm{Mn}_{0.85} \mathrm{Bi}_{4.10} \mathrm{Te}_{7}$ and 5.8(1) $\mu_{\mathrm{B}}$ for $\mathrm{Mn}_{0.81} \mathrm{Bi}_{6.13} \mathrm{Te}_{10}$, consistent with the high-spin $d^{5}$ configuration of $\mathrm{Mn}^{2+}(S=5 / 2)$. Positive values of $\theta_{\mathrm{CW}}=14(2)$ and $17(2) \mathrm{K}$ for $\mathrm{Mn}_{0.85} \mathrm{Bi}_{4.10} \mathrm{Te}_{7}$ and $\mathrm{Mn}_{0.81} \mathrm{Bi}_{6.13} \mathrm{Te}_{10}$, respectively, indicate predominantly ferromagnetic coupling. Magnetization curves as function of the magnetic field (Fig. 11) confirm dominating ferromagnetic interactions in both compounds with pronounced magnetic hysteresis at $T=2 \mathrm{~K}$ up to about $\mu_{0} H=0.2 \mathrm{~T}$ and an almost saturated magnetization close to the expected value for $\mathrm{Mn}$ (II) for fields above $\sim 2 \mathrm{~T}$. The remanent magnetization and the coercive field are slightly larger for $\mathrm{Mn}_{0.85} \mathrm{Bi}_{4.10} \mathrm{Te}_{7}\left(\mu_{0} H_{\mathrm{c}}=0.08 \mathrm{~T}\right)$.
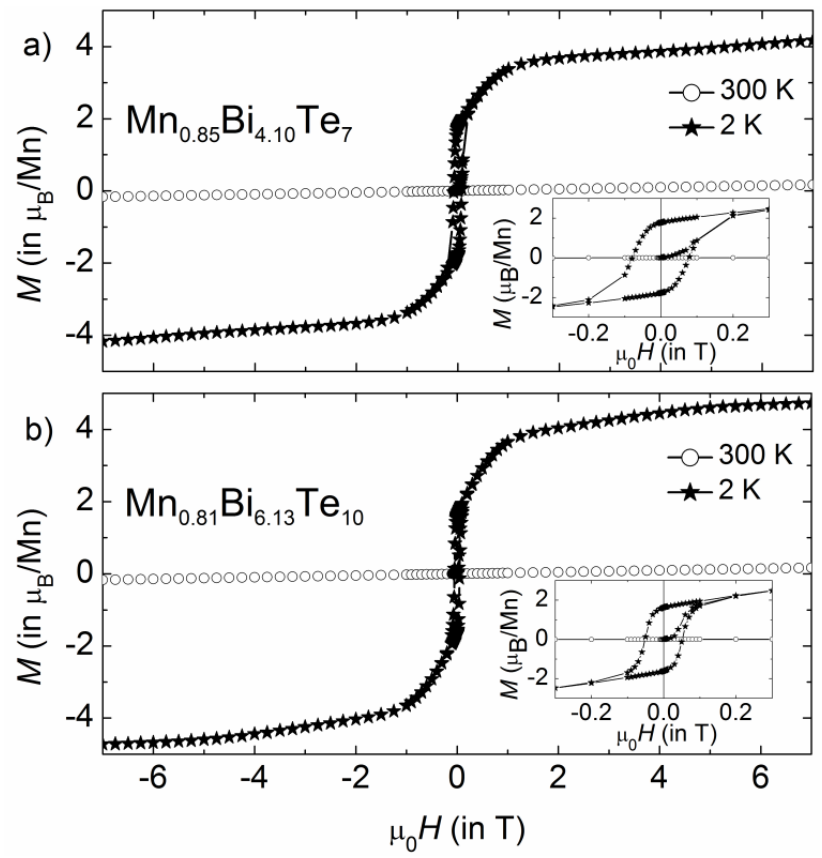

Fig. 11 Magnetic hysteresis curves of (a) $\mathrm{Mn}_{0.85} \mathrm{Bi}_{4.10} T \mathrm{e}_{7}$ and (b) $\mathrm{Mn}_{0.81} \mathrm{Bi}_{6.13} \mathrm{Te}_{10}$ at 300 and $2 \mathrm{~K}$. The samples were cooled in zero field from $320 \mathrm{~K}$.

\subsection{Thermoelectric properties}

Thermoelectric measurements (Fig. 12) were conducted on parts of compact ingots between RT and $400{ }^{\circ} \mathrm{C}$ in three consecutive cycles. The temperature evolution of the electrical conductivity $\sigma$ indicates metallic behavior above RT. Whereas $\mathrm{MnBi}_{2} \mathrm{Te}_{4}$ has been reported to be a p-type conductor with rather low $\sigma$ (39 $\mathrm{S} \mathrm{cm}^{-1}$ at $\mathrm{RT}$ ), ${ }^{31}$ other investigations on comparable materials indicate $n$-type conduction, concluding from a negative Seebeck coefficient $S$ and a much higher $\sigma$ (450 S cm ${ }^{-1}$ at RT). ${ }^{32}$ Similarly, $\mathrm{Mn}_{0.85} \mathrm{Bi}_{4.10} \mathrm{Te}_{7}$ and $\mathrm{Mn}_{0.81} \mathrm{Bi}_{6.13} \mathrm{Te}_{10}$ exhibit negative $S$ and thus are n-type conductors. Despite the shallow minimum in the thermal evolution of $S$, the bandgap was roughly estimated using the Goldsmid-Sharp relationship, ${ }^{68} E_{\mathrm{g}}=2 e S_{\max } T_{\max }$, with the maximum absolute Seebeck coefficient $S_{\max }$ and the corresponding temperature $T_{\text {max }}$. This yields narrow bandgaps of $E_{\mathrm{g}} \approx 0.14 \mathrm{eV}$ for both $\mathrm{Mn}_{0.85} \mathrm{Bi}_{4.10} \mathrm{Te}_{7}$ and $\mathrm{Mn}_{0.81} \mathrm{Bi}_{6.13} \mathrm{Te}_{10}$. This bandgap corresponds with the high electrical conductivity and with the $E_{\mathrm{g}}$ of other compounds with layered $\mathrm{GeBi}_{4} \mathrm{Te}_{7}$ - or $\mathrm{GeBi}_{6} \mathrm{Te}_{10}$-type structures (Table 4).

Thermal conductivities are rather low and almost constant up to $400{ }^{\circ} \mathrm{C}$ with $1.47 \mathrm{~W} \mathrm{~m}^{-1} \mathrm{~K}^{-1}$ for $\mathrm{Mn}_{0.85} \mathrm{Bi}_{4.10} \mathrm{Te}_{7}$ and $1.63 \mathrm{~W} \mathrm{~m}^{-}$ ${ }^{1} \mathrm{~K}^{-1}$ for $\mathrm{Mn}_{0.81} \mathrm{Bi}_{6.13} \mathrm{Te}_{10}$. However, the small value of $S$ limits the maximum $z T$ values up to 0.25 at $375^{\circ} \mathrm{C}$ and 0.28 at $325^{\circ} \mathrm{C}$ for $\mathrm{Mn}_{0.85} \mathrm{Bi}_{4.10} \mathrm{Te}_{7}$ and $\mathrm{Mn}_{0.81} \mathrm{Bi}_{6.13} \mathrm{Te}_{10}$, respectively. The $z T$ values decrease slightly from cycle to cycle, which could be attributed to the metastability of the manganese bismuth 
tellurides. The ex situ PXRD measurements performed after the thermoelectric measurements (Fig. S7, ESIt) show that still up to $80 \%$ of the main phase is present in both compounds. SEM investigations (Fig. S15 and Table S10, ESIt) confirm that the samples slowly decompose over several measurement cycles (cf. sections 3.1 and 3.2).
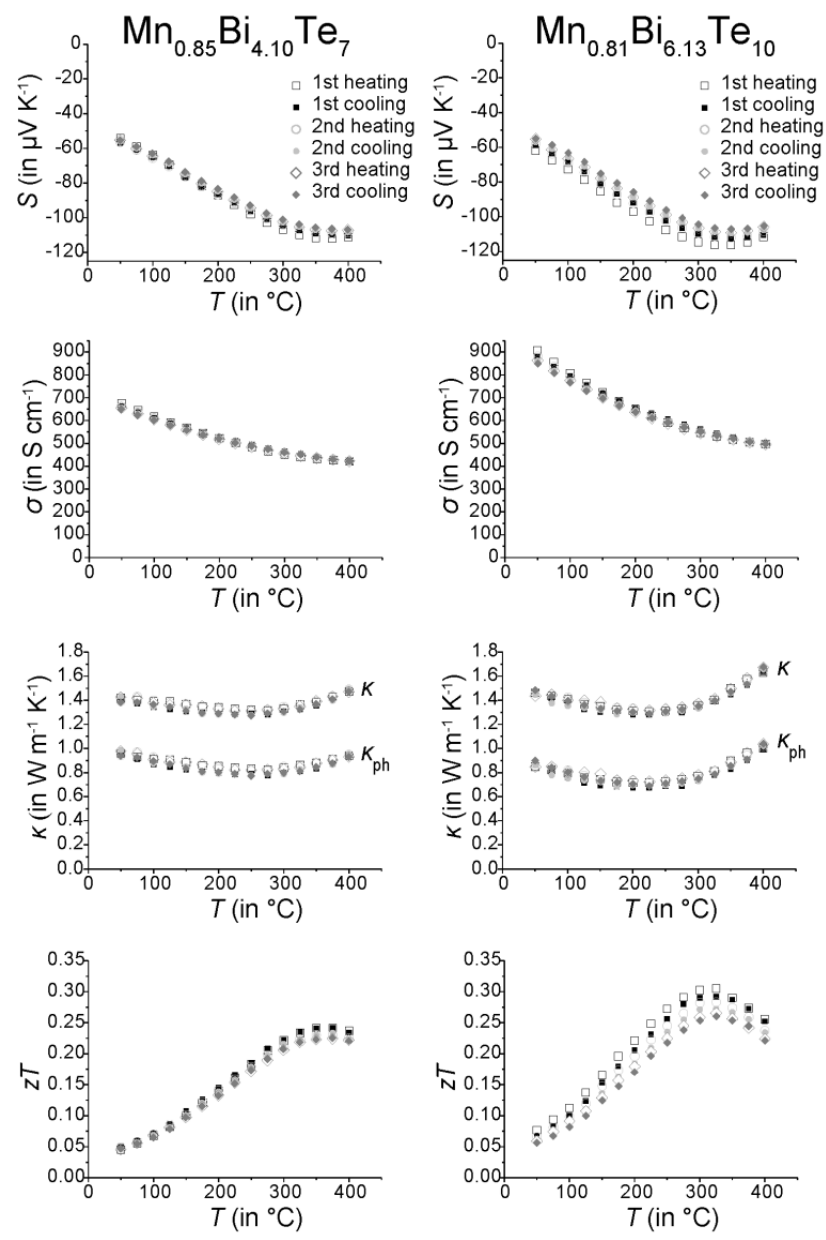

Fig. 12 Thermoelectric properties of $\mathrm{Mn}_{0.85} \mathrm{Bi}_{4.10} \mathrm{Te}_{7}$ (left column) and $\mathrm{Mn}_{0.81} \mathrm{Bi}_{6.13} \mathrm{Te}_{10}$ (right column); Seebeck coefficient (first row), electrical conductivity (second row), thermal conductivity and its phononic contribution (third row, calculated according to the Wiedemann-Franz relationship; the decrease of the Lorenz number $L$ has been derived from the increase of the absolute value of $S$ according to $L=1.5+\mathrm{e}^{(-|S| / 116)}$ where $L$ is in $10^{-8} \mathrm{~W} \Omega \mathrm{K}^{-2}$ and $S$ in $\mu \mathrm{V} \mathrm{K}^{-1}$ ); this equation is accurate within $5 \%$ for single parabolic band/acoustic phonon scattering assumption. ${ }^{69}$ and $z T$ values (fourth row); three subsequent heating and cooling cycles.

The quality factor $B$ (eq. 1), the figure of merit $z T=S^{2} \sigma T / \kappa$ (eq. 2) and the phononic part of the thermal conductivity $\kappa_{\mathrm{ph}}$ were calculated as a function of the electrons' chemical potential $\eta$ from the measured transport properties $\sigma, S$ and $\kappa$ of the first cycle of the thermoelectric measurement (Fig. 12), which is only very little affected by the decomposition. An effective mass model was used to calculate the optimal carrier concentration $z T_{\text {opt }}$. Details of the calculations are described at the end of the ESIt and can also be found in several references. ${ }^{70-75}$ This approach allows one to calculate the intrinsic electrical conductivity $\sigma_{\mathrm{E} 0}$ and $\kappa_{\mathrm{ph}}$ and therefore also the material quality factor $B$ (eq. 1). These intrinsic properties are independent of doping and thus can be separated from doping and its optimization. The optimal $z T$ values for different temperatures and therefore different $B$ factors are shown in Fig. 13.

$$
\begin{aligned}
& B=\left(\frac{k_{B}}{e}\right)^{2} \frac{\sigma_{E_{0}}}{\kappa_{p h}} T \\
& Z T(\eta)=\frac{S^{2}(\eta)}{\frac{\left(k_{B} / e\right)^{2}}{B \ln \left(1+e^{\eta}\right)}+L(\eta)}
\end{aligned}
$$

The measured $z T$ values of $\mathrm{Mn}_{0.85} \mathrm{Bi}_{4.10} \mathrm{Te}_{7}$ and $\mathrm{Mn}_{0.81} \mathrm{Bi}_{6.13} \mathrm{Te}_{10}$ indicate that in both compounds the carrier concentrations are higher than optimal as the measured $z T$ values are on the high$\eta$ side of the maximal $z T(\eta)$ (note that the carrier concentration is a monotonically increasing function of $\eta$ ). With ideal carrier concentration (i.e. optimal $\eta$ ) the maximum of $z T$ for manganese bismuth tellurides with $\mathrm{GeBi}_{4} \mathrm{Te}_{7}$-type structure could increase up to 0.35 at $300{ }^{\circ} \mathrm{C}$ and up to 0.47 at $300{ }^{\circ} \mathrm{C}$ for the $\mathrm{GeBi}_{6} \mathrm{Te}_{10}$-type structure.

Table 4 Electronic properties of $M \mathrm{Bi}_{4} \mathrm{Te}_{7}, \mathrm{MBi}_{6} \mathrm{Te}_{10}(M=\mathrm{Sn}, \mathrm{Pb}, \mathrm{Ge}), \mathrm{Mn}_{0.85} \mathrm{Bi}_{2.1} \mathrm{Te}_{4}$, $\mathrm{Mn}_{0.85} \mathrm{Bi}_{4.10} \mathrm{Te}_{7}$ and $\mathrm{Mn}_{0.81} \mathrm{Bi}_{6.13} \mathrm{Te}_{10}$.

\begin{tabular}{ccccc}
\hline Compound & $\begin{array}{c}S \text { at RT } \\
\left.\text { (in } \mu \mathrm{N} \mathrm{K}^{-1}\right)\end{array}$ & $\begin{array}{c}\sigma \text { at RT } \\
\left(\text { in } \mathrm{Sm}^{-1}\right)\end{array}$ & $\begin{array}{c}E_{\mathrm{g}} \\
\text { (in eV) }\end{array}$ & Ref. \\
\hline $\mathrm{MnBi}_{2} \mathrm{Te}_{4}$ & 168 & 39 & $\sim 0.4$ & 31 \\
$\mathrm{Mn}_{0.85} \mathrm{Bi}_{2.1} \mathrm{Te}_{4}$ & -5 & 475 & 0.15 & 32 \\
$\mathrm{Mn}_{0.85} \mathrm{Bi}_{4.10} \mathrm{Te}_{7}$ & -55 & 700 & 0.14 & this \\
$\mathrm{GeBi}_{4} \mathrm{Te}_{7}$ & -127 & 435 & 0.21 & work \\
& -160 & 230 & & 24 \\
$\mathrm{SnBi}_{4} \mathrm{Te}_{7}$ & -92 & 250 & 0.22 & 76 \\
$\mathrm{PbBi}_{4} \mathrm{Te}_{7}$ & -68 & 1666 & - & 76 \\
& -66 & 1070 & & 24 \\
$\mathrm{Mn}_{0.81} \mathrm{Bi}_{6.13} \mathrm{Te}_{10}$ & -60 & 900 & 0.14 & this \\
$\mathrm{GeBi}_{6} \mathrm{Te}_{10}$ & -65 & 920 & - & work \\
$\mathrm{PbBi}_{6} \mathrm{Te}_{10}$ & -47 & 870 & - & 24 \\
\hline
\end{tabular}

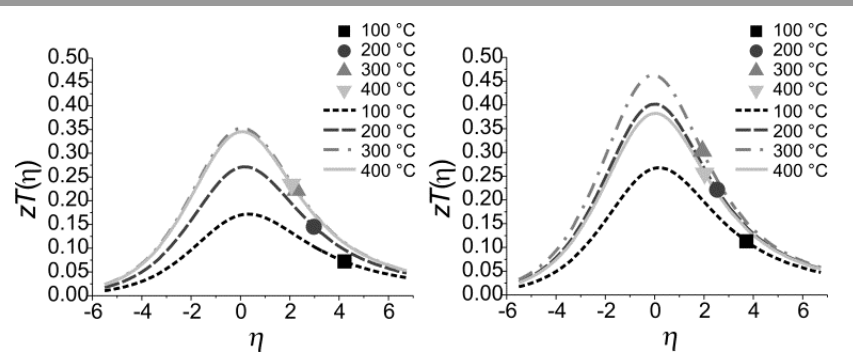

Fig. 13 Calculated and measured $z T$ values for $\mathrm{Mn}_{0.85} \mathrm{Bi}_{4.10} \mathrm{Te}_{7}$ (left) and $\mathrm{Mn}_{0.81} \mathrm{Bi}_{6.13} \mathrm{Te}_{10}$ (right) as a function of $\eta$ at $100{ }^{\circ} \mathrm{C}, 200{ }^{\circ} \mathrm{C}, 300^{\circ} \mathrm{C}$ and $400{ }^{\circ} \mathrm{C}$ with $B=0.047,0.078$, 0.105 and 0.102 for $\mathrm{Mn}_{0.85} \mathrm{Bi}_{4.10} \mathrm{Te}_{7}$ and $\mathrm{B}=0.076,0.122,0.144$ and 0.115 for $\mathrm{Mn}_{0.81} \mathrm{Bi}_{6.13} \mathrm{Te}_{10}$.

\section{Conclusions}

The crystal-structure determinations of two new compounds in the manganese-bismuth-telluride system reveal unexpected combinations of chemical composition and structure type. Diffraction data of $\mathrm{Mn}_{0.85} \mathrm{Bi}_{4.10} \mathrm{Te}_{7}$ and 
$\mathrm{Mn}_{0.73} \mathrm{Bi}_{6.18} \mathrm{Te}_{10}$ indicate that the compounds are isostructural to $\mathrm{GeBi}_{4} \mathrm{Te}_{7}{ }^{27,29}$ and $\mathrm{GeBi}_{6} \mathrm{Te}_{10}{ }^{24}$ respectively. This is confirmed by a combination of X-ray diffraction, including the application of microfocused synchrotron radiation (for $\mathrm{Mn}_{0.73} \mathrm{Bi}_{6.18} \mathrm{Te}_{10}$ ), of TEM imaging and of EDX spectroscopy. ${ }^{43}$ According to the magnetization measurements, the oxidation state of $\mathrm{Mn}^{\text {" }}$ is established. This corresponds to the situation in $\mathrm{MnBi}_{2} \mathrm{Te}_{4}{ }^{32,33}$ The structures contain significant amounts of cation vacancies. Intermixing of $\mathrm{Mn}$ and $\mathrm{Bi}$ on the cation sites is very pronounced and highly significant. Other layered chalcogenides of the $\mathrm{GeBi}_{2} \mathrm{Te}_{4}, \mathrm{GeBi}_{4} \mathrm{Te}_{7}$ and $\mathrm{GeBi}_{6} \mathrm{Te}_{10}$ structure types also exhibit very characteristic mixed cation occupancies. ${ }^{24,27,28,76-79}$ This phenomenon is also typical and, in principle, to be expected for manganese bismuth tellurides in these structure types. The non-stoichiometry of $\mathrm{Mn}_{1-x} \square_{x / 3} \mathrm{Bi}_{4+2 x / 3} \mathrm{Te}_{7}(x=0.15-0.2$ ) (space group P3m1 with $\mathrm{GeBi}_{4} \mathrm{Te}_{7}$-type structure) and $\mathrm{Mn}_{1-x} \square_{x / 3} \mathrm{Bi}_{6+2 x / 3} \mathrm{Te}_{10}(x=0.19-$ 0.26) (space group $R 3 m$ with $\mathrm{GeBi}_{6} \mathrm{Te}_{10}$-type structure) is comparable to the situation in the related compound $33 R$ $\mathrm{Ge}_{4 x} \mathrm{Sb}_{2 y} \mathrm{Te}_{7}(x, y \approx 0.1)$, which is isostructural to $\mathrm{Ge}_{3} \mathrm{Sb}_{2} \mathrm{Te}_{6}$ despite a different stoichiometry. ${ }^{80}$ The manganese bismuth tellurides with $\mathrm{GeBi}_{4} \mathrm{Te}_{7^{-}}$and $\mathrm{GeBi}_{6} \mathrm{Te}_{10}$-type structures are metastable and start decomposing at approximately $250{ }^{\circ} \mathrm{C}$ into a $\mathrm{Mn}$-doped $\mathrm{Bi}_{2} \mathrm{Te}_{3}$-like structure, Bi-rich bismuth tellurides and a manganese-rich phase. This result is crucial concerning physical measurements at elevated temperatures. This decomposition was not observed in our DSC measurements, as it is very slow and extends over a wide temperature range $(\sim 70 \mathrm{~K})$. Yet, the DSC measurements show that these phases are not accessible by slow cooling of melts. An annealing step in the solid state followed by quenching to room temperature is essential to obtain phase pure samples, as kinetic effects impede the immediate decomposition at elevated temperatures. Small variations in the annealing temperature may lead to different structures. The rather broad DSC signal for the $\mathrm{GeBi}_{6} \mathrm{Te}_{10}$-type structure might indicate other structure variants. The $z T$ values of these layered manganese bismuth tellurides indicate decent thermoelectric properties and may be affected by the metastability, but have plenty of room for optimization. The first step towards optimization would be to increase the stability, e.g. by partial substitution of manganese with group 14 elements as preliminary experiments indicate that such substitution is possible. For an increased thermoelectric performance, doping should decrease the concentration of the charge carriers. Much beyond thermoelectrics, the access to single-phase compounds in this ternary system is crucial for various more specialized analyses such as ARPES and detailed investigations of magnetic effects. $\mathrm{MnBi}_{2} \mathrm{Te}_{4}$ has attracted much attraction as the first antiferromagnetic topological insulator, with special focus on theoretical calculations. ${ }^{33,81}$ As these may be questionable if they are based on simple ordered models, the crystal-structure data presented in this study should be the basis for realistic calculations that take into account vancancies and $\mathrm{Mn} / \mathrm{Bi}$ disorder. The new layered manganese bismuth tellurides may be promising candidates for topologically non-trivial materials and thus for studies of mutual influence between long-range magnetic ordering at low temperatures and non-trivial band-structure topology. The single-phase materials, which were only accessible by taking the non-stoichiometry into account, may also be a perspective for magnetic sensing if they should exhibit the anomalous Hall effect like, e.g., $\mathrm{Mn}$-doped $\mathrm{Bi}_{2} \mathrm{Te}_{3}$. ${ }^{17,82}$

\section{Acknowledgments}

The authors thank the ESRF, Grenoble, for granting beamtime (experiments $\mathrm{CH}-5140$ and $\mathrm{CH}-5142$ ) as well as Dr. Jonathan Wright, Lucien Eisenburger, Tobias Stollenwerk, Christina Fraunhofer and Dr. Christopher Benndorf for help with the synchrotron measurements. Kristina Leger and Przemyslaw Blaschkewitz are acknowledged for support with the magnetization studies and the DSC measurements, respectively. We further thank Dr. Ziya S. Aliev (Baku, Azerbaijan) for helpful discussions. This work was supported by the German Research Foundation (DFG) by project $O E$ 530/5-1 and in the framework of the Special Priority Program (SPP 1666, IS 250/2-1) "Topological Insulators", by the ERAChemistry Program (RU 766/15-1), and by CRC "Correlated Magnetism: From Frustration to Topology" (SFB 1143).

\section{Notes and references}

1 J. E. Moore, Nature, 2010, 464, 194-198.

2 M. Z. Hasan and C. L. Kane, Rev. Mod. Phys., 2010, 82, 30453067.

3 Y. L. Chen, J. G. Analytis, J.-H. Chu, Z. K. Liu, S.-K. Mo, X. L. Qi, H. J. Zhang, D. H. Lu, X. Dai, Z. Fang, S. C. Zhang, R. Z. Fisher, Z. Hussain and Z.-X. Shen, Science, 2009, 325, 178-181.

4 P. Jood and M. Ohta, Materials, 2015, 8, 1124-1149.

5 Y. Mizuguchi, Chem. Rec., 2016, 16, 633-651.

6 S. Sasaki, M. Kriener, K. Segawa, K. Yada, Y. Tanaka, M. Sato and Y. Ando, Phys. Rev. Lett., 2011, 107, 217001.

7 T. V. Bay, T. Naka, Y. K. Huang, H. Luigjes, M. S. Golden and A. de Visser, Phys. Rev. Lett., 2012, 108, 57001.

8 B. Poudel, Q. Hao, Y. Ma, Y. Lan, A. Minnich, B. Yu, X. Yan, D. Wang, A. Muto, D. Vashaee, X. Chen, J. Liu, M. S. Dresselhaus, G. Chen and Z. Ren, Science, 2008, 320, 634638.

9 W.-S. Liu, Q. Zhang, Y. Lan, S. Chen, X. Yan, Q. Zhang, H. Wang, D. Wang, G. Chen and Z. Ren, Adv. Energy Mater., 2011, 1, 577-587.

10 G. Sun, X. Qin, D. Li, J. Zhang, B. Ren, T. Zou, H. Xin, S. B. Paschen and X. Yan, J. Alloy. Compd., 2015, 639, 9-14.

11 A. K. Bohra, R. Bhatt, A. Sigh, R. Basu, S. Bhattacharya, K. N. Meshram, S. Ahmad, A. K. Debnath, A. K. Chauhan, P. Bhatt, K. Shah, K. Bhotkar, S. Sharma, D. K. Aswal, K. P. Muthe and S. C. Gadkari, Energ. Convers. Manag., 2017, 145, 415-424.

12 H. Zhang, C.-X. Liu, X.-L. Qi, X. Dai, Z. Fang and S.-C. Thang, Nat. Phys., 2009, 5, 438-442.

13 D. Hsieh, Y. Xia, D. Qian, L. Wray, F. Meier, J. H. Dil, J. Osterwalder, L. Patthey, A. V. Fedorov, H. Lin, A. Bansil, D. Grauer, Y. S. Hor, R. J. Cava and M. Z. Hansan, Phys. Rev. Lett., 2009, 103, 146401.

14 Y. Xia, D. Qian, D. Hsieh, L. Wray, A. Pal, H. Lin, A. Bansil, D. Grauer, Y. S. Hor, R. J. Cava and M. Z. Hasan, Nat. Phys., 2009, 5, 398-402.

15 C.-Z. Chang, J. Zhang, X. Feng, J. Shen, Z. Zhang, M. Guo, K. Li, Y. Ou, P. Wei, L.-L. Wang, Z.-Q. Ji, Y. Feng, S. Ji, X. Chen, J.-F. 
Jia, X. Dai, Z. Fang, S.-C. Zhang, K. He, Y. Wang, L. Lu, X.-C. Ma and Q.-K. Xue, Science, 2013, 340, 161-170.

16 Y. H. Choi, N. H. Jo, K. J. Lee, J. B. Yoon, C. Y. You and M. H. Jung, J. Appl. Phys., 2011, 109, 07E312.

17 Y. S. Hor, P. Roushan, H. Beidenkopf, J. Seo, D. Qu, J. G. Checkelsky, L. A. Wray, D. Hsieh, Y. Xia, S.-Y. Xu, D. Qian, M. Z. Hasan, N. P. Ong, A. Yazdani and R. J. Cava, Phys. Rev. B, 2010, 81, 195203

18 I. Vorobnik, U. Manju, J. Fujii, F. Borgatti, P. Torelli, D. Krizmancic, Y. S. Hor, R. J. Cava and G. Panaccione, Nano Lett., 2011, 11, 4079-4082.

19 Y. Ni, Z. Zhang, I. C. Nlebedim, R. L. Hadimani and D. C. Jiles, IEEE Trans. Magn., 2015, 51, 1-4.

20 J. Choi, S. Choi, J. Choi, Y. Park, H.-M. Park, H.-W. Lee, B.-C. Woo and S. Cho, Phys. Status Solidi. B, 2004, 241, 15411544.

21 J. Růžička, O. Caha, V. Holý, H. Steiner, V. Volobuiev, A. Ney, G. Bauer, T. Duchoň, K. Veltruská, I. Khalakhan, V. Matolın, E. F. Schwier, H. Iwasawa, K. Shimada and G. Springholz, New J. Phys., 2015, 17, 013028.

22 M. D. Watson, L. J. Collins-McIntyre, L. R. Shelford, A. I. Coldea, D. Prabhakaran, S. C. Speller, T. Mousavi, C. R. M. Grovenor, Z. Salman, S. R. Giblin and G. van der Laan, New J. Phys., 2013, 15, 103016.

$23 \mathrm{Y}$. Ni, Z. Zhang, I. C. Nlebedim and D. C. Jiles, IEEE Trans. Magn., 2016, 52, 1-4.

24 L. E. Shelimova, O. G. Karpinskii, P. P. Konstantinov, E. S. Avilov, M. A. Kretova and V. S. Zemskov, Inorg. Mater., 2004, 40, 451-460.

25 R. Vilaplana, J. A. Sans, F. J. Manjón, A. Andrada-Chacón, J. Sánchez-Benítez, C. Popescu, O. Gomis, A. L. J. Pereira, B. García-Domene, P. Rodríguez-Hernández, A. Munoz, D. Daisenberger and O. Oeckler, J. Alloys Compd., 2016, 685, 962-970.

26 S. Souma, K. Eto, M. Nomura, K. Nakayama, T. Sato, T. Takahashi, K. Segawa and Y. Ando, Phys. Rev. Lett., 2012, 108, 116801.

27 L. E. Shelimova, O. G. Karpinskii, M. A. Kretova and G. U. A Lubman, Inorg. Mater., 1993, 29, 56-60.

28 L. E. Shelimova, P. P. Konstantinov, O. G. Karpinsky, E. S. Avilov, M. A. Kretova and V. S. Zemskov, J. Alloys Compd., 2001, 329, 50-62.

29 O. G. Karpinsky, L. E. Shelimova, M. A. Kretova and J.-P. Fleurial, J. Alloys Compd., 1998, 265, 170-175.

30 S. Welzmiller, F. Heinke, P. Huth, G. Bothmann, E.-W Scheidt, G. Wagner, W. Scherer, A. Pöppl and O. Oeckler, J. Alloys Compd., 2015, 652, 74-82.

31 D. S. Lee, T.-H. Kim, C.-H. Park, C.-Y. Chung, Y. S. Lim, W.-S. Seo and H.-H. Park, CrystEngComm, 2013, 15, 5532-5538.

32 A. Zeugner, F. Nietschke, A. U. B. Wolter, S. Gaß, R. C. Vidal, T. R. F. Peixoto, D. Pohl, C. Damm, A. Lubk, R. Hentrich, S. K. Moser, C. Fornari, C. H. Min, S. Schatz, K. Kißner, M. Ünzelmann, M. Kaiser, F. Scaravaggi, B. Rellinghaus, K. Nielsch, C. Heß, B. Büchner, F. Reinert, H. Bentmann, O. Oeckler, T. Doert, M. Ruck and A. Isaeva, Chem. Mater. 2018, 31, 2795-2806.

33 M. M. Otrokov, I. I. Klimovskikh, H. Bentmann, A. Zeugner, Z. S. Aliev, S. Gaß, A. U. B. Wolter, A. V. Koroleva, D. Estyunin A. M. Shikin, M. BlancoRey, M. Hoffmann, A. Y. Vyazovskaya, S. V. Eremeev, Y. M. Koroteev, I. R. Amiraslanov, M. B. Babanly, N. T. Mamedov, N. A. Abdullayev, V. N. Zverev, B. Büchner, E. F. Schwier, S. Kumar, A. Kimura, L. Petaccia, G. Di Santo, R. C. Vidal, S. Schatz, K. Kiner, C.-H. Min, S. K. Moser, T. R. F. Peixoto, F. Reinert, A. Ernst, P. M. Echenique, A Isaeva and E. V. Chulkov, 2018, arxiv.org/abs/1809.07389.

34 Z. S. Aliev, I. R. Amiraslanov, D. I. Nasonova, A. V. Shevelkov,
N. A. Abdullayev, Z. A. Jahangirli, E. N. Orujlu, M. M. Otrokov, N. T. Mamedov, M. B. Babanly and E. V. Chulkov, J. Alloys Compd., 2019, 789, 443-450. Note that this publication has appeared at the stage of reviewing, it reports similar compounds as the present study with a focus on the tentative phase diagram of the system $\mathrm{Mn} / \mathrm{Bi} / \mathrm{Te}$ and on the interpretation of multi-phase powder diffraction patterns.

35 J. A. Hagmann, X. Li, S. Chowdhury, S.-N. Dong, S. Rouvimov, S. J. Pookpanratana, K. Man Yu, T. A. Orlova, T. B. Bolin, C. U. Segre, D. G. Seiler, C. A. Richter, X. Liu, M. Dobrowolska and J. K. Furdyna, New J. Phys., 2017, 19, 085002.

36 WINXPOW, v. 2.2.1, Stoe \& Cie. GmbH, Darmstadt, Germany, 2007.

37 A. Coelho, TOPAS Academic, v. 5, Coelho Software, Brisbane, 2015.

38 R. S. Pease, Acta Crystallogr., 1952, 5, 356-361.

39 X-Area, v. 1.77.1 STOE \& Cie GmbH, Darmstadt, Germany, 2016.

40 X-RED32, v. 1.63.1, STOE \& Cie GmbH, Darmstadt, Germany, 2016.

41 X-Shape, v. 2.18, STOE \& Cie, Darmstadt, Germany, 2015.

42 W. Herrendorf, Dissertation, Universität Karlsruhe, 1993.

43 F. Fahrnbauer, T. Rosenthal, T. Schmutzler, G. Wagner, G. B. M. Vaughan, J. P. Wright and O. Oeckler, Angew. Chem. Int Ed., 2015, 54, 10020-10023.

44 J.-C. Labiche, O. Mathon, S. Pascarelli, M. A. Newton, G. G. Ferre, C. Curfs, G. Vaughan, A. Homs and D. F. Carreiras, Rev. Sci. Instrum., 2007, 78, 91301.

45 CrysAlis Pro 171.38.41, Agilent Technologies, Yarnton, Oxfordshire, England, 2015.

46 SADABS, v. 2.05, Bruker AXS Inc., Madison, Wisconsin, USA, 2001.

47 G. Wu, B. L. Rodrigues and P. Coppens, J Appl. Crystallogr., 2002, 35, 356-359.

48 G. M. Sheldrick, Acta Crystallogr. Sect. C, 2015, 71, 3-8.

49 K. Brandenburg, Diamond 3; Crystal Impact GbR, Bonn, Germany, 2014.

50 INCA Suite, v. 4.09, Oxford Instruments Analytical Limited, Scotts Valley, USA, $1998-2007$.

51 Genesis, v. 6.1, EDAX, Mahwah, USA, 2010.

52 analySIS, v. 2.1, Olympus Soft Imaging Solutions, Münster Germany, 1996.

53 a) P. A. Stadelmann, jEMS, v. 4.4631 U2016, CIME-EPFL, Lausanne, Switzerland, 2016; b) P. A. Stadelmann, Ultramicroscopy, 1987, 21, 131-145.

54 Digital Micrograph, v. 3.6.5, Gatan, 1999.

55 L. Dusza, High Temp. - High Pressures 1995/1996, 27/28, 467-473.

56 L. Yang, Z.-G. Chen, M. Hong, G. Han and J. Zou, Appl. Mater. Interfaces, 2015, 7, 23694-23699.

57 L. Pan, J. Li, D. Berardan and N. Dragoe, J. Solid State Chem., 2015, 168, 168-173.

58 A. S. Skoropanov, B. L. Valevxky, V. F. Skums, G. I. Samal and A. A. Vecher, Thermochim. Acta, 1985, 90, 331-334.

59 V. V. Atuchin, T. A. Gavrilova, K. A. Kokh, N. V. Kuratieva, N. V. Pervukhina and N. V. Surovtsev, Solid State Commun., 2012, 152, 1119-1122.

60 H. Fjellvåg, A. Kjekshus, T. Chattopadhyay, H. D. Hochheimer, W. Hönle and H. G. von Schnering, Phys. Lett. A, 1985, 112, 411-413.

61 R. F. Brebrick, J. Appl. Crystallogr., 1968, 1, 241-246.

62 K. Yamana, K. Kihara and T. Matsumoto, Acta Crystallogr Sect. $B, 1979,35,147-149$.

63 Y. Feutelais, B. Legendre, N. Rodier and V. Agafonov, Mater. Res. Bull., 1993, 28, 591-596. 
64 M. Ruck, in Between Covalent and Metallic Bonding: From Clusters to Intermetallics of Bismuth. In Reference Module in Chemistry, Molecular Sciences and Chemical Engineering, ed. J. Reedijk, Elsevier, Waltham, MA, 2015, DOI: 10.1016/B9780-12-409547-2.11445-3.

65 J. W. G. Bos, M. Lee, E. Morosan, H. W. Zandbergen, W. L. Lee, N. P. Ong and R. J. Cava, Phys. Rev. B, 2006, 74, 184429.

66 A. N. Mansour, W. Wong-Ng, W. Huang, W. Tang, A. Tompson and J. Sharp, J. Appl. Phys., 2014, 116, 083513.

67 R. D. Shannon, Acta Crystallogr. Sect. A, 1976, 32, 751-767.

68 H. J. Goldsmid and J. W. Sharp, J. Electron. Mater., 1999, 28, 869-872.

69 H.-S. Kim, Z. M. Gibbs, Y. Tang, H. Wang and G. J. Snyder, Appl. Mater., 2015, 3, 041506-1-041506-5.

70 R. P. Chasmar and R. Stratton, J. Electron. Control, 1959, 7, $52-72$.

71 H. J. Goldsmid, in Introduction to Thermoelectricity; SpringerVerlag, Berlin, Heidelberg, 2016, ch. 4, pp. 45-66.

72 H. Wang, Y. Pei, A. D. LaLonde and G. J. Snyder, in Thermoelectric Nanomaterials: Materials Design and Applications eds. K. Koumoto, T. Mori, Springer, Berlin, Heidelberg, 2013, ch. 1, pp. 3-32.

73 S. D. Kang and G. J. Snyder, Nat. Mater., 2017, 16, 252-257.

74 A. F. May and G. J. Snyder, in Thermoelectrics and its Energy Harvesting, ed. D. M. Rowe, CRC Press, Boca Raton, FL, 2012, ch. 11, pp. 1-18.

75 S. D. Kang and G. J. Snyder, 2018, arXiv:1710.06896v2.

76 L. A. Kuznetsova, V. L. Kuznetsov and D. M. Rowe, J. Phys. Chem. Solids, 2000, 61, 1269-1274.

77 T. B. Zhukova and A. I. Zaslavskii, Sov. Phys. Crystallogr., 1972, 16, 796-800.

78 O. G. Karpinsky, L. E. Shelimova, M. A. Kretova and J.-P. Fleurial, J. Alloys Compd., 1998, 265, 170-175.

79 T. Matsunaga, R. Kojima, N. Yamada, T. Fujita, K. Kifune, Y. Kubota and M. Takata, Acta Crystallogr. Sect. B, 2010, 66 407-411.

80 M. N. Schneider and O. Oeckler, Z. Anorg. Allg. Chem., 2008, 634, 2557-2561.

81 M. M. Otrokov, T. V. Menshchikova, M. G. Vergniory, I. P. Rusinov, A. Yu. Vyazovskaya, Yu. M. Koroteev, G. Bihlmayer, A. Ernst, P. M. Echenique, A. Arnau and E. V. Chulkov, 2D Mater., 2017, 4, 025082.

82 S. H. Lee, Y. Zhu, Y. Wang, L. Miao, T. Pillsbury, S. Kempinger, D. Graf, N. Alem, C.-Z. Chang, N. Samarth and Z. Mao, 2018, arXiv:1812.00339. 


\title{
Supporting Information
}

\author{
for
}

\section{Layered Manganese Bismuth Tellurides with $\mathrm{GeBi}_{4} \mathrm{Te}_{7}-$ and $\mathrm{GeBi}_{6} \mathrm{Te}_{10}$-type Structures: Towards Multifunctional Materials}

Daniel Souchay, ${ }^{\dagger}$ Markus Nentwig, ${ }^{\dagger}$ Daniel Günther, ${ }^{\dagger}$ Simon Keilholz, ${ }^{\dagger}$ Johannes de Boor, ${ }^{\#}$ Alexander Zeugner, ${ }^{\ddagger}$ Anna Isaeva, ${ }^{\S \S}$ Michael Ruck, ${ }^{\dagger}$ Anja U. B. Wolter, ${ }^{\S}$ Bernd Büchner, ${ }^{\S}, \S$ Oliver Oeckler ${ }^{\dagger} *$

${ }^{\dagger}$ Institute for Mineralogy, Crystallography and Materials Science; Faculty of Chemistry and Mineralogy, Leipzig University, Scharnhorststr. 20, 04275 Leipzig, Germany

\# Institute of Materials Research, German Aerospace Center, Linder Höhe, 51170 Cologne, Germany

${ }^{\ddagger}$ Faculty of Chemistry and Food Chemistry, Technische Universität Dresden, 01062 Dresden, Germany

${ }^{\S}$ Leibniz-Institute for Solid State and Materials Research, Helmholtzstr. 10, 01069 Dresden, Germany

${ }^{\S}$ Institute of Solid State Physics, Technische Universität Dresden, 01062 Dresden, Germany 

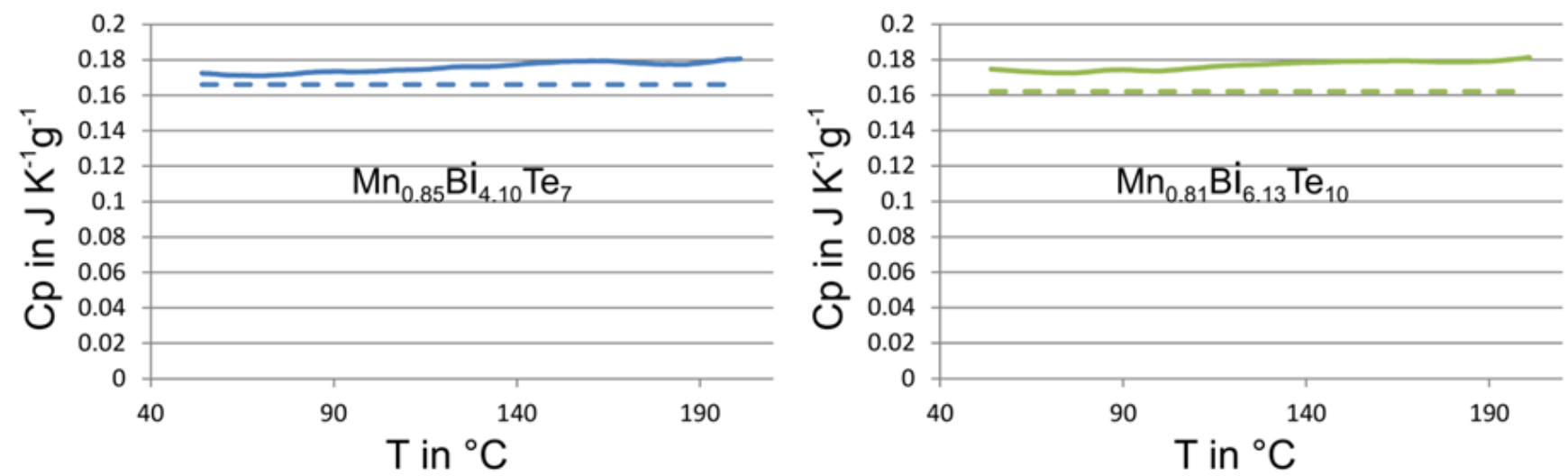

Figure S1: Heat capacity $\mathrm{C}_{\mathrm{p}}$ determined by DSC measurements (Netzsch DSC 404, Pt crucibles with alumina inlays) for samples $\mathrm{Mn}_{0.85} \mathrm{Bi}_{4.10} \mathrm{Te}_{4}$ (left) and $\mathrm{Mn}_{0.81} \mathrm{Bi}_{6.13} \mathrm{Te}_{10}$ (right) as used for thermoelectric characterization and comparison with the Dulong-Petit approximation.

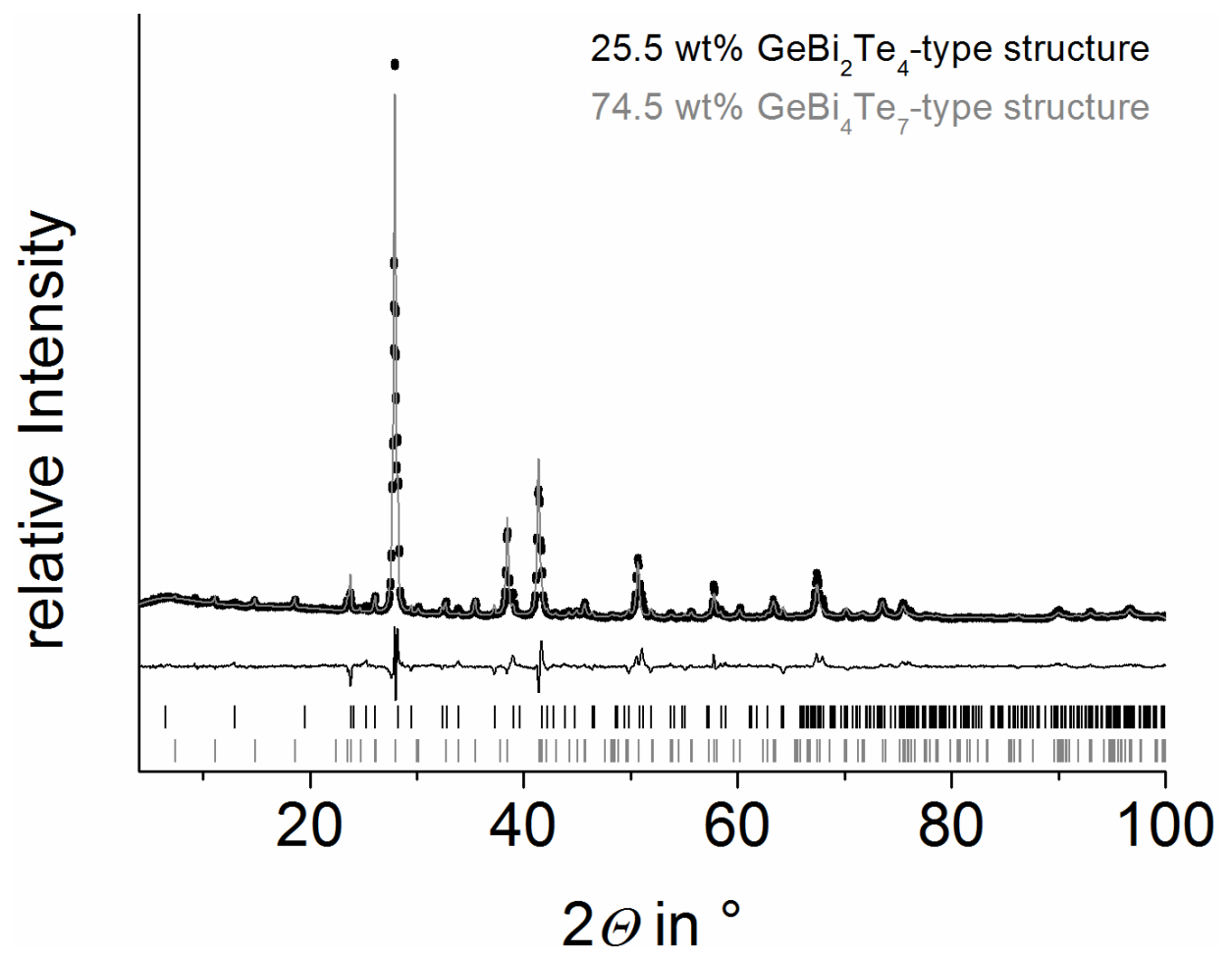

Figure S2: PXRD pattern of a sample with the nominal composition $\mathrm{MnBi}_{4} \mathrm{Te}_{7}$ (black points); Rietveld refinement taking into account structure models for $\mathrm{Mn}_{0.85} \mathrm{Bi}_{2.1} \mathrm{Te}_{4}\left(\mathrm{GeBi}_{2} \mathrm{Te}_{4}\right.$-type structure) [Zeugner, A.; Nietschke, F.; Wolter A. U. B.; Gaß, S.; Vidal, R. C.; Peixoto, T. R. F.; Pohl, D.; Damm, C.; Lubk, A.; Hentrich, R.; Moser, S. K.; Fornari, C.; Min, C. H., Schatz, S.; Kißner, K.; Ünzelmann, M.; Kaiser, M.; Scaravaggi, F. Rellinghaus, B.; Nielsch, K.; Heß, C.; Büchner, B.; Reinert, F.; Bentmann, H.; Oeckler, O.; Doert, T.; Ruck, M.; Isaeva, A. Chemical Aspects of the Antiferromagnetic Topological Insulator $\mathrm{MnBi}_{2} \mathrm{Te}_{4}$; available at arxiv.org/abs/1812.03106] and $\mathrm{Mn}_{0.85} \mathrm{Bi}_{4.10} \mathrm{Te}_{7}\left(\mathrm{GeBi}_{4} \mathrm{Te}_{7}\right.$-type structure) based on SCXRD refinements (see chapter 3.3), sum of calculated patterns light gray and experimental data black points; difference plot (black) and reflection markers (black lines $\mathrm{GeBi}_{2} \mathrm{Te}_{4}$-type structure, gray lines $\mathrm{GeBi}_{4} \mathrm{Te}_{7}$-type structure). 


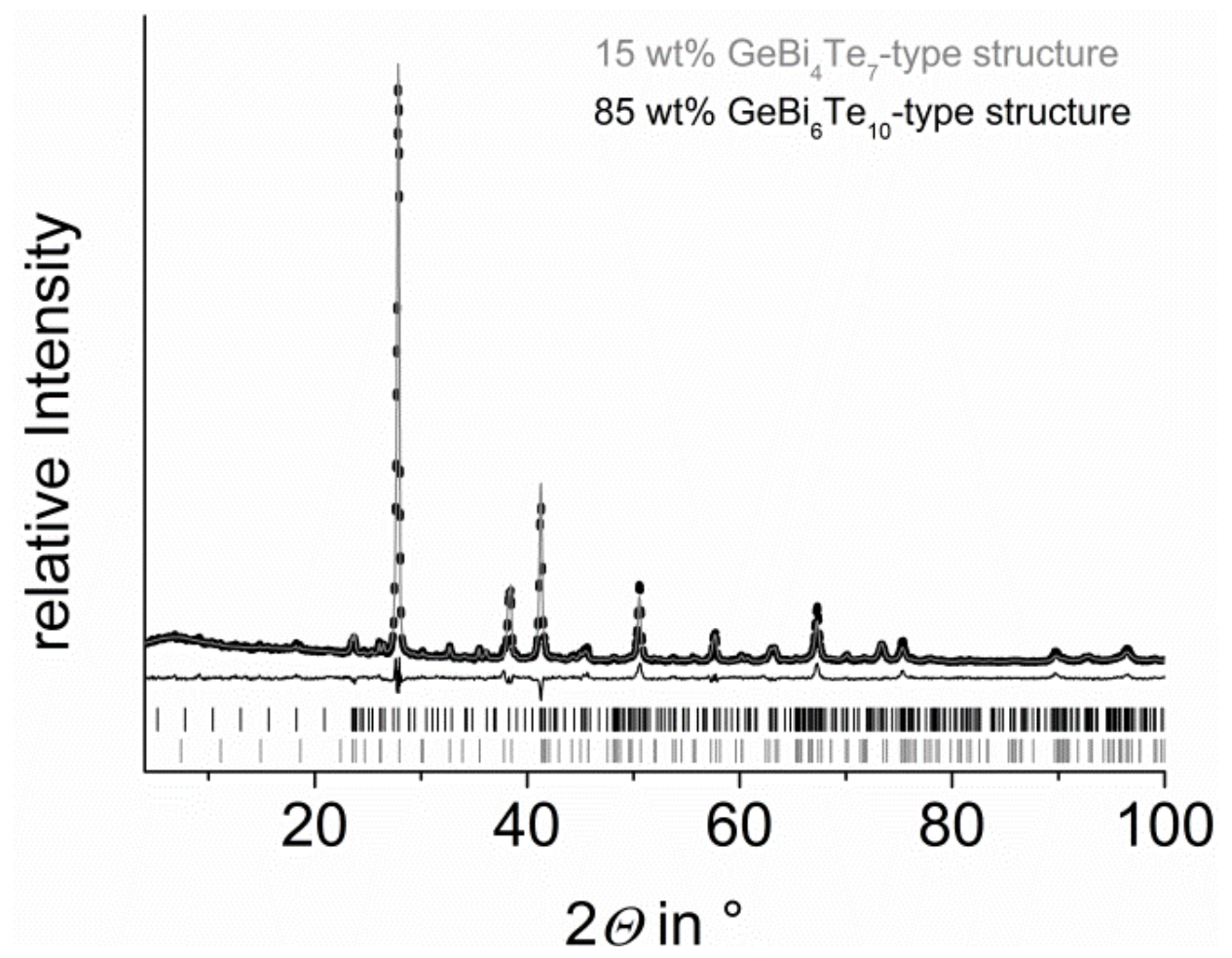

Figure S3: PXRD pattern of a sample with the nominal composition $\mathrm{MnBi}_{6} \mathrm{Te}_{10}$ (black points); Rietveld refinement taking into account structure models for $\mathrm{Mn}_{0.85} \mathrm{Bi}_{4.10} \mathrm{Te}_{7}\left(\mathrm{GeBi}_{4} \mathrm{Te}_{7}\right.$-type structure) and $\mathrm{Mn}_{0.73} \mathrm{Bi}_{6.18} \mathrm{Te}_{10}\left(\mathrm{GeBi}_{6} \mathrm{Te}_{10}\right.$-type structure) based on the SCXRD refinements (see chapter 3.3), sum of calculated patterns light gray and experimental data black points; difference plot (black) and reflection markers (black lines $\mathrm{GeBi}_{6} \mathrm{Te}_{10}$-type structure, gray lines $\mathrm{GeBi}_{4} \mathrm{Te}_{7}$-type structure).

Table S1: Details of the Rietveld refinements of samples with the nominal compositions $\mathrm{Mn}_{0.85} \mathrm{Bi}_{4.10} \mathrm{Te}_{7}$ and $\mathrm{Mn}_{0.81} \mathrm{Bi}_{6.13} \mathrm{Te}_{10}$ based on structure models for $\mathrm{Mn}_{0.85} \mathrm{Bi}_{4.1} \mathrm{Te}_{7}\left(\mathrm{GeBi}_{4} \mathrm{Te}_{7}\right.$-type structure) and $\mathrm{Mn}_{0.73} \mathrm{Bi}_{6.18} \mathrm{Te}_{10}\left(\mathrm{GeBi}_{6} \mathrm{Te}_{10}\right.$-type structure, the slightly different $\mathrm{Mn}$ content has no influence on the fit) from the SCXRD refinement (section 3.3).

\begin{tabular}{|c|c|c|}
\hline formula & $\mathrm{Mn}_{0.85} \mathrm{Bi}_{4.10} \mathrm{Te}_{7}$ & $\mathrm{Mn}_{0.73} \mathrm{Bi}_{6.18} \mathrm{Te}_{10}$ \\
\hline $\mathrm{M}\left(\right.$ in $\left.\mathrm{g} \mathrm{mol}^{-1}\right)$ & 1796.715 & 7824.35 \\
\hline $\mathrm{Z}$ & 1 & 3 \\
\hline$F(000)$ & 725.55 & 3154 \\
\hline crystal system & trigonal & trigonal \\
\hline space group (no.) & $P 3 m 1$ (164) & $R 3 m(166)$ \\
\hline cell parameter (in $\AA$ ) & $\begin{array}{l}a=4.3613(1) \\
c=23.794(2)\end{array}$ & $\begin{array}{l}a=4.3694(2) \\
c=101.870(7)\end{array}$ \\
\hline cell volume (in $\AA^{3}$ ) & $391.95(3)$ & $1674.3(2)$ \\
\hline $\mathrm{X}$-ray density (in $\mathrm{g} \mathrm{cm}^{-3}$ ) & 7.61 & 7.71 \\
\hline radiation & $\mathrm{Cu}-K_{\alpha 1}(\lambda=1.540596 \AA)$ & \\
\hline $2 \theta$ range (in ${ }^{\circ}$ ) & $4 \leq 2 \theta \leq 100$ & \\
\hline number of reflections & 216 & 310 \\
\hline refined parameter / thereof background & $27 / 18$ & $27 / 18$ \\
\hline $\mathrm{R}_{\mathrm{p}} / \mathrm{R}_{\mathrm{wp}}$ & $0.0172 / 0.0269$ & $0.0171 / 0.0264$ \\
\hline $\mathrm{R}_{\text {Bragg }}$ & 0.021 & 0.021 \\
\hline GooF & 1.01 & 1.01 \\
\hline
\end{tabular}


Table S2: Wyckoff positions and atomic parameters (coordinates $x$ y $z$, site occupancy factors s.o.f. and isotropic displacement parameters $B_{\text {eq }}$, all from single-crystal data and not further refined) used in the Rietveld refinement of $\mathrm{Mn}_{0.85} \mathrm{Bi}_{4.10} \mathrm{Te}_{7}$.

\begin{tabular}{|c|c|c|c|c|c|c|}
\hline Atom & Wyckoff & $x$ & $y$ & $z$ & s. o.f. & $\boldsymbol{B}_{\mathrm{ea}}$ \\
\hline Mn1 / Bi1 / & $1 b$ & 0 & 0 & $1 / 2$ & $0.694 / 0.255 / 0.051$ & 2.58 \\
\hline $\mathrm{Mn} 2 / \mathrm{Bi} 2$ & $2 d$ & $1 / 3$ & $2 / 3$ & 0.3423 & 0.0414 / 0.959 & 2.63 \\
\hline Mn3 / Bi3 & $2 d$ & $1 / 3$ & $2 / 3$ & 0.0860 & $0.035 / 0.965$ & 2.51 \\
\hline $\mathrm{Te} 1$ & $2 d$ & $1 / 3$ & $2 / 3$ & 0.5680 & 1 & 2.54 \\
\hline $\mathrm{Te} 3$ & $2 d$ & $1 / 3$ & $2 / 3$ & 0.8413 & 1 & 2.34 \\
\hline $\mathrm{Te} 4$ & $1 \mathrm{a}$ & 0 & 0 & 0 & 1 & 2.12 \\
\hline
\end{tabular}

Table S3: Wyckoff positions and atomic parameters (coordinates $x$ y $z$, site occupancy factors s.o.f. and isotropic displacement parameters $B_{\text {eq }}$, all from single-crystal data and not further refined) used in the Rietveld refinement of $\mathrm{Mn}_{0.81} \mathrm{Bi}_{6.13} \mathrm{Te}_{10}$.

\begin{tabular}{lllllll}
\hline Atom & Wyck. & $\mathrm{x}$ & $\mathrm{y}$ & $\mathrm{z}$ & s. o. f. & $\mathrm{B}_{\mathrm{eq}}$ \\
\hline Mn1/Bi1/ $\square$ & $3 a$ & 0 & 0 & 0 & $0.634 / 0.275 / 0.09$ & 1.79 \\
Mn2/Bi2 & $6 c$ & 0 & 0 & 0.29647 & $0.017 / 0.983$ & 1.92 \\
Mn3/Bi3 & $6 c$ & 0 & 0 & 0.23671 & $0.015 / 0.985$ & 1.79 \\
Mn4/Bi4 & $6 c$ & 0 & 0 & 0.47010 & $0.014 / 0.986$ & 1.80 \\
Te1 & $6 c$ & 0 & 0 & 0.34922 & 1 & 1.77 \\
Te2 & $6 c$ & 0 & 0 & 0.05365 & 1 & 1.61 \\
Te3 & $6 c$ & 0 & 0 & 0.41290 & 1 & 1.55 \\
Te4 & $6 c$ & 0 & 0 & 0.11658 & 1 & 1.38 \\
Te5 & $6 c$ & 0 & 0 & 0.17957 & 1 & 1.54 \\
\hline
\end{tabular}

Table S4: Lattice parameters of $\mathrm{Mn}_{1-\mathrm{x}} \square_{\mathrm{x} / 3} \mathrm{Bi}_{4+2 \mathrm{x} / 3} \mathrm{Te}_{7}$ with $\mathrm{x}=0.15,0.167$ and 0.2 from Rietveld refinements compared with single crystal data of $\mathrm{Mn}_{0.85} \square_{0.05} \mathrm{Bi}_{4.10} \mathrm{Te}_{7}$.

\begin{tabular}{|c|c|c|c|}
\hline nominal composition & $a($ in $\AA)$ & $c($ in $\AA)$ & $R_{\text {wp }}$ \\
\hline $\mathrm{Mn}_{0.80} \mathrm{Bi}_{4.13} \mathrm{Te}_{7}$ & $4.3610(1)$ & $23.792(2)$ & 0.028 \\
\hline $\mathrm{Mn}_{0.833} \mathrm{Bi}_{4.11} \mathrm{Te}_{7}$ & $4.3606(2)$ & $23.794(2)$ & 0.029 \\
\hline $\mathrm{Mn}_{0.85} \mathrm{Bi}_{4.10} \mathrm{Te}_{7}$ & $4.3613(1)$ & $23.794(2)$ & 0.027 \\
\hline $\operatorname{SCXRD~} \mathrm{Mn}_{0.85} \mathrm{Bi}_{4.10} \mathrm{Te}_{7}$ & $4.3591(3)$ & $23.769(2)$ & $0.033(R 1$ for $\mathrm{I}>2 \sigma(\mathrm{I}))$ \\
\hline $\begin{array}{l}\mathrm{GeBi}_{4} \mathrm{Te}_{7} \text {-type phase in a heterogeneous sam- } \\
\text { ple with nominal composition } \mathrm{MnBi}_{6} \mathrm{Te}_{10}\end{array}$ & $4.3612(6)$ & $23.769(4)$ & 0.025 \\
\hline
\end{tabular}

Table S5: SEM-EDX results for samples with the nominal compositions $\mathrm{Mn}_{0.85} \mathrm{Bi}_{4.10} \mathrm{Te}_{7}$ and $\mathrm{Mn}_{0.81} \mathrm{Bi}_{6.13} \mathrm{Te}_{10}$ (data averaged from 7-8 point measurements), compared with the nominal compositions $\mathrm{MnBi}_{4} \mathrm{Te}_{7}$ and $\mathrm{MnBi}_{6} \mathrm{Te}_{10}$, respectively.

\begin{tabular}{llll}
\hline nominal composition & at.-\% measured (8 points) & at.-\% calc. for $\mathrm{Mn}_{0.85} \mathrm{Bi}_{4.10} \mathrm{Te}_{7}$ & at.- $\%$ calc. for $\mathrm{MnBi}_{4} \mathrm{Te}_{7}$ \\
$\mathrm{Mn}_{0.85} \mathrm{Bi}_{4.10} \mathrm{Te}_{7}$ & $\mathbf{M n}: 6.6(6) ; \mathbf{B i}: 34.7(3) ; \mathbf{T e}: 58.7(4)$ & $\mathbf{M n}: 7.1 ; \mathbf{B i}: 34.3 ; \mathbf{T e}: 58.6$ & Mn: $8.33 ; \mathbf{B i}: 33.33 ; \mathbf{T e}: 58.33$ \\
\hline & at.-\% measured (7 points) & at.-\% calc. for $\mathrm{Mn}_{0.81} \mathrm{Bi}_{6.13} \mathrm{Te}_{10}$ & at.-\% calc. for $\mathrm{MnBi}_{6} \mathrm{Te}_{10}$ \\
$\mathrm{Mn}_{0.81} \mathrm{Bi}_{6.13} \mathrm{Te}_{10}$ & Mn: $4.5(3) ; \mathbf{B i}: 36.5(5) ; \mathbf{T e}: 59.1(5)$ & $\mathbf{M n}: 4.78 ; \mathbf{B i}: 36.19 ; \mathbf{T e}: 59.03$ & Mn: $5.9 ; \mathbf{B i}: 35.3 ; \mathbf{T e}: 58.8$ \\
\hline
\end{tabular}




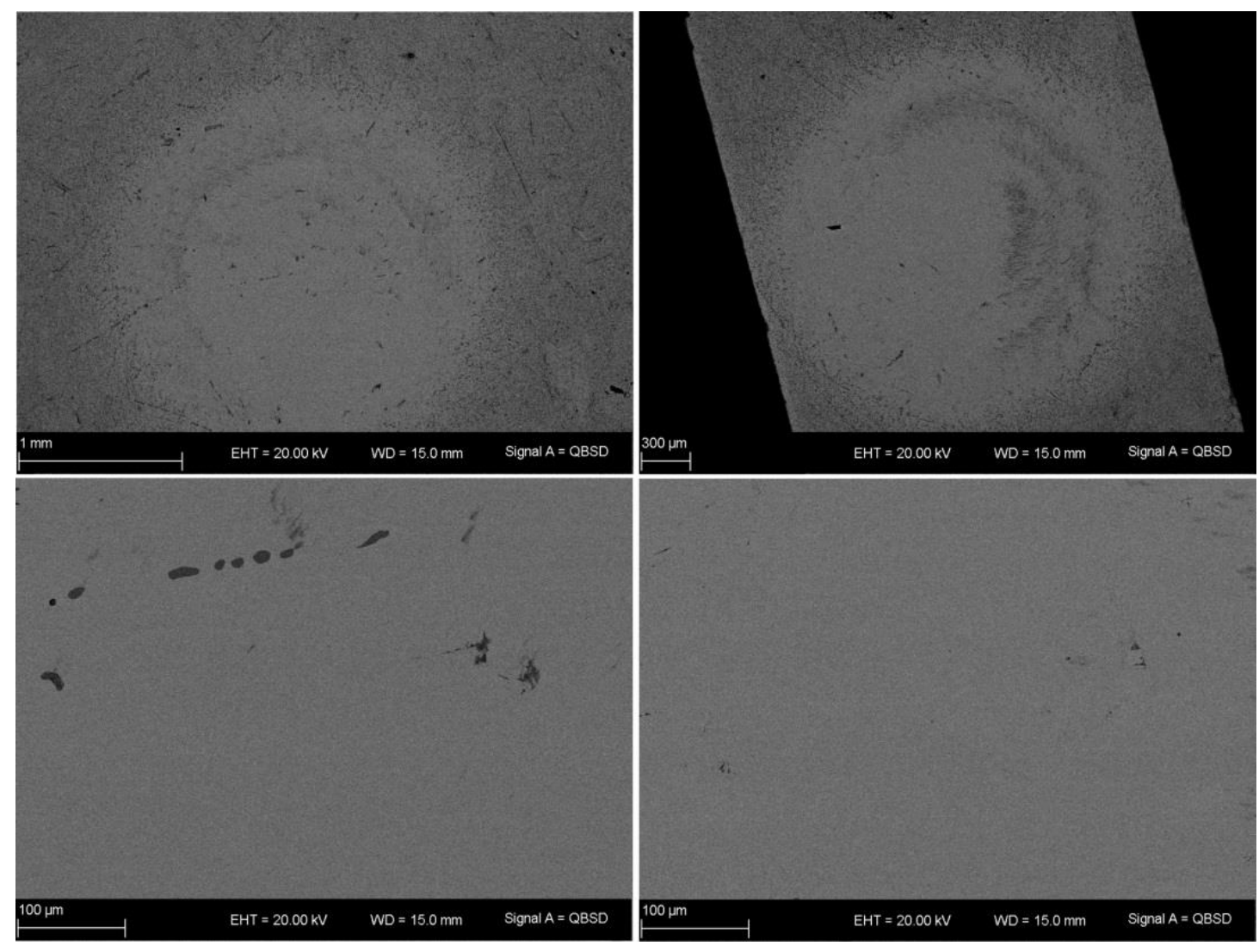

Figure S4: SEM images (backscattered electrons) of samples with the nominal compositions $\mathrm{Mn}_{0.85} \mathrm{Bi}_{4.10} \mathrm{Te}_{7}(\mathrm{left})$ and $\mathrm{Mn}_{0.81} \mathrm{Bi}_{6.13} \mathrm{Te}_{10}$

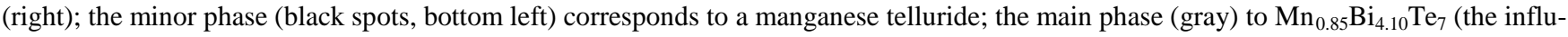
ence of the minor phase on the composition is negligible) and $\mathrm{Mn}_{0.81} \mathrm{Bi}_{6.13} \mathrm{Te}_{10}$, respectively.
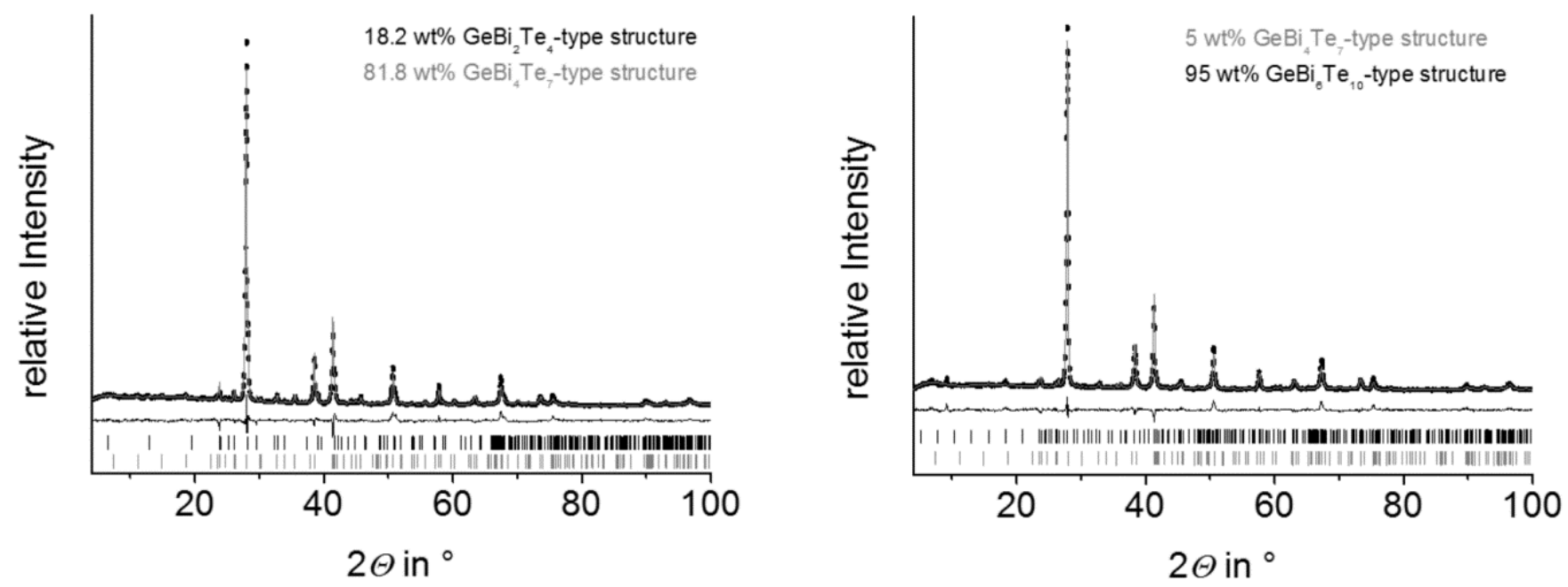

Figure S5: PXRD pattern of samples with the nominal compositions $\mathrm{Mn}_{0.89} \mathrm{Bi}_{4.11} \mathrm{Te}_{7}$ (left) and $\mathrm{Mn}_{0.85} \mathrm{Bi}_{6.15} \mathrm{Te}_{10}$ (right); Rietveld refinements taking into account structure models for $\mathrm{Mn}_{0.85} \mathrm{Bi}_{4.10} \mathrm{Te}_{7}\left(\mathrm{GeBi}_{4} \mathrm{Te}_{7}\right.$-type structure, section 3.3), $\mathrm{Mn}_{0.73} \mathrm{Bi}_{6.18} \mathrm{Te}_{10}\left(\mathrm{GeBi}_{6} \mathrm{Te}_{10}\right.$-type structure, section 3.3) and $\mathrm{Mn}_{0.85} \mathrm{Bi}_{2.1} \mathrm{Te}_{4}$ [Zeugner, A.; Nietschke, F.; Wolter A. U. B.; Gaß, S.; Vidal, R. C.; Peixoto, T. R. F.; Pohl, D.; Damm, C.; Lubk, A.; Hentrich, R.; Moser, S. K.; Fornari, C.; Min, C. H., Schatz, S.; Kißner, K.; Ünzelmann, M.; Kaiser, M.; Scaravaggi, F. Rellinghaus, B.; Nielsch, K.; Heß, C.; Büchner, B.; Reinert, F.; Bentmann, H.; Oeckler, O.; Doert, T.; Ruck, M.; Isaeva, A. Chemical Aspects of the Antiferromagnetic Topological Insulator $\mathrm{MnBi}_{2} \mathrm{Te}_{4}$; available at arxiv.org/abs/1812.03106] based on SCXRD refinements; sum of calculated patterns light gray and experimental data as black points; difference plot (gray) and reflection markers below, gray markers for $\mathrm{GeBi}_{4} \mathrm{Te}_{7}$-type structure, black markers $\mathrm{GeBi}_{6} \mathrm{Te}_{10}$-type structure (right) and $\mathrm{GeBi}_{2} \mathrm{Te}_{4}$-type structure (left). 

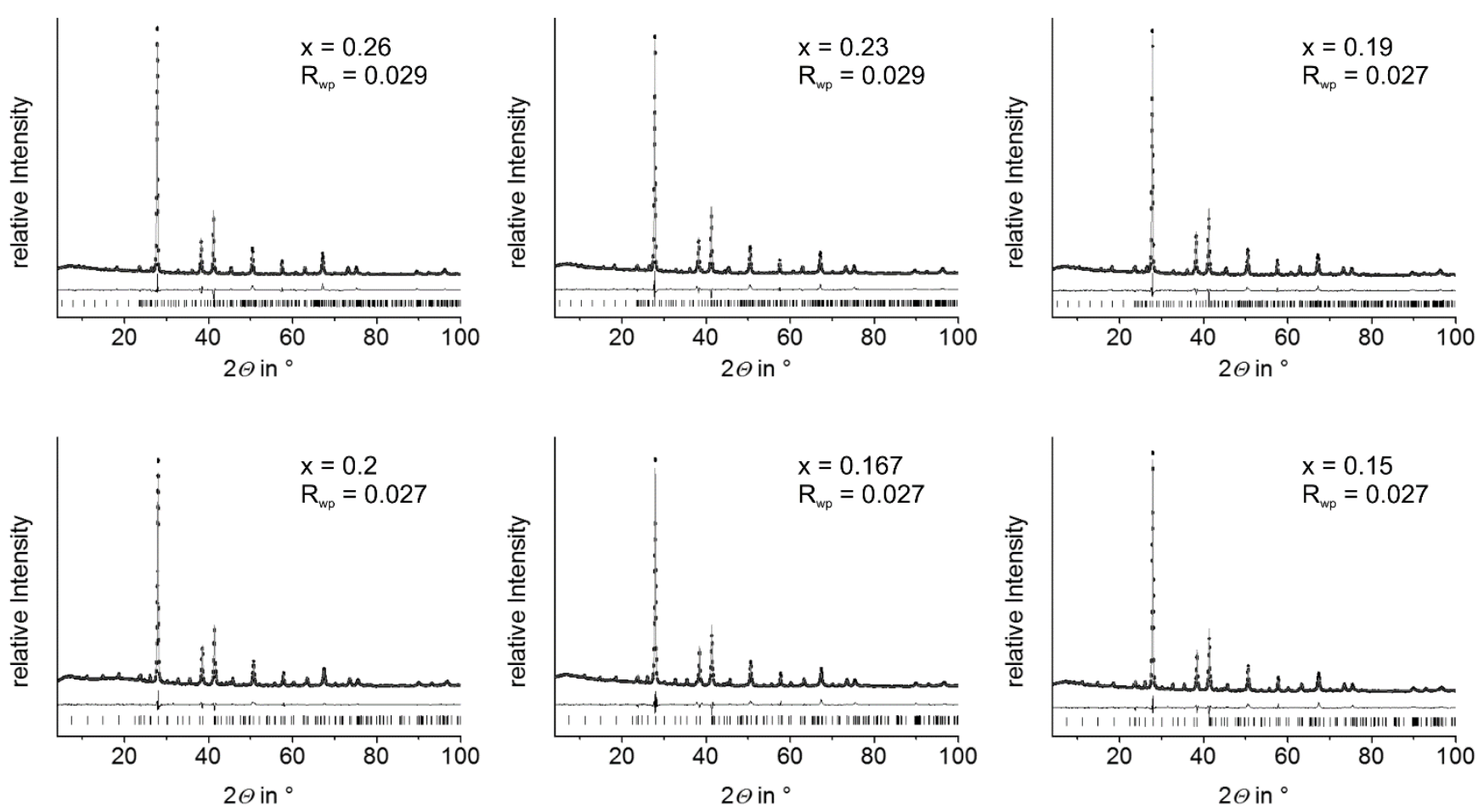

Figure S6: PXRD patterns of samples $\mathrm{Mn}_{1-\mathrm{x}} \square_{\mathrm{x} / 3} \mathrm{Bi}_{6+2 \mathrm{x} / 3} \mathrm{Te}_{10}$ with $\mathrm{x}=0.19,0.23$ and 0.26 (top row) and $\mathrm{Mn}_{1-\mathrm{x}} \square_{\mathrm{x} / 3} \mathrm{Bi}_{4+2 \mathrm{x} / 3} \mathrm{Te}_{7}$ with $\mathrm{x}=0.15$, 0.167 and 0.2 (bottom row); Rietveld refinements taking into account structure models for $\mathrm{Mn}_{0.85} \mathrm{Bi}_{4.10} \mathrm{Te}_{7}\left(\mathrm{GeBi}_{4} \mathrm{Te}_{7}\right.$ type) and $\mathrm{Mn}_{0.73} \mathrm{Bi}_{6.18} \mathrm{Te}_{10}\left(\mathrm{GeBi}_{6} \mathrm{Te}_{10}\right.$ type) based on SCXRD (section 3.3); difference plots (gray), sum of calculated patterns light gray, experimental data as black points; reflection markers: black lines for $\mathrm{GeBi}_{4} \mathrm{Te}_{7}$ type (top) and $\mathrm{GeBi}_{6} \mathrm{Te}_{10}$ type (bottom), respectively.

Table S6: SEM-EDX data of $\mathrm{Mn}_{1-\mathrm{x}} \square_{\mathrm{x} / 3} \mathrm{Bi}_{4+2 \mathrm{x} / 3} \mathrm{Te}_{7}$ with $\mathrm{x}=0.15,0.167$ and 0.2 (top) and $\mathrm{Mn}_{1-\mathrm{x}} \square_{\mathrm{x} / 3} \mathrm{Bi}_{6+2 \mathrm{x} / 3} \mathrm{Te}_{10}$ with $\mathrm{x}=0.19,0.23$ and 0.26 (bottom) (averaged from eight point measurements) compared with the nominal composition $\mathrm{MnBi}_{4} \mathrm{Te}_{7}$ and $\mathrm{MnBi}_{6} \mathrm{Te}_{10}$.

\begin{tabular}{|c|c|c|c|c|}
\hline Composition & & at.- $\%$ measured & at. $-\%$ calculated (nominal) & at.- $\%$ calculated for $\mathrm{MnBi}_{4} \mathrm{Te}_{7}$ \\
\hline $\mathrm{Mn}_{0.80} \mathrm{Bi}_{4.13} \mathrm{Te}_{7}$ & $(\mathrm{x}=0.2)$ & Mn: 6.5(5) Bi: 34.2(7) Te: 59.3(7) & Mn: 6.7 Bi: 34.6 Te: 58.7 & Mn: 8.3 Bi: 33.3 Te: 58.3 \\
\hline $\mathrm{Mn}_{0.833} \mathrm{Bi}_{4.11} \mathrm{Te}_{7}$ & $(x=0.167)$ & Mn: 6.7(5) Bi: 34.6(5) Te: 58.7(5) & Mn: 7.0 Bi: 34.4 Te: 58.6 & Mn: 8.3 Bi: 33.3 Te: 58.3 \\
\hline $\mathrm{Mn}_{0.85} \mathrm{Bi}_{4.10} \mathrm{Te}_{7}$ & $(x=0.15)$ & Mn: 6.6(6); Bi: 34.7(3); Te: 58.7(4) & Mn: 7.1; Bi: 34.3 ; Te: 58.6 & Mn: 8.3 Bi: 33.3 Te: 58.3 \\
\hline
\end{tabular}

Compositon

$\mathrm{Mn}_{0.74} \mathrm{Bi}_{6.18} \mathrm{Te}_{10}(\mathrm{x}=0.26)$

$\mathrm{Mn}_{0.77} \mathrm{Bi}_{6.15} \mathrm{Te}_{10}(\mathrm{x}=0.23)$

$\mathrm{Mn}_{0.81} \mathrm{Bi}_{6.13} \mathrm{Te}_{10}(\mathrm{x}=0.19)$ at.-\% measured

Mn: 4.2(7); Bi: 36.5(4); Te: 59.4(4)

Mn: 4.5(6); Bi: 36.4(4); Te: 59.2(7)

Mn: 4.5(3); Bi: 36.5(5); Te: 59.1(5) at.- $\%$ calculated (nominal)

at.- $\%$ calculated for $\mathrm{MnBi}_{6} \mathrm{Te}_{10}$

Mn: 4.4 Bi: 36.5 Te: 59.1

Mn: 5.9 Bi: 35.3 Te: 58.8

Mn: 4.5 Bi: 36.4 Te: 59.1

Mn: 5.9 Bi: 35.3 Te: 58.8

Mn: 4.8; Bi: 36.2; Te: 59.0

Mn: 5.9 Bi: 35.3 Te: 58.8

Table S7: Lattice parameters of $\mathrm{Mn}_{1-\mathrm{x}} \square_{\mathrm{x} / 3} \mathrm{Bi}_{6+2 \mathrm{x} / 3} \mathrm{Te}_{10}$ with $\mathrm{x}=0.19,0.23$ and 0.26 from Rietveld refinements compared with single-crystal data of $\mathrm{Mn}_{0.73} \square_{0.09} \mathrm{Bi}_{6.18} \mathrm{Te}_{10}$.

\begin{tabular}{llll}
\hline nominal composition & $a$ (in $\AA$ ) & $c$ (in $\AA$ ) & $R_{\mathrm{wp}}$ \\
\hline $\mathrm{Mn}_{0.74} \mathrm{Bi}_{6.18} \mathrm{Te}_{10}$ & $4.3739(1)$ & $101.818(8)$ & 0.027 \\
$\mathrm{Mn}_{0.77} \mathrm{Bi}_{6.15} \mathrm{Te}_{10}$ & $4.3697(2)$ & $101.863(8)$ & 0.027 \\
$\mathrm{Mn}_{0.81} \mathrm{Bi}_{6.13} \mathrm{Te}_{10}$ & $4.3694(1)$ & $101.870(7)$ & 0.030 \\
$\mathrm{SCXRD} \mathrm{Mn}_{0.73} \mathrm{Bi}_{6.18} \mathrm{Te}_{10}$ & $4.3698(3)$ & $101.829(8)$ & $0.0303(R 1$ for I $>2 \sigma(\mathrm{I}))$ \\
\hline
\end{tabular}



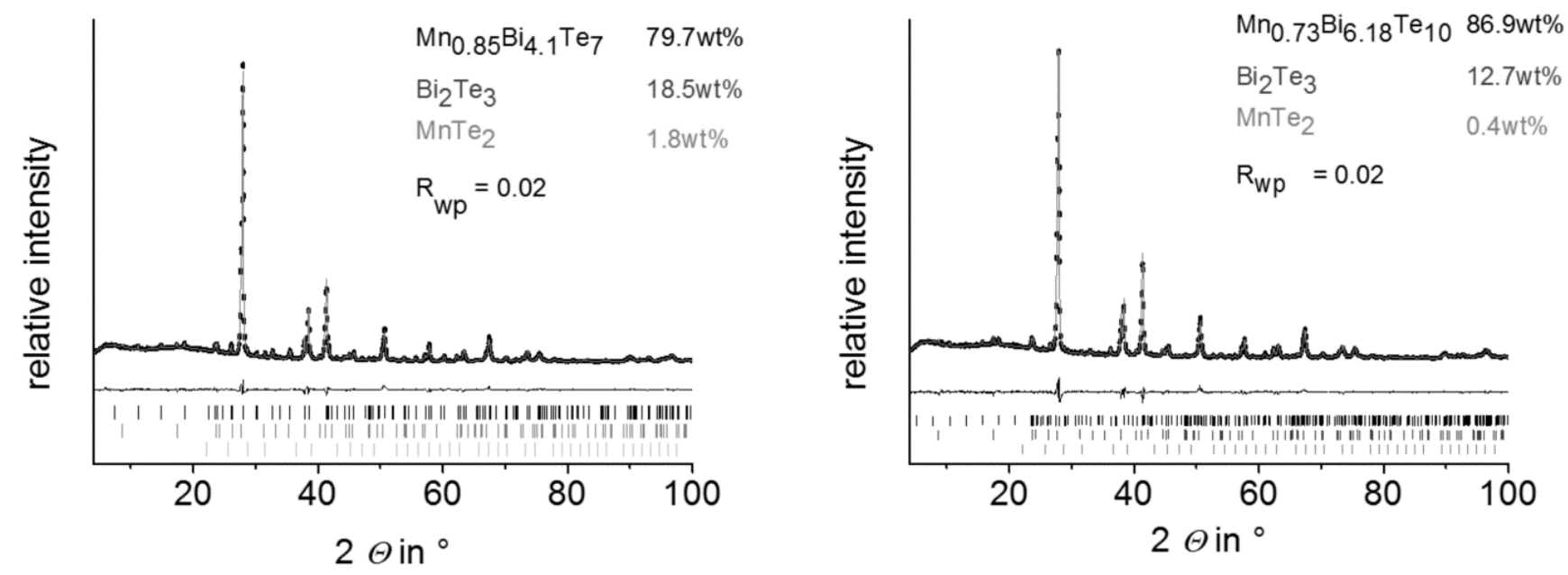

Figure S7: PXRD for samples with the nominal compositions $\mathrm{Mn}_{0.85} \mathrm{Bi}_{4.10} \mathrm{Te}_{7}$ (left) and $\mathrm{Mn}_{0.81} \mathrm{Bi}_{6.13} \mathrm{Te}_{10}$ (right) after thermoelectric characterization; Rietveld refinements taking into account structure models for $\mathrm{Mn}_{0.85} \mathrm{Bi}_{4.10} \mathrm{Te}_{7}\left(\mathrm{GeBi}_{4} \mathrm{Te}_{7} \mathrm{type}\right), \mathrm{Mn}_{0.73} \mathrm{Bi}_{6.18} \mathrm{Te}_{10}\left(\mathrm{GeBi}_{6} \mathrm{Te}_{10}\right.$ type) based on SCXRD (section 3.3), for $\mathrm{Bi}_{2} \mathrm{Te}_{3}$ [Atuchin, V. V.; Gavrilova, T. A.; Kokh, K. A.; Kuratieva, N.V.; Pervukhina, N.B.; Surovtsev, N. V. Solid State Commun. 2012, 152, 1119-1122] and for $\mathrm{MnTe}_{2}\left(\mathrm{FeS}_{2}\right.$-type structure, space group Pa3) [Fjellvåg, H.; Kjekshus, A.; Chattopadhyay, T.; Hochheimer, H. D.; Hönle, W.; von Schnering, H. G. Phys. Lett. 1985, 112A, 411-413]; experimental data (black points), refined curve (gray), difference plot (black) and reflection positions: black $\mathrm{GeBi}_{4} \mathrm{Te}_{7}$ type (left) and $\mathrm{GeBi}_{6} \mathrm{Te}_{10}$ type (right), respectively, dark gray $\mathrm{Bi}_{2} \mathrm{Te}_{3}$ type and light gray $\mathrm{MnTe}_{2}$.
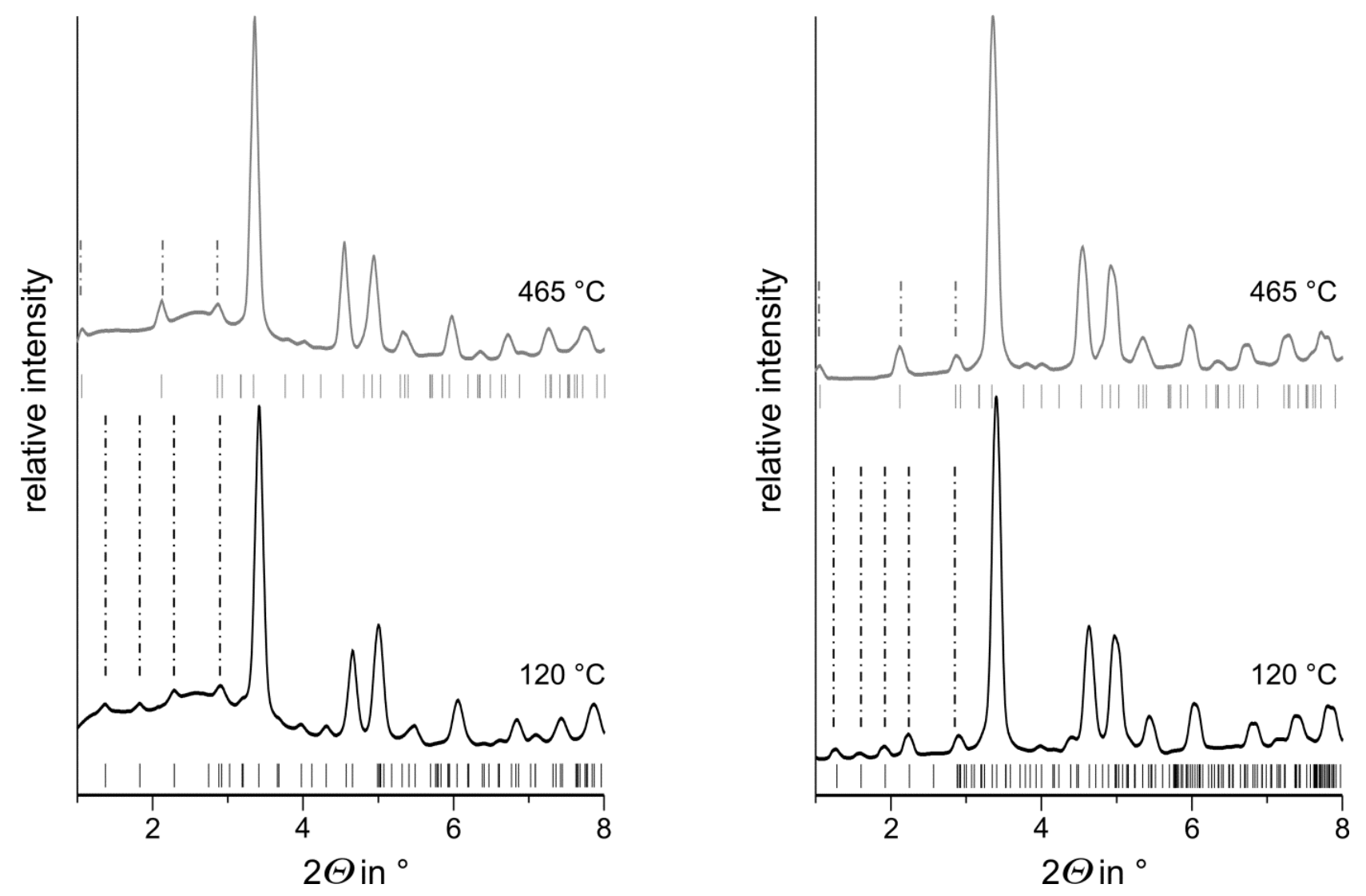

Figure S8: PXRD patterns (taken from Fig. $2, \lambda=0.18972 \AA$ ) of $\mathrm{Mn}_{0.85} \mathrm{Bi}_{4.10} \mathrm{Te}_{7}$ (left) and $\mathrm{Mn}_{0.81} \mathrm{Bi}_{6.13} \mathrm{Te}_{10}$ (right) at $120{ }^{\circ} \mathrm{C}$ (black curve) and $465{ }^{\circ} \mathrm{C}$ (gray curve; $\mathrm{Bi}_{2} \mathrm{Te}_{3}$ type resulting from decomposition); vertical black lines and dashed black lines indicate the reflection positions of $\mathrm{GeBi}_{4} \mathrm{Te}_{7}$-type structure (left) and of $\mathrm{GeBi}_{6} \mathrm{Te}_{10}$-type structure (right), respectively; vertical gray lines and gray dashed lines indicate reflection positons of $\mathrm{a}_{2} \mathrm{Te}_{3}$-type structure; note that the strongest reflections may easily be confused with each other. 
Table S8: Signals of $\mathrm{Mn}_{0.85} \mathrm{Bi}_{4.10} \mathrm{Te}_{7}$ in the DSC experiment and possible assignments.

\begin{tabular}{llll}
\hline Run & Signal & $\mathbf{T}_{\text {peak }} /{ }^{\circ} \mathbf{C}$ & possible assignment \\
\hline $\mathbf{1}^{\text {st }}$ heating & $\begin{array}{l}\text { shoulder } \\
\text { of } 1\end{array}$ & & melting of $\mathrm{Bi}_{2} \mathrm{Te}_{3}$ \\
& 1 & 590.2 & melting of $\mathrm{Mn}_{0.85} \mathrm{Bi}_{4.10} \mathrm{Te}_{7}$ \\
\hline & 2 & 598.2 & melting of $\mathrm{Mn}_{2} \mathrm{BiTe}_{4}$ \\
\hline $\mathbf{1}^{\text {st }}$ cooling & 1 & 588.7 & solidification of $\mathrm{Mn}_{2} \mathrm{BiTe}_{4}$ \\
\hline & 2 & 584.5 & solidification of $\mathrm{Mn}_{0.85} \mathrm{Bi}_{4.10} \mathrm{Te}_{7}$ \\
\hline $\mathbf{2}^{\text {nd }}$ heating & 1 & 580.5 & solidification of $\mathrm{Bi}_{2} \mathrm{Te}_{3}$ \\
\hline & 1 ' & 589.2 & melting of $\mathrm{Bi}_{2} \mathrm{Te}_{3}$ \\
& 2 & 590.5 & melting of $\mathrm{Mn}_{0.85} \mathrm{Bi}_{4.10} \mathrm{Te}_{7}$ \\
\hline $\mathbf{2}^{\text {nd }}$ cooling & 1 & 588.7 & melting of $\mathrm{Mn}_{2} \mathrm{BiTe}_{4}$ \\
\hline & 2 & 584.5 & solidification of $\mathrm{Mn}_{2} \mathrm{BiTe}_{4}$ \\
\hline & 3 & 580.5 & solidification of $\mathrm{Mn}_{0.85} \mathrm{Bi}_{4.10} \mathrm{Te}_{7}$ \\
\hline
\end{tabular}
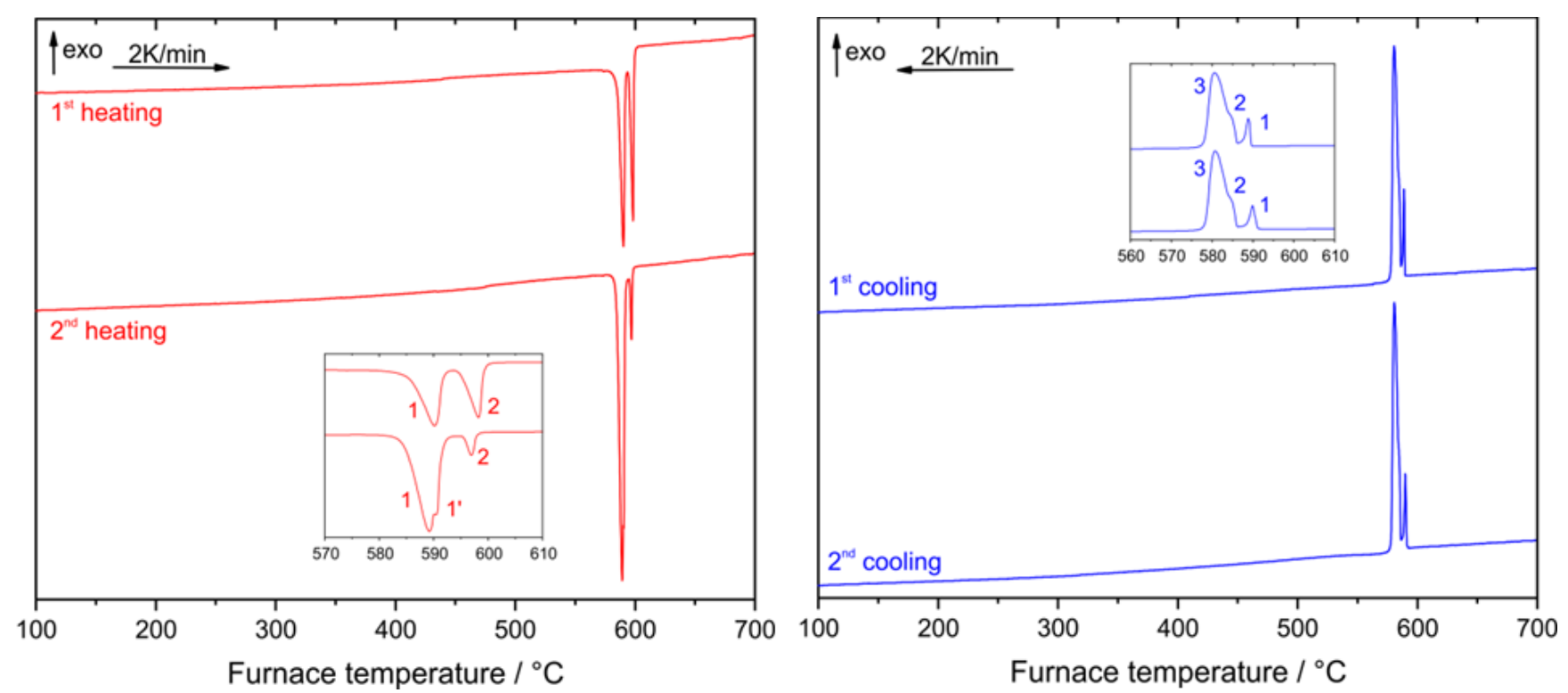

Figure S9: DSC experiments (two heating-cooling cycles from $100-700{ }^{\circ} \mathrm{C}$ ) for $\mathrm{Mn}_{0.85} \mathrm{Bi}_{4.10} \mathrm{Te}_{7}$. 
Table S9: Signals of $\mathrm{Mn}_{0.81} \mathrm{Bi}_{6.13} \mathrm{Te}_{10}$ DSC experiment and possible assignment.

\begin{tabular}{|c|c|c|c|}
\hline Run & Signal & $\mathbf{T}_{\text {peak }} /{ }^{\circ} \mathbf{C}$ & Possible assignment \\
\hline \multirow[t]{4}{*}{$1^{\text {st }}$ heating } & 1 & 574.0 & Melting Bi-rich $\mathrm{Bi}_{\mathrm{x}} \mathrm{Te}_{\mathrm{y}}$ \\
\hline & 2 & 588.3 & Melting $\mathrm{Mn}_{0.81} \mathrm{Bi}_{6.13} \mathrm{Te}_{10}$ \\
\hline & 3 & 590.0 & Melting $\mathrm{Mn}_{0.85} \mathrm{Bi}_{4.10} \mathrm{Te}_{7}$ \\
\hline & 4 & 598.2 & Melting $\mathrm{Mn}_{2} \mathrm{BiTe}_{4}$ \\
\hline $1^{\text {st }}$ cooling & $\begin{array}{l}1 \quad \text { (broad } \\
\text { unstructured } \\
\text { signal) }\end{array}$ & & $\begin{array}{l}\mathrm{Bi}_{2} \mathrm{Te}_{3} \text { and Mn-poorer } \square_{0.06} \mathrm{Mn}_{0.81} \mathrm{Bi}_{6.13} \mathrm{Te}_{10} \text { and } \\
\square_{0.05} \mathrm{Mn}_{0.85} \mathrm{Bi}_{4.10} \mathrm{Te}_{7}\end{array}$ \\
\hline \multirow[t]{2}{*}{$2^{\text {nd }}$ heating } & 1 & & $\begin{array}{l}\mathrm{Bi}_{2} \mathrm{Te}_{3} \text { and Mn-poorer } \square_{0.06} \mathrm{Mn}_{0.81} \mathrm{Bi}_{6.13} \mathrm{Te}_{10} \text { and } \\
\square_{0.05} \mathrm{Mn}_{0.85} \mathrm{Bi}_{4.10} \mathrm{Te}_{7}\end{array}$ \\
\hline & 2 & & Melting $\mathrm{Mn}_{2} \mathrm{BiTe}_{4}$ \\
\hline $2^{\text {nd }}$ cooling & $\begin{array}{l}1 \quad \text { (broad } \\
\text { unstructured } \\
\text { signal) }\end{array}$ & & $\begin{array}{l}\mathrm{Bi}_{2} \mathrm{Te}_{3} \text { and Mn-poorer } \square_{0.06} \mathrm{Mn}_{0.81} \mathrm{Bi}_{6.13} \mathrm{Te}_{10} \text { and } \\
\square_{0.05} \mathrm{Mn}_{0.85} \mathrm{Bi}_{4.10} \mathrm{Te}_{7}\end{array}$ \\
\hline
\end{tabular}
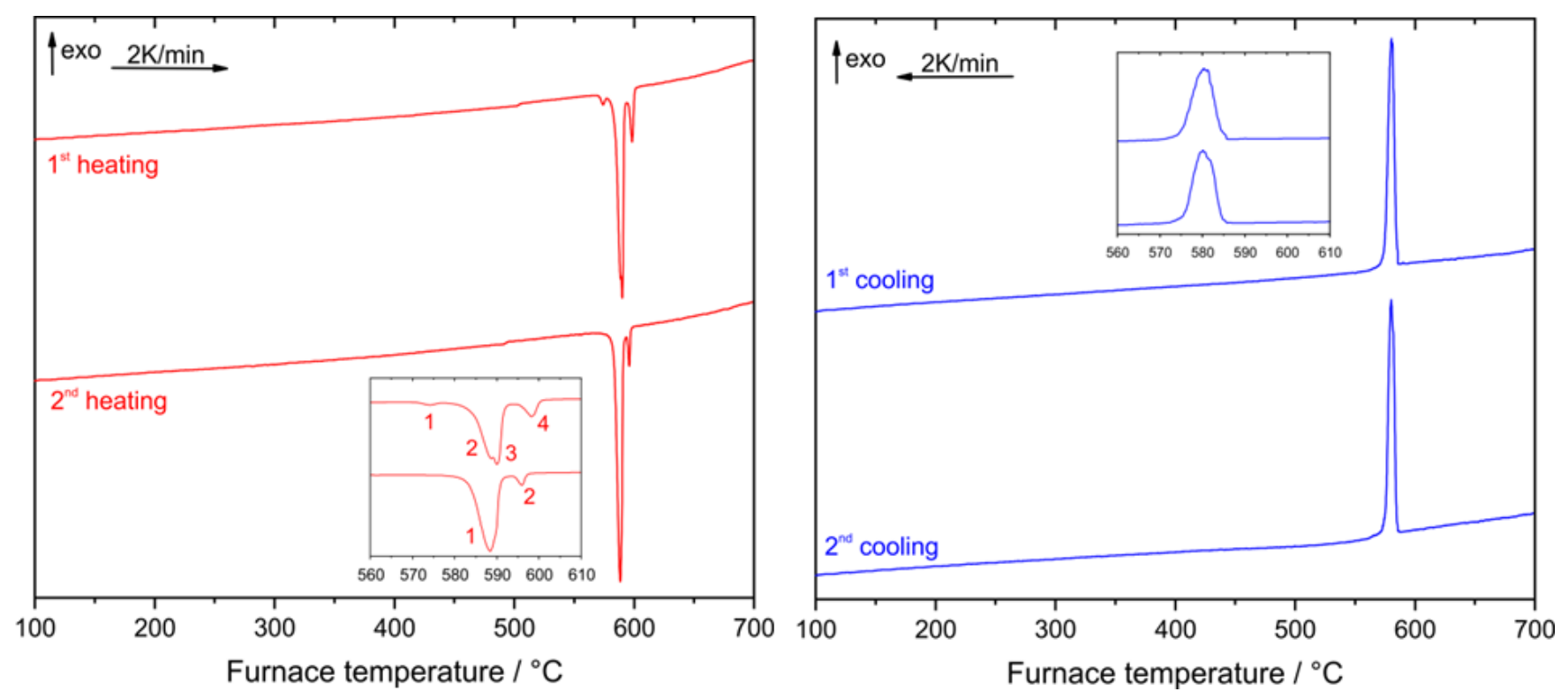

Figure S10: DSC experiments (two heating-cooling cycles from $100-700{ }^{\circ} \mathrm{C}$ ) for $\mathrm{Mn}_{0.81} \mathrm{Bi}_{6.13} \mathrm{Te}_{10}$. 


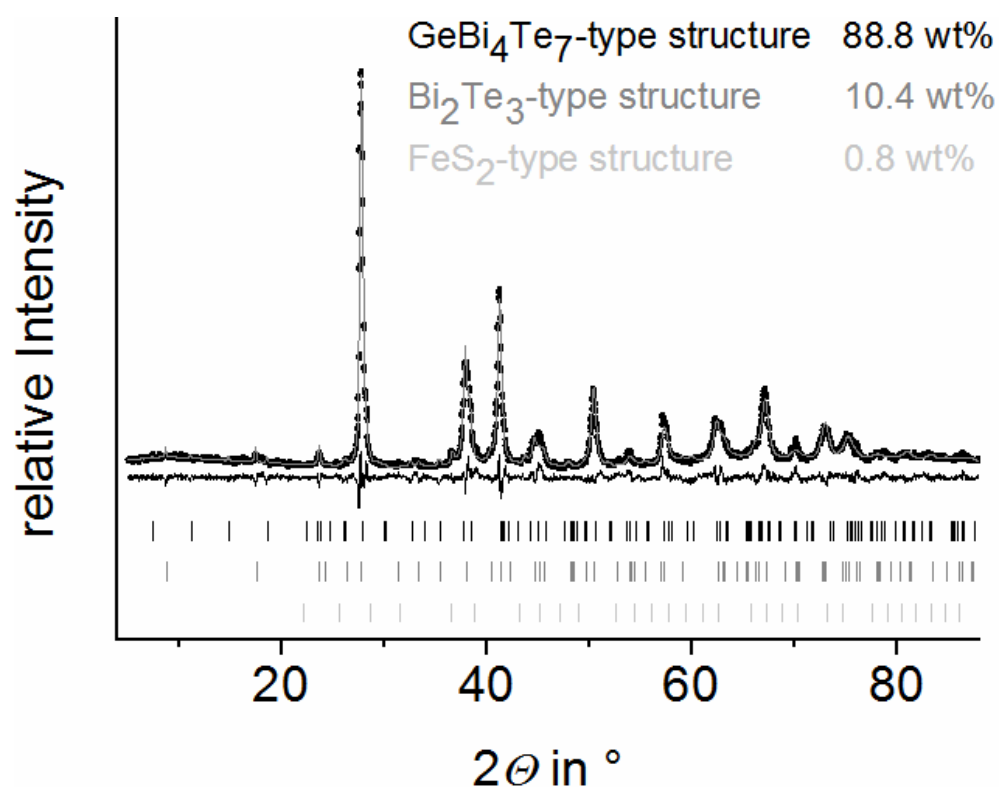

Figure S11: PXRD pattern of the decomposition product of a sample with the nominal composition $\mathrm{Mn}_{0.85} \mathrm{Bi}_{4.10} \mathrm{Te}_{7}$ after DSC heating up to $400{ }^{\circ} \mathrm{C}$; Rietveld refinements taking into account structure models for $\mathrm{Mn}_{0.85} \mathrm{Bi}_{4.10} \mathrm{Te}_{7}\left(\mathrm{GeBi}_{4} \mathrm{Te}_{7}\right.$ type $), \mathrm{Mn}_{0.73} \mathrm{Bi}_{6.18} \mathrm{Te}_{10}\left(\mathrm{GeBi}_{6} \mathrm{Te}_{10}\right.$ type) based on SCXRD refinements (section 3.3), for $\mathrm{Bi}_{2} \mathrm{Te}_{3}$ [Atuchin, V. V.; Gavrilova, T. A.; Kokh, K. A.; Kuratieva, N.V.; Pervukhina, N.B.; Surovtsev, N. V. Solid State Commun. 2012, 152, 1119-1122] and for $\mathrm{MnTe}_{2}\left(\mathrm{FeS}_{2}\right.$-type structure, space group Pa3) [Fjellvåg, H.; Kjekshus, A.; Chattopadhyay, T.; Hochheimer, H. D.; Hönle, W.; von Schnering, H. G. Pressure induced phase transition in MnTe 2. Phys. Lett. 1985, 112A, 411-413]; experimental data (black points), refined curve (gray), difference plot (black) and reflection markers: black $\mathrm{GeBi}_{4} \mathrm{Te}_{7}$ type, dark gray $\mathrm{Bi}_{2} \mathrm{Te}_{3}$ type and light gray $\mathrm{MnTe}_{2}$.

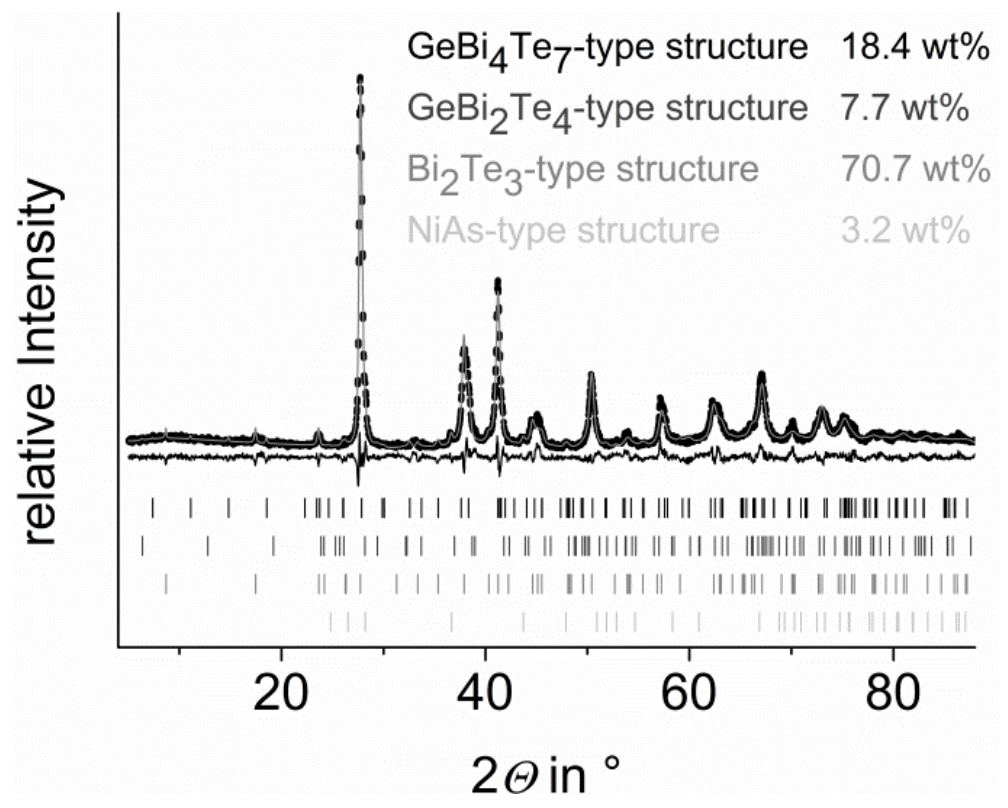

Figure S12: PXRD of the decomposition product of $\mathrm{Mn}_{0.85} \mathrm{Bi}_{4.10} \mathrm{Te}_{7}$ after a DSC experiment with two consecutive cycles from RT up to $700{ }^{\circ} \mathrm{C}$; Rietveld refinements taking into account structure models for $\mathrm{Mn}_{0.85} \mathrm{Bi}_{4.10} \mathrm{Te}_{7}\left(\mathrm{GeBi}_{4} \mathrm{Te}_{7}-\mathrm{type}_{\mathrm{p}}\right.$ structure, section 3.3), $\mathrm{Mn}_{0.85} \mathrm{Bi}_{2.1} \mathrm{Te}_{4}$ [ $\mathrm{GeBi}_{2} \mathrm{Te}_{4}$-type structure: [Zeugner, A.; Nietschke, F.; Wolter A. U. B.; Gaß, S.; Vidal, R. C.; Peixoto, T. R. F.; Pohl, D.; Damm, C.; Lubk, A.; Hentrich, R.; Moser, S. K.; Fornari, C.; Min, C. H., Schatz, S.; Kißner, K.; Ünzelmann, M.; Kaiser, M.; Scaravaggi, F. Rellinghaus, B.; Nielsch, K.; Heß, C.; Büchner, B.; Reinert, F.; Bentmann, H.; Oeckler, O.; Doert, T.; Ruck, M.; Isaeva, A. Chemical Aspects of the Antiferromagnetic Topological Insulator $\mathrm{MnBi}_{2} \mathrm{Te}_{4}$; available at arxiv.org/abs/1812.03106]; experimental data (black points), for $\mathrm{Bi}_{2} \mathrm{Te}_{3}$ [Atuchin, V. V.; Gavrilova, T. A.; Kokh, K. A.; Kuratieva, N.V.; Pervukhina, N.B.; Surovtsev, N. V. Solid State Commun. 2012, 152, 1119-1122] and for MnTe (NiAstype structure) [Efrem D'Sa, J.B.C.; Bhobe, P. A.; Riolkar, K. R.; Das, A.; Paranjpe, S. K.; Prabhu, R. B.; Sarode, P. R. J. Magn. Magn. Mater. 2005, 285, 267-271], refined curve (gray), difference plot (black) and reflection positions (black $\mathrm{GeBi}_{4} \mathrm{Te}_{7}$ type; dark gray $\mathrm{GeBi}_{2} \mathrm{Te}_{4}$ type, gray $\mathrm{Bi}_{2} \mathrm{Te}_{3}$ type and light gray NiAs-type structure of $\mathrm{MnTe}$ ). 


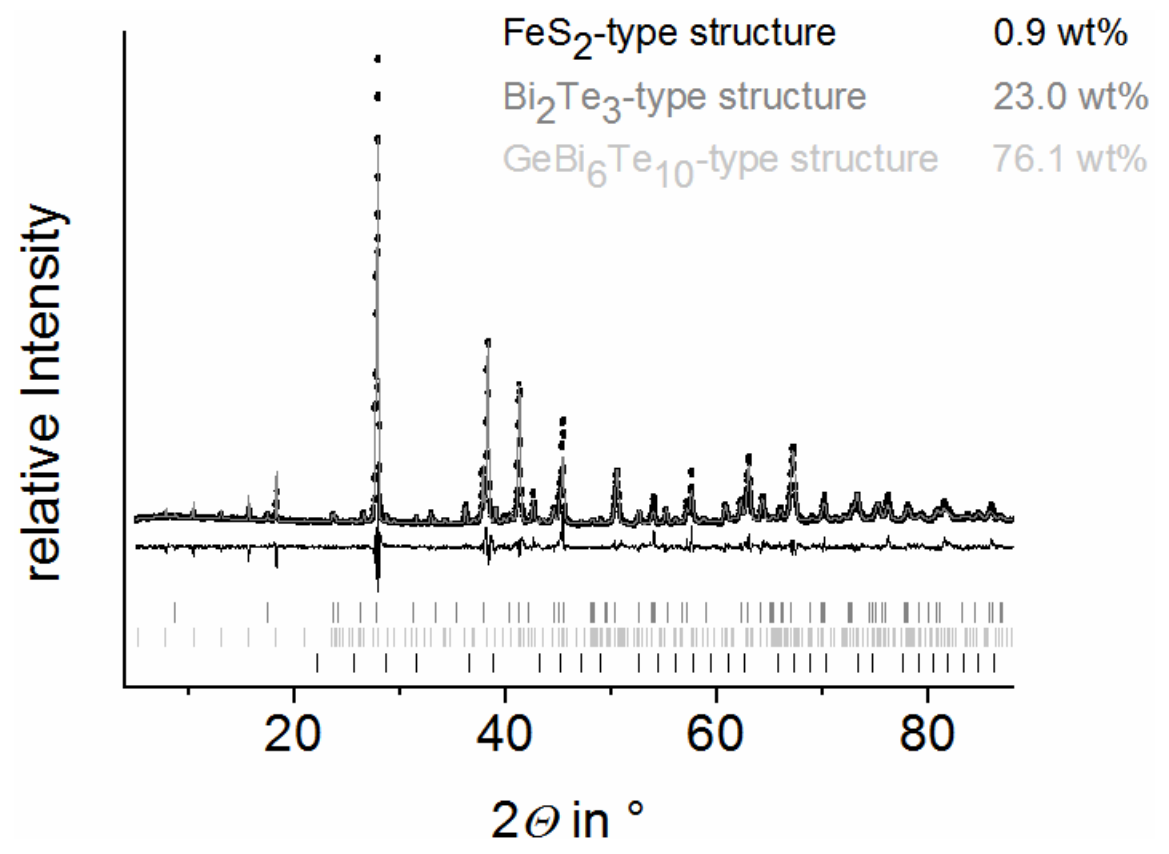

Figure S13: PXRD pattern of the decomposition product of $\mathrm{Mn}_{0.81} \mathrm{Bi}_{6.13} \mathrm{Te}_{10}$ after DSC (heating up to $400{ }^{\circ} \mathrm{C}$ ); Rietveld refinement taking into account structure models for $\mathrm{Mn}_{0.85} \mathrm{Bi}_{4.10} \mathrm{Te}_{7}\left(\mathrm{GeBi}_{4} \mathrm{Te}_{7}\right.$-type structure), $\mathrm{Mn}_{0.73} \mathrm{Bi}_{6.18} \mathrm{Te}_{10}\left(\mathrm{GeBi}_{6} \mathrm{Te}_{10}\right.$-type structure) based on $\mathrm{SCXRD}$ (section 3.3), for $\mathrm{Bi}_{2} \mathrm{Te}_{3}$ [Atuchin, V. V.; Gavrilova, T. A.; Kokh, K. A.; Kuratieva, N. V.; Pervukhina, N. B.; Surovtsev, N. V. Solid State Commun. 2012, 152, 1119-1122] and for $\mathrm{MnTe}_{2}\left(\mathrm{FeS}_{2}\right.$-type structure, space group Pa3) [Fjellvåg, H.; Kjekshus, A.; Chattopadhyay, T.; Hochheimer, H. D.; Hönle, W.; von Schnering, H. G. Phys. Lett. 1985, 112A, 411-413]; experimental data (black points), refined curve (gray), difference plot (black) and reflection markers (black $\mathrm{GeBi}_{6} \mathrm{Te}_{10}$ type, dark gray $\mathrm{Bi}_{2} \mathrm{Te}_{3}$ type and light gray $\mathrm{MnTe}_{2}$ ).

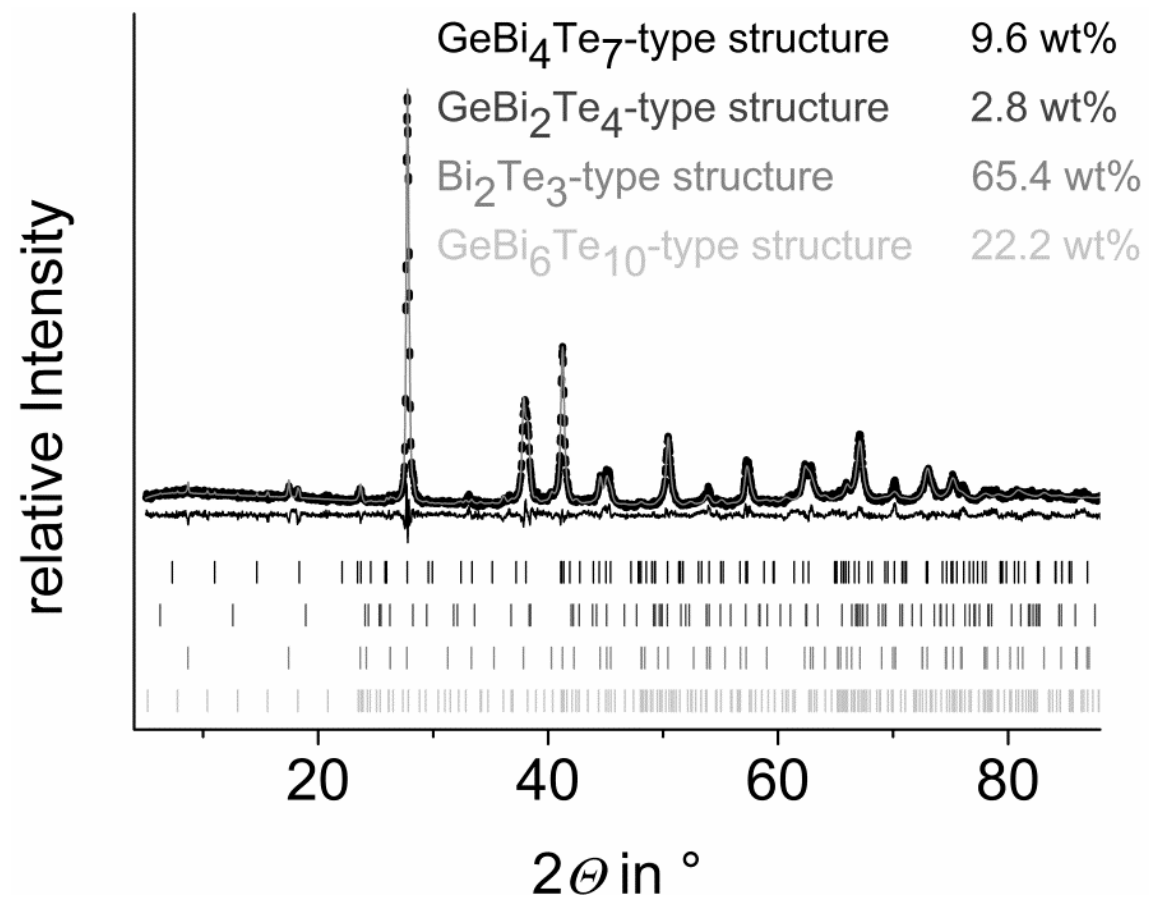

Figure S14: PXRD of the decomposition product of $\mathrm{Mn}_{0.81} \mathrm{Bi}_{6.13} \mathrm{Te}_{10}$ after a DSC experiment with two consecutive cycles from RT up to $700{ }^{\circ} \mathrm{C}$; Rietveld refinement taking into account structure models for $\mathrm{Mn}_{0.85} \mathrm{Bi}_{4.10} \mathrm{Te}_{7}\left(\mathrm{GeBi}_{4} \mathrm{Te}_{7}\right.$ type $), \mathrm{Mn}_{0.73} \mathrm{Bi}_{6.18} \mathrm{Te}_{10}\left(\mathrm{GeBi}_{6} \mathrm{Te}_{10}\right.$ type $)$ based on SCXRD (section 3.3), and $\mathrm{Mn}_{0.85} \mathrm{Bi}_{2.1} \mathrm{Te}_{4}$ [Zeugner, A.; Nietschke, F.; Wolter A. U. B.; Gaß, S.; Vidal, R. C.; Peixoto, T. R. F.; Pohl, D.; Damm, C.; Lubk, A.; Hentrich, R.; Moser, S. K.; Fornari, C.; Min, C. H., Schatz, S.; Kißner, K.; Ünzelmann, M.; Kaiser, M.; Scaravaggi, F. Rellinghaus, B.; Nielsch, K.; Heß, C.; Büchner, B.; Reinert, F.; Bentmann, H.; Oeckler, O.; Doert, T.; Ruck, M.; Isaeva, A. Chemical Aspects of the Antiferromagnetic Topological Insulator $\mathrm{MnBi}_{2} \mathrm{Te}_{4}$; available at arxiv.org/abs/1812.03106] and for $\mathrm{Bi}_{2} \mathrm{Te}_{3}$ [Atuchin, V. V.; Gavrilova, T. A.; Kokh, K. A.; Kuratieva, N. V.; Pervukhina, N. B.; Surovtsev, N. V. Solid State Commun. 2012, 152, 11191122]; experimental data (black points), refined curve (gray), difference plot (black) and reflection markers (black $\mathrm{GeBi}_{4} \mathrm{Te}_{7}$ type; dark gray $\mathrm{GeBi}_{2} \mathrm{Te}_{4}$ type, gray $\mathrm{Bi}_{2} \mathrm{Te}_{3}$ type and light gray $\mathrm{GeBi}_{6} \mathrm{Te}_{10}$ type). 

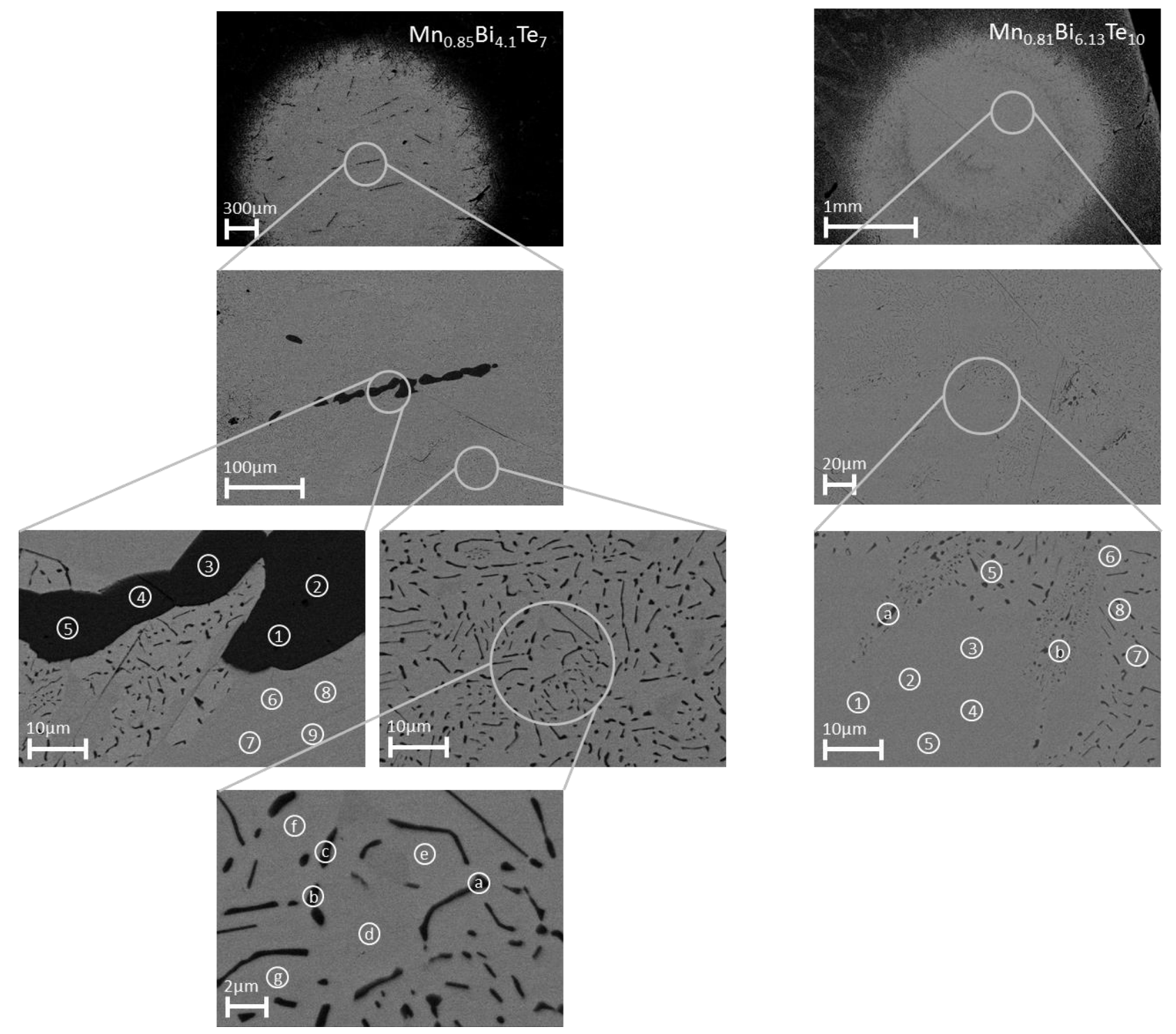

Figure S15: SEM images (backscattered electrons) after thermoelectric measurements (3 cycles; RT $\left.-400{ }^{\circ} \mathrm{C}\right)$ of samples with the nominal composition $\mathrm{Mn}_{0.85} \mathrm{Bi}_{4.10} \mathrm{Te}_{7}$ (left) and $\mathrm{Mn}_{0.81} \mathrm{Bi}_{6.13} \mathrm{Te}_{10}$ (right) with increasing magnification from top to bottom; black areas (lines, spots) correspond to manganese tellurides and possibly other Mn-rich phases, light gray areas to Mn-doped $\mathrm{Bi}_{2} \mathrm{Te}_{3}$ and the dark gray main phase to $\mathrm{Mn}_{0.85} \mathrm{Bi}_{4.10} \mathrm{Te}_{7}$ and $\mathrm{Mn}_{0.81} \mathrm{Bi}_{6.13} \mathrm{Te}_{10}$, respectively; EDX results are given in Table $\mathrm{S} 10$.

Table S10: Results of SEM-EDX analyses (marked in Fig. S15) for samples with the nominal compositions $\mathrm{Mn}_{0.85} \mathrm{Bi}_{4.1} \mathrm{Te}_{7}$ and $\mathrm{Mn}_{0.81} \mathrm{Bi}_{6.13} \mathrm{Te}_{10}$ after thermoelectric measurements ( 3 cycles; RT-400 ${ }^{\circ} \mathrm{C}$ ) taking into account formed precipitates; data averaged from $2-5$ point measurements; the small size of the precipitates can result in large errors as surrounding matrix material may contribute to point measurements.

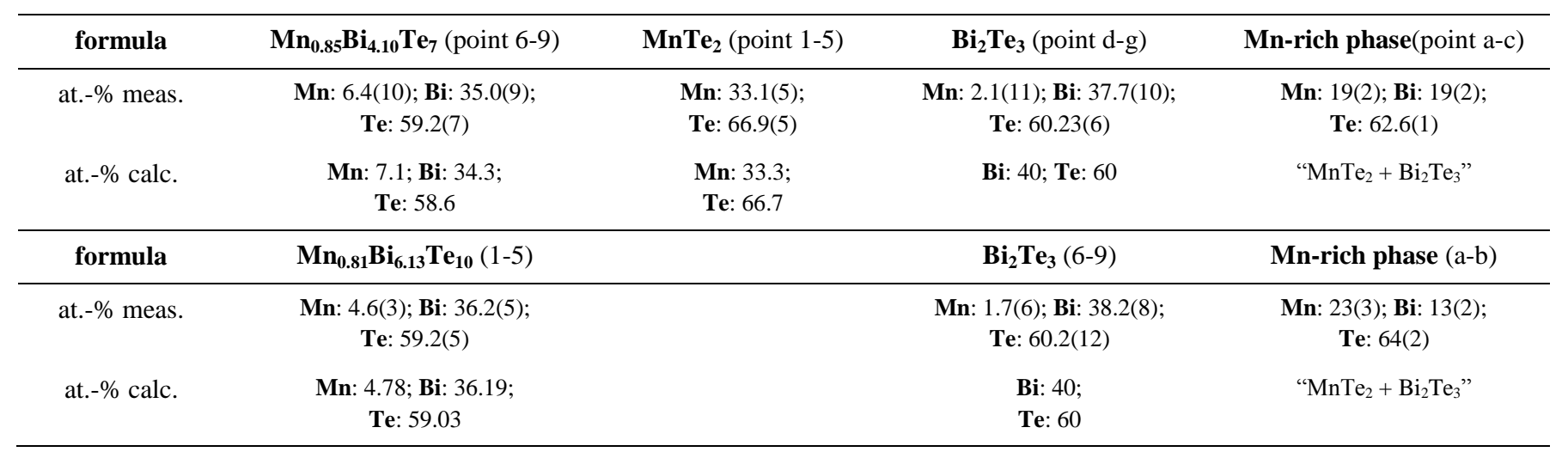




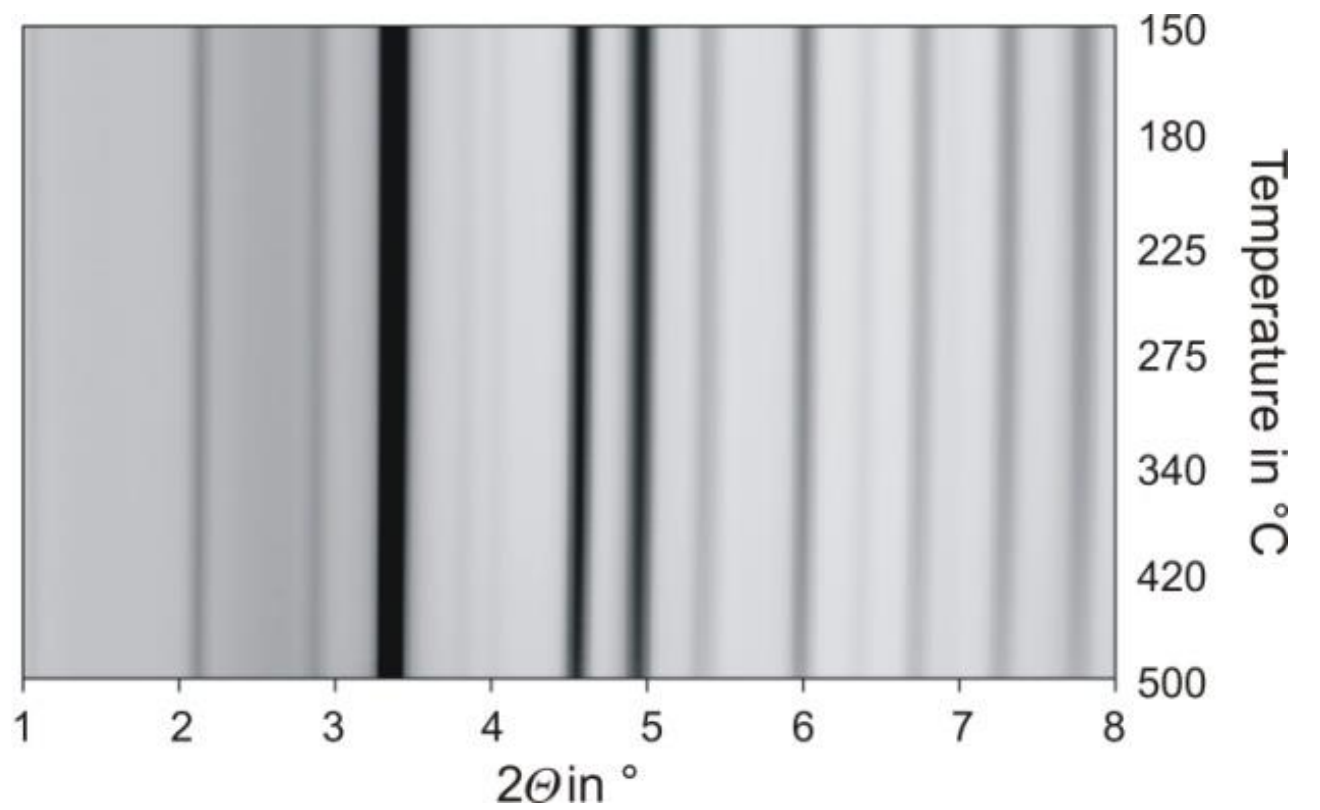

Figure S16: Temperature-dependent PXRD patterns of $\mathrm{Mn}_{0.85} \mathrm{Bi}_{4.10} \mathrm{Te}_{7}$ during cooling (decomposition into a $\mathrm{Bi}_{2} \mathrm{Te}_{3}$-like structure took place during heating): the starting materials were not regained during cooling and the $\mathrm{Bi}_{2} \mathrm{Te}_{3}$-like structure remains $(\lambda=0.18972 \AA$, synchrotron radiation).

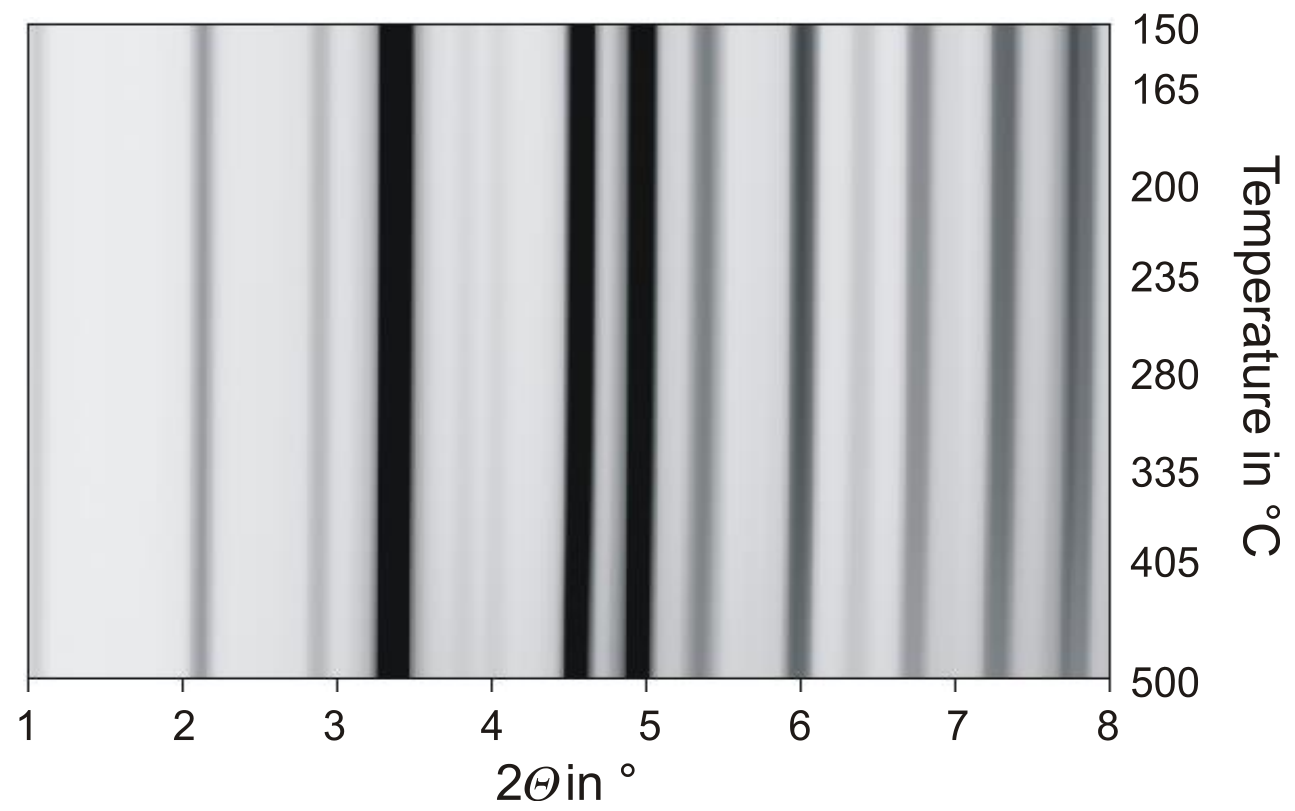

Figure S17: Temperature-dependent PXRD patterns of $\mathrm{Mn}_{0.81} \mathrm{Bi}_{6.13} \mathrm{Te}_{10}$ during cooling (decomposition into a $\mathrm{Bi}_{2} \mathrm{Te}_{3}$-like structure took place during heating): the starting materials were not regained during cooling and the $\mathrm{Bi}_{2} \mathrm{Te}_{3}$-like structure remains $(\lambda=0.18972 \AA$, synchrotron radiation). 

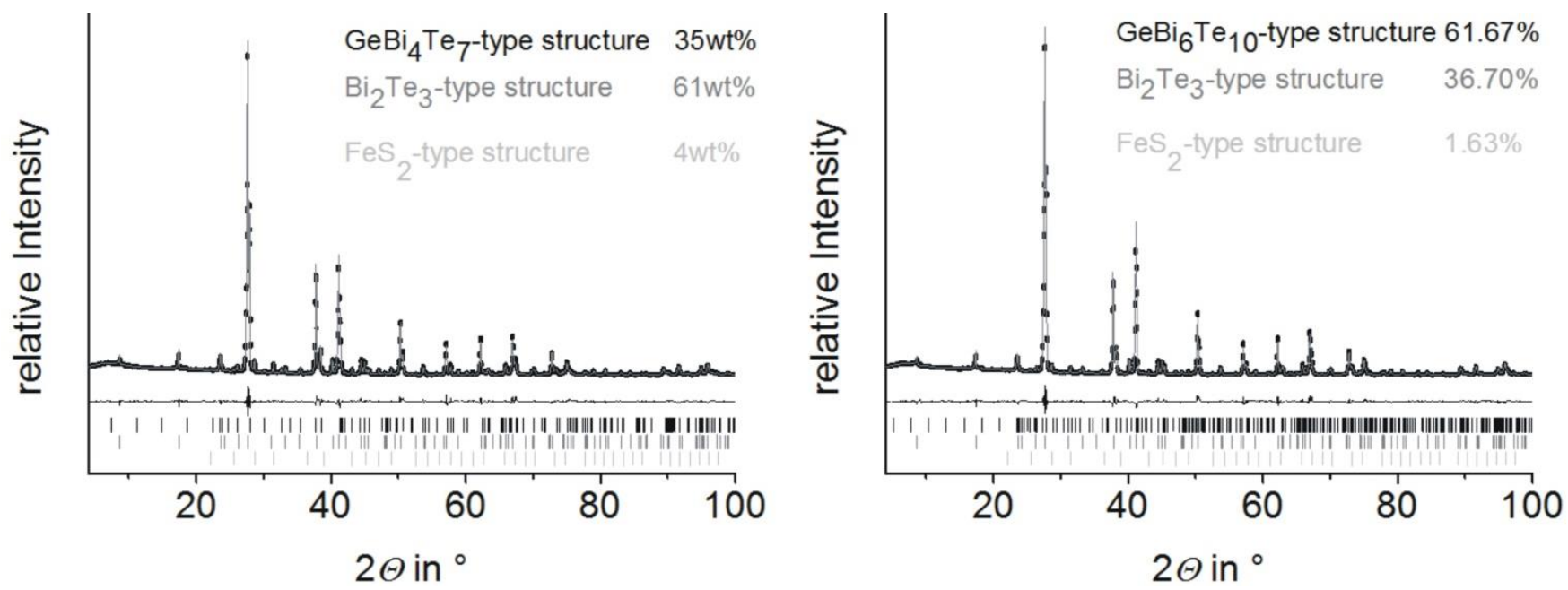

Figure S18: PXRD patterns of the decomposition products of $\mathrm{Mn}_{0.85} \mathrm{Bi}_{4.15} \mathrm{Te}_{7}$ (left) and $\mathrm{Mn}_{0.81} \mathrm{Bi}_{6.13} \mathrm{Te}_{10}$ (right) after $1 \mathrm{~d}$ at $300{ }^{\circ} \mathrm{C}$; Rietveld refinements taking into account structure models for $\mathrm{Mn}_{0.85} \mathrm{Bi}_{4.10} \mathrm{Te}_{7}\left(\mathrm{GeBi}_{4} \mathrm{Te}_{7}\right.$ type $), \mathrm{Mn}_{0.73} \mathrm{Bi}_{6.18} \mathrm{Te}_{10}\left(\mathrm{GeBi}_{6} \mathrm{Te}_{10}\right.$ type $)$ based on $\mathrm{SCXRD}$ data (section 3.3), for $\mathrm{Bi}_{2} \mathrm{Te}_{3}$ [Atuchin, V. V.; Gavrilova, T. A.; Kokh, K. A.; Kuratieva, N. V.; Pervukhina, N. B.; Surovtsev, N. V. Solid State Commun. 2012, 152, 1119-1122] and for $\mathrm{MnTe}_{2}\left(\mathrm{FeS}_{2}\right.$-type structure, space group Pa3) [Fjellvåg, H.; Kjekshus, A.; Chattopadhyay, T.; Hochheimer, H. D.; Hönle, W.; von Schnering, H. G. Phys. Lett. 1985, 112A, 411-413]; experimental data (black points), refined curve (gray), difference plot (black) and reflection markers black $\mathrm{GeBi}_{4} \mathrm{Te}_{7}$ type (left) or $\mathrm{GeBi}_{6} \mathrm{Te}_{10}$ type (right), dark $\mathrm{gray} \mathrm{Bi}_{2} \mathrm{Te}_{3}$ type and light gray $\left.\mathrm{MnTe}_{2}\right)$.
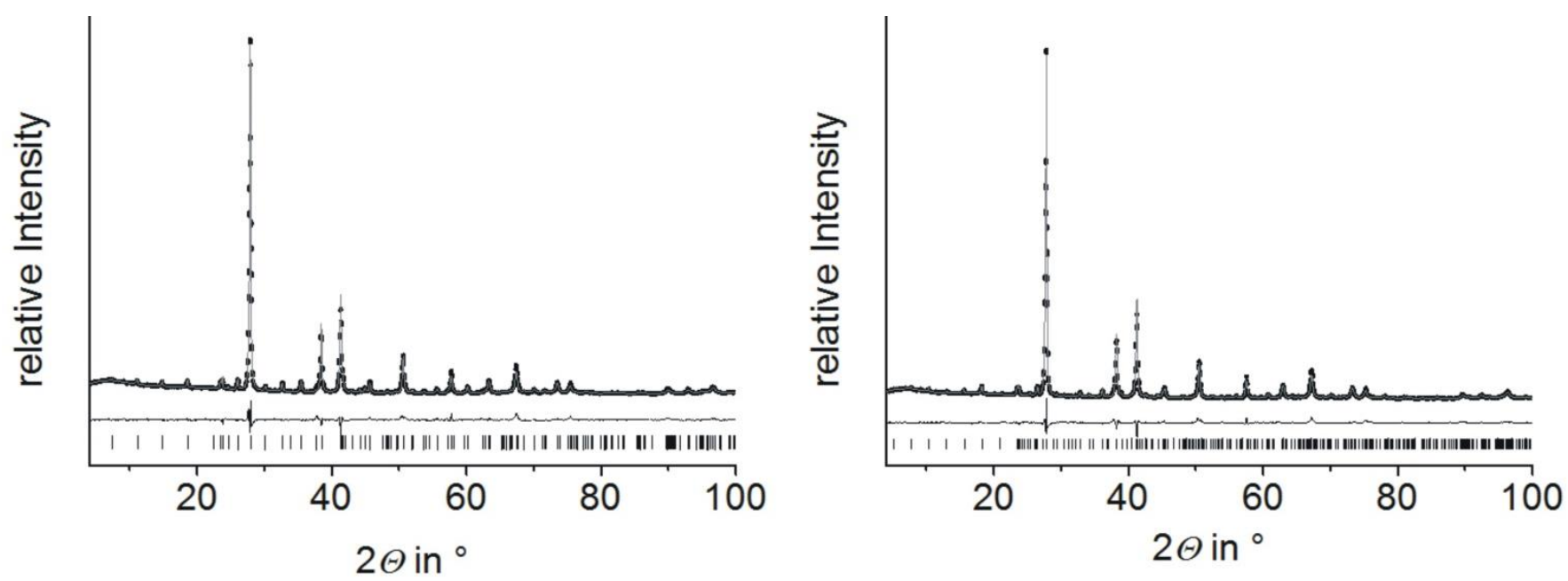

Figure S19: The decomposition products of Figure S18 were again treated like during the initial melt synthesis (section 2) and result in phase pure samples again: $\mathrm{Mn}_{0.85} \mathrm{Bi}_{4.10} \mathrm{Te}_{7}$ (left) and $\mathrm{Mn}_{0.81} \mathrm{Bi}_{6.13} \mathrm{Te}_{10}$ (right); Rietveld refinements taking into account structure models for $\mathrm{Mn}_{0.85} \mathrm{Bi}_{4.10} \mathrm{Te}_{7}\left(\mathrm{GeBi}_{4} \mathrm{Te}_{7}\right.$ type) and $\mathrm{Mn}_{0.73} \mathrm{Bi}_{6.18} \mathrm{Te}_{10}\left(\mathrm{GeBi}_{6} \mathrm{Te}_{10}\right.$ type) based on SCXRD refinements (section 3.3); calculated patterns light gray, experimental data black points; difference plot (black) and reflection markers (black lines for $\mathrm{GeBi}_{4} \mathrm{Te}_{7}$ type and $\mathrm{GeBi}_{6} \mathrm{Te}_{10}$ type, respectively). 


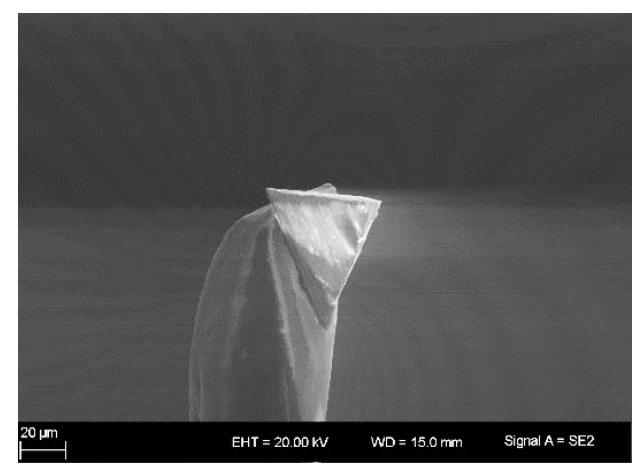

Figure S20: SEM SE image of the $\mathrm{Mn}_{0.85} \mathrm{Bi}_{4.10} \mathrm{Te}_{7}$ single crystal used for structure analysis.

Table S11: SEM-EDX data of the $\mathrm{Mn}_{0.85} \mathrm{Bi}_{4.10} \mathrm{Te}_{7}$ crystal used for structure analysis (averaged from five point measurements).

\begin{tabular}{|c|c|c|c|c|}
\hline at.- $\%$ measured & $\begin{array}{l}\text { at.- } \% \\
\text { for } \mathrm{Mn}_{0.85} \mathrm{Bi}_{4.10} \mathrm{Te}_{7}\end{array}$ & calculated & $\begin{array}{l}\text { at.- } \% \\
\text { for } \mathrm{MnBi}_{4} \mathrm{Te}_{7}\end{array}$ & calculated \\
\hline
\end{tabular}

Mn: 5.8(5); Bi: 35.9(5); Te: 58.3(3) Mn: 7.1; Bi: 34.3; Te: $58.6 \quad$ Mn: 8.33 Bi: 33.33 Te: 58.33

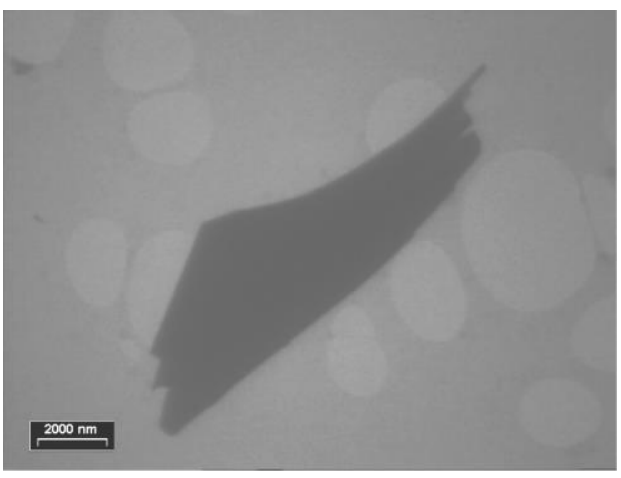

Figure S21: TEM image of the $\mathrm{Mn}_{0.73} \mathrm{Bi}_{6.18} \mathrm{Te}_{10}$ single crystal used for structure analysis.

Table S12: TEM-EDX data of the $\mathrm{Mn}_{0.73} \mathrm{Bi}_{6.18} \mathrm{Te}_{10}$ crystal used for structure analysis (averaged from two point measurements).

\begin{tabular}{lll}
\hline at.-\% measured & $\begin{array}{l}\text { at.-\% calculated } \\
\text { for } \mathrm{Mn}_{0.73} \mathrm{Bi}_{6.18} \mathrm{Te}_{10}\end{array}$ & $\begin{array}{l}\text { at.-\% calculated } \\
\text { for } \mathrm{MnBi}_{6} \mathrm{Te}_{10}\end{array}$ \\
\hline Mn: 5.4(4); Bi: 36.4(4); Te: $58.2(2)$ & $\mathbf{M n}: 4.3 ; \mathbf{B i}: 36.5 ;$ Te: 59.1 & Mn: 5.9 Bi: 35.3 Te: 58.8 \\
\hline
\end{tabular}


Table S13: Selected interatomic distances (in $\AA$ ) for $\mathrm{Mn}_{0.85} \mathrm{Bi}_{2.10} \mathrm{Te}_{4}$ [Zeugner, A.; Nietschke, F.; Wolter A. U. B.; Gaß, S.; Vidal, R. C.; Peixoto, T. R. F.; Pohl, D.; Damm, C.; Lubk, A.; Hentrich, R.; Moser, S. K.; Fornari, C.; Min, C. H., Schatz, S.; Kißner, K.; Ünzelmann, M.; Kaiser, M.; Scaravaggi, F. Rellinghaus, B.; Nielsch, K.; Heß, C.; Büchner, B.; Reinert, F.; Bentmann, H.; Oeckler, O.; Doert, T.; Ruck, M.; Isaeva, A. Chemical Aspects of the Antiferromagnetic Topological Insulator $\mathrm{MnBi}_{2} \mathrm{Te}_{4}$; available at arxiv.org/abs/1812.03106], $\mathrm{Bi}_{2} \mathrm{Te}_{3}$ [Mansour, A. N.; Wong-Ng, W.; Huang, W.: Tang, W.; Tompson, A.; Sharp, J. J. Appl. Phys. 2014, 116, 083513] as well as $\mathrm{Mn}_{0.85} \mathrm{Bi}_{4.10} \mathrm{Te}_{7}$ and $\mathrm{Mn}_{0.73} \mathrm{Bi}_{6.18} \mathrm{Te}_{10}$ (this work).

\begin{tabular}{|c|c|c|c|c|c|c|c|}
\hline $\mathrm{Mn}_{0.73} \mathrm{Bi}_{6.18} \mathrm{Te}_{10}$ & $\begin{array}{l}\text { bond length } \\
\text { in } \AA\end{array}$ & $\mathbf{M n}_{0.85} \mathbf{B i}_{4.10} \mathbf{T e}_{7}$ & $\begin{array}{l}\text { bond length } \\
\text { in } \AA\end{array}$ & $\mathbf{M n}_{0.85} \mathbf{B i}_{2.1} \mathbf{T e}_{4}$ & $\begin{array}{l}\text { bond length } \\
\text { in } \AA\end{array}$ & $\mathrm{Bi}_{2} \mathrm{Te}_{3}$ & $\begin{array}{l}\text { bond length } \\
\text { in } \AA\end{array}$ \\
\hline septuple layer & & septuple layer & & septuple layer & & & \\
\hline $\mathrm{Mn} 2 / \mathrm{Bi} 2-\mathrm{Te} 2$ & $3.0473(5)$ & $\mathrm{Mn} 2 / \mathrm{Bi} 2-\mathrm{Te} 2$ & $3.0436(7)$ & $\mathrm{Bi} 1 / \mathrm{Mn} 1-\mathrm{Te} 2$ & $3.027(1)$ & & \\
\hline $\mathrm{Mn} 2 / \mathrm{Bi} 2-\mathrm{Te} 1$ & $3.3055(6)$ & $\mathrm{Mn} 2 / \mathrm{Bi} 2-\mathrm{Te} 1$ & $3.2987(9)$ & $\mathrm{Bi} 1 / \mathrm{Mn} 1-\mathrm{Te} 1$ & $3.291(1)$ & & \\
\hline Mn1/Bi1 - Te1 & $2.9969(4)$ & $\mathrm{Mn} 1 / \mathrm{Bi} 1-\mathrm{Te} 1$ & $2.9909(7)$ & $\mathrm{Bi} 2 / \mathrm{Mn} 2-\mathrm{Te} 1$ & $2.977(1)$ & & \\
\hline van der Waals gap & & van der Waals gap & & van der Waals gap & & van der Waals gap & \\
\hline $\mathrm{Te} 2 \cdots \mathrm{Te} 3$ & $3.6516(5)$ & $\mathrm{Te} 2 \cdots \mathrm{Te} 3$ & $3.6559(7)$ & $\mathrm{Te} 2 \cdots \mathrm{Te} 2$ & $3.699(1)$ & $\mathrm{Te} 2-\mathrm{Te} 2$ & 3.630 \\
\hline Te $5 \cdots$ Te 5 & $3.6432(5)$ & & & & & & \\
\hline quintuple layers & & quintuple layer & & quintuple layer & & quintuple layer & \\
\hline $\mathrm{Mn} 3 / \mathrm{Bi} 3-\mathrm{Te} 3$ & $3.0628(5)$ & $\mathrm{Mn} 3 / \mathrm{Bi} 3-\mathrm{Te} 3$ & $3.0543(7)$ & & & $\mathrm{Bi}-\mathrm{Te} 2$ & 3.067 \\
\hline Mn3/Bi3 - Te4 & $3.2395(5)$ & $\mathrm{Mn} 3 / \mathrm{Bi} 3-\mathrm{Te} 4$ & $3.2410(4)$ & & & $\mathrm{Bi}-\mathrm{Te} 1$ & 3.254 \\
\hline Mn4/Bi4 - Te4 & $3.2536(5)$ & & & & & & \\
\hline $\mathrm{Mn} 4 / \mathrm{Bi} 4-\mathrm{Te} 5$ & $3.0594(5)$ & & & & & & \\
\hline
\end{tabular}




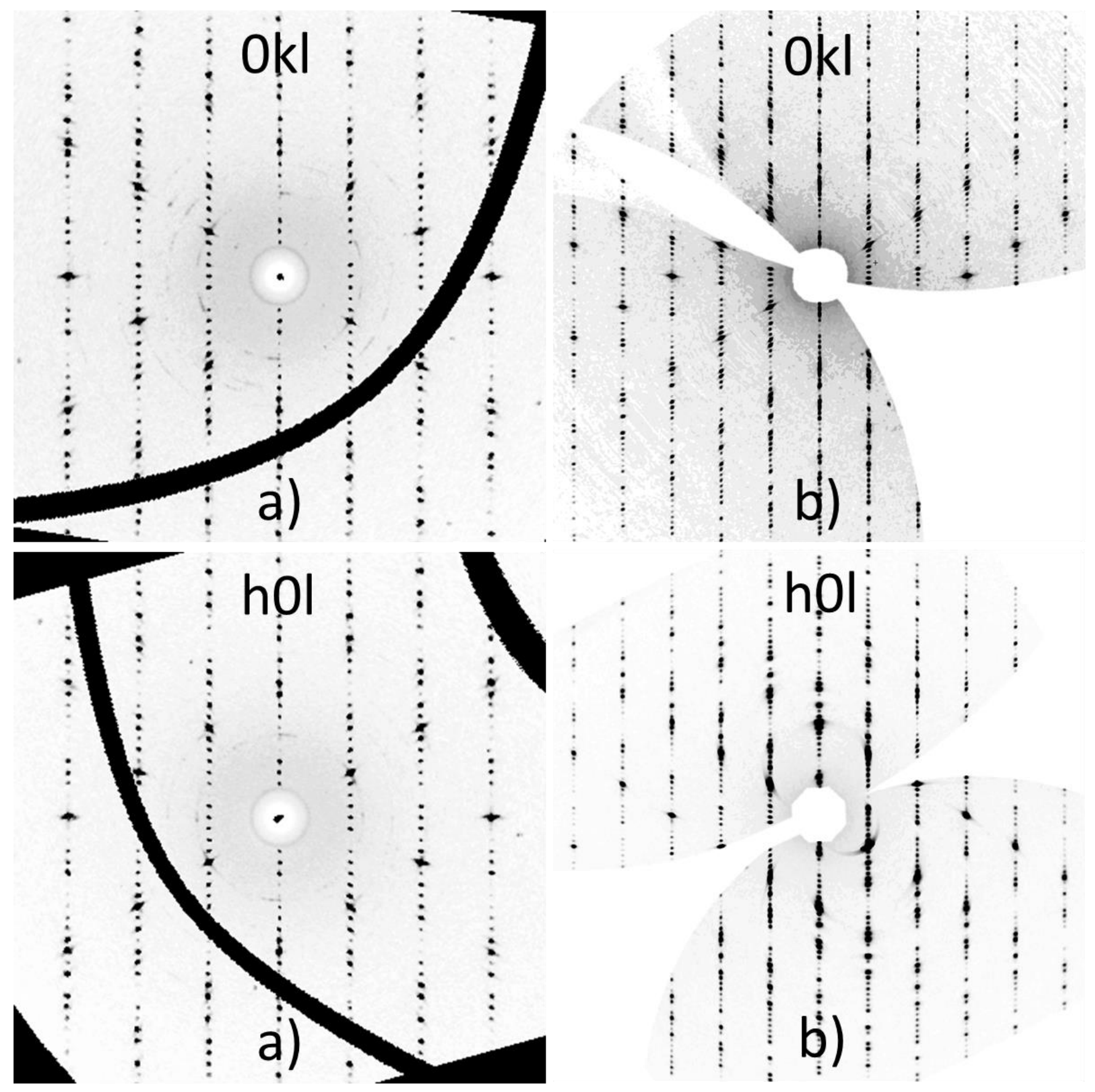

Figure S22: Reconstructed reciprocal lattice sections $0 \mathrm{kl}$ (top) and $h 0 l$ (bottom) from the data of the crystals used for structure analysis: a) $\mathrm{Mn}_{0.85} \mathrm{Bi}_{4.10} \mathrm{Te}_{7}$ single crystal $\left(\mathrm{GeBi}_{4} \mathrm{Te}_{7}\right.$-type structure $)$ and $\left.\mathrm{b}\right) \mathrm{Mn}_{0.73} \mathrm{Bi}_{6.18} \mathrm{Te}_{10}$ single crystal $\left(\mathrm{GeBi}_{6} \mathrm{Te}_{10}\right.$-type structure). No pronounced diffuse streaks, which would suggest stacking disorder, are visible in the experimental diffraction patterns of both crystals. 


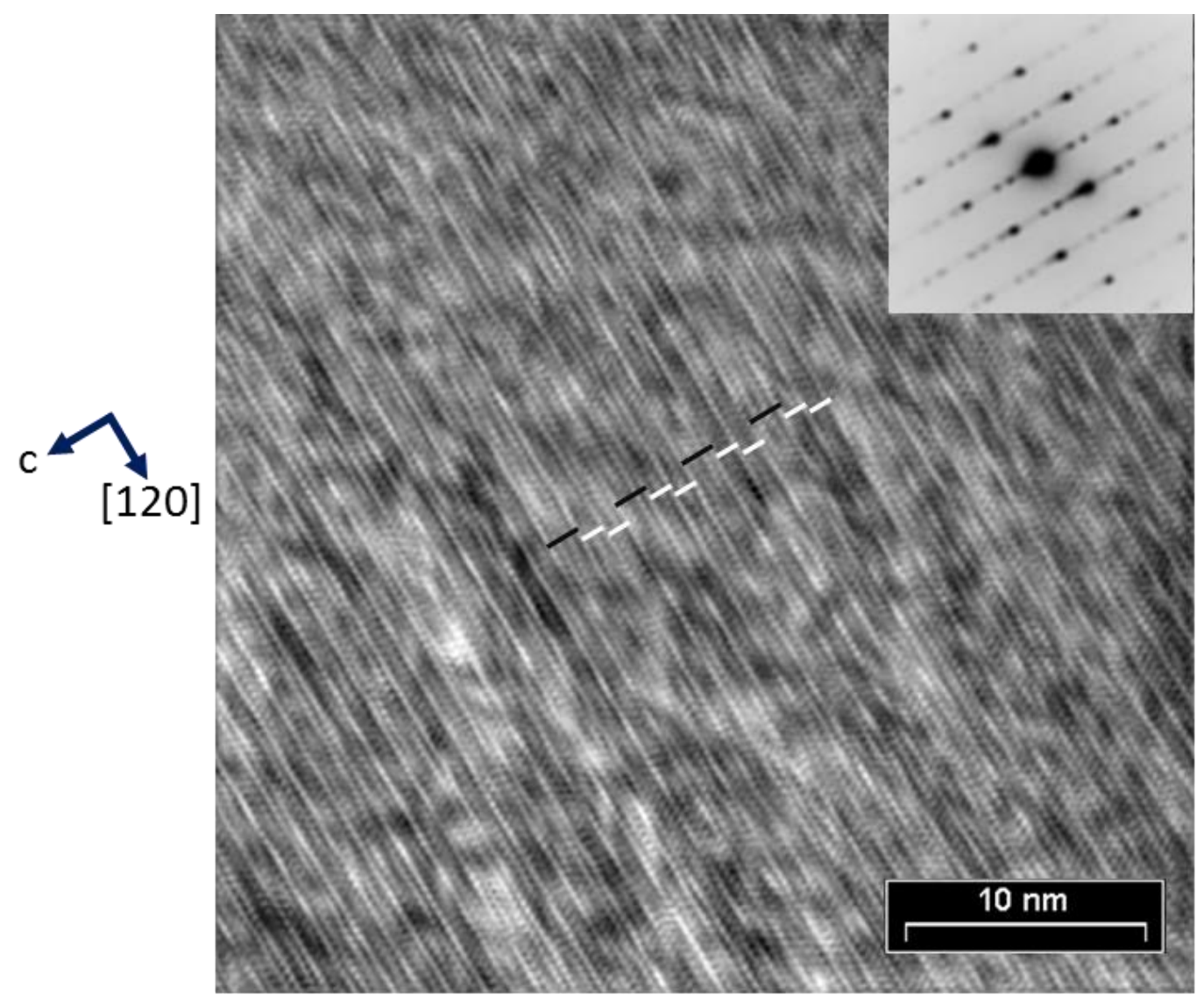

Figure S23: HRTEM image (zone axis [100], Fourier filtered) of manganese bismuth tellurides with $\mathrm{GeBi}_{6} \mathrm{Te}_{10}$ structure type (space group $R 3 m, a=4.370 \AA, c=101.82 \AA, \Delta f=-67 \mathrm{~nm}, t=0.88 \mathrm{~nm}$; beam semiconvergence 1.2 mrad, defocus spread $15 \mathrm{~nm}$ ), with a corresponding SAED pattern in the upper right corner; in order to symbolize the long-range order, white bars symbolize quintuple $\mathrm{Bi}_{2} \mathrm{Te}_{3}$-like slab and black lines symbolize septuple layers characteristic of $\mathrm{MnBi}_{2} \mathrm{Te}_{4}$.

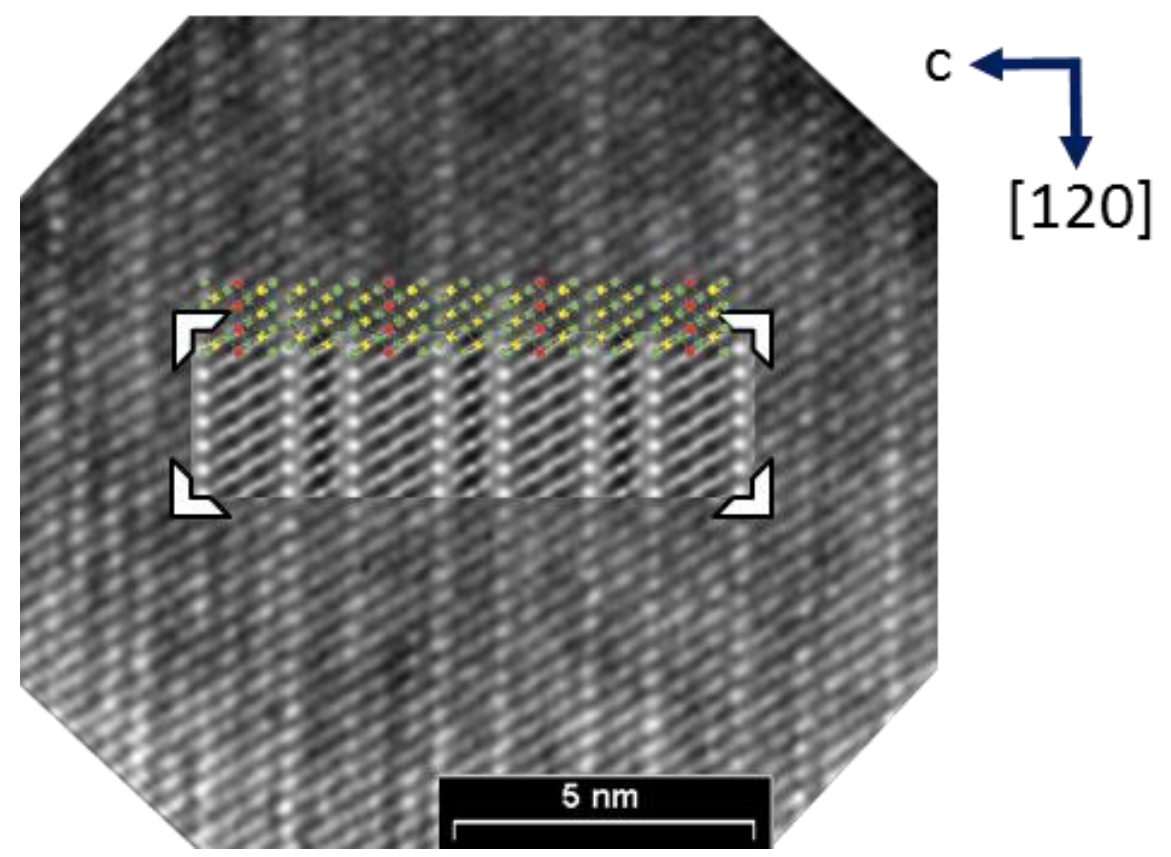

Figure 24: HRTEM image (zone axis [100]) of a manganese bismuth telluride with $\mathrm{GeBi}_{4} \mathrm{Te}_{7}$-type structure; inset: simulation based on single-crystal data of $\mathrm{Mn}_{0.85} \mathrm{Bi}_{4.10} \mathrm{Te}_{7}$ (space group $P 3 m 1, a=4.359 \AA, c=23.77 \AA, \Delta f=-85 \mathrm{~nm}, t=8.36 \mathrm{~nm}$; beam semiconvergence $1.2 \mathrm{mrad}$, defocus spread $15 \mathrm{~nm}$ ); in the upper part of the simulation, the atom positions of the $\mathrm{GeBi}_{4} \mathrm{Te}_{7}$-type structure are illustrated ( green $=$ Te; yellow $=$ Bi-rich cation position; red = Mn-rich cation position); for the exact cation distribution, including mixed sites, cf. Tables 2 and 4 . 


\section{$\underline{\text { Modelling of transport properties and thermoelectric data }}$}

First, the electron chemical potential $\eta$ was estimated from the measured Seebeck coefficient at a given temperature by numerical methods:

$$
S(\eta)=\frac{k_{B}}{e}\left(2 \frac{F_{1}(\eta)}{F_{0}(\eta)}-\eta\right)
$$

with the Fermi integrals $F(\eta)$ being defined as:

$$
F_{x}(\eta)=\int f \varepsilon^{x} d \varepsilon=\int \frac{\varepsilon^{x} d \varepsilon}{1+\exp (\varepsilon-\eta)}
$$

From $\eta$ and the measured electrical conductivity $\sigma$, the intrinsic electrical conductivity $\sigma_{\mathrm{E} 0}$ was calculated:

$$
\sigma_{E_{0}}=\frac{\sigma}{\ln \left(1+e^{\eta}\right)}
$$

Further, the phononic part of thermal conductivity $\kappa_{\mathrm{ph}}$ was calculated from the measured $\sigma$ and thermal conductivity $\kappa$ :

$$
\kappa_{p h}=\kappa-L(\eta) \sigma T
$$

with the Lorenz number $L(\eta)$ being calculated as:

$$
L(\eta)=\frac{k_{B}{ }^{2}}{e^{2}} \frac{3 F_{0}(\eta) F_{2}(\eta)-4 F_{1}(\eta)^{2}}{F_{0}(\eta)^{2}}
$$

The quality factor $B$ was obtained from the following equation:

$$
B=\left(\frac{k_{B}}{e}\right)^{2} \frac{\sigma_{E_{0}}}{\kappa_{p h}} T
$$

For a given B, $\eta$ was varied in order to find the optimal doping level, obtaining ZT for different chemical potentials $\eta$ (see chapter 3.6):

$$
z T(\eta)=\frac{S^{2}(\eta)}{\frac{\left(k_{B} / e\right)^{2}}{B \ln \left(1+e^{\eta}\right)}+L(\eta)}
$$


